\title{
Production of docosahexaenoic acid by Crypthecodinium cohnii using continuous-mode process
}

Deniz Inan

West Virginia University

Follow this and additional works at: https://researchrepository.wvu.edu/etd

\section{Recommended Citation}

Inan, Deniz, "Production of docosahexaenoic acid by Crypthecodinium cohnii using continuous-mode process" (2008). Graduate Theses, Dissertations, and Problem Reports. 4383.

https://researchrepository.wvu.edu/etd/4383

This Thesis is protected by copyright and/or related rights. It has been brought to you by the The Research Repository @ WVU with permission from the rights-holder(s). You are free to use this Thesis in any way that is permitted by the copyright and related rights legislation that applies to your use. For other uses you must obtain permission from the rights-holder(s) directly, unless additional rights are indicated by a Creative Commons license in the record and/ or on the work itself. This Thesis has been accepted for inclusion in WVU Graduate Theses, Dissertations, and Problem Reports collection by an authorized administrator of The Research Repository @ WVU. For more information, please contact researchrepository@mail.wvu.edu. 


\title{
Production of Docosahexaenoic Acid by Crypthecodinium cohnii using Continuous-Mode Process
}

\author{
Deniz Inan
}

A Thesis submitted to the Davis College of Agriculture, Forestry and Consumer Sciences at West Virginia University In Partial Fulfillment of the Requirements

for the degree of

Master of Science

in

Human Nutrition and Foods

Kristen E. Matak, Ph. D., Chair

Jacek Jaczynski, Ph. D.

Kim Barnes, Ph. D

Department of Animal and Nutritional Sciences

Morgantown, West Virginia

2008

Keywords: Crypthecodinium cohnii, DHA, algae, algal DHA 


\section{ABSTRACT}

\section{Production of Docosahexaenoic Acid by Crypthecodinium cohnii using Continuous- Mode Process}

\section{Deniz Inan}

Docosahexaenoic acid (DHA), an omega-3 fatty acid found in cold-water fish, has positive health benefits. While the suggested amount of $220 \mathrm{mg} / \mathrm{day}$ for adults may be attained by consuming fish, this may increase exposure to environmental pollutants. The heterotrophic marine alga Crypthecodinium cohnii is an important source of DHA because $C$. cohnii can accumulate lipid greater than $20 \%$ of their biomass with a large fraction of DHA (30-50\%). Commercially, DHA production by C. cohnii is conducted in large bioreactors $\left(\sim 100 \mathrm{~m}^{3}\right.$ capacity) using a batch-mode process. The purpose of this study was to investigate lipid and DHA production by $C$. cohnii using batch-mode and continuous-mode processes. The long term objective is to maximize DHA production from a safe and reliable marine source.

Batch cultivation of $C$. cohnii was carried in a $15 \mathrm{~L}$ bioreactor vessel at 27 ${ }^{\circ}$ C. C. cohnii (ATCC 30772) was grown in ATCC complex media 460 for 10 days at $25{ }^{\circ} \mathrm{C}$, transferred to simple media $(9 \mathrm{~g} / \mathrm{L}$ glucose, $2 \mathrm{~g} / \mathrm{L}$ yeast, and $25 \mathrm{~g} / \mathrm{L}$ salt) and incubated statically for 8 days at $25{ }^{\circ} \mathrm{C}$. Cultures were subsequently transferred to larger volumes of simple media and incubated at $25^{\circ} \mathrm{C}$ in an orbital shaker incubator at $100 \mathrm{rpm}$. At each transfer, a $10 \%(\mathrm{v} / \mathrm{v})$ inoculum level was maintained. Cultivation of $C$. cohnii was conducted in a $15 \mathrm{~L}$ computer controlled bioreactor vessel. Temperature was maintained at $27^{\circ} \mathrm{C}$ by a computer controlled heating jacket. A $25 \%$ glucose solution was administered continuously at a rate of $0.78 \mathrm{~mL} / \mathrm{min}$.

Continuous cultivation of $C$. cohnii was conducted in two $15 \mathrm{~L}$ computer controlled bioreactor vessels. Temperature of both vessels was maintained at $27^{\circ} \mathrm{C}$ during the growth mode of the study and standard media $(25 \mathrm{~g} / \mathrm{L}$ glucose, $5.5 \mathrm{~g} / \mathrm{L}$ yeast, and $25 \mathrm{~g} / \mathrm{L}$ salt) was administered to both bioreactors. After $40 \mathrm{~h}$, the system was switched to "continuous" mode where one vessel was maintained as a growth vessel at $27^{\circ} \mathrm{C}$, and the other as a lipid accumulation vessel at $17^{\circ} \mathrm{C}$. In continuous mode, standard media was administered to the growth vessel and a $25 \%$ glucose solution was administered to the lipid accumulation vessel.

In both studies algal growth was monitored spectrophotometrically and measured every $12 \mathrm{~h}$ at $470 \mathrm{~nm}$. The biomass concentration, lipid content and fatty acid profile were determined by harvesting samples from the vessel.

Results of the study showed that $C$. cohnii growth was achieved in batch-

mode and continuous-mode cultivation with lipid and DHA production. Maximum values for volumetric DHA productivity, biomass, lipid and DHA concentrations in the batch study were $3.61 \mathrm{mg} / \mathrm{L} . \mathrm{h}, 8.35 \mathrm{~g} / \mathrm{L}, 0.89 \mathrm{~g} / \mathrm{L}$ and $0.32 \mathrm{~g} / \mathrm{L}$ respectively. In 
continuous study the maximum values were $4.132 \mathrm{mg} / \mathrm{L} . \mathrm{h}, 3.75 \mathrm{~g} / \mathrm{L}, 0.55 \mathrm{~g} / \mathrm{L}$ and $0.145 \mathrm{~g} / \mathrm{L}$ respectively. Although DHA concentration was higher in the batch mode process, volumetric DHA productivity of continuous mode process exceed volumetric DHA productivity of batch mode because of higher production rate of continuous mode process. These values did not exceed the reported values of other batch processes that used a $50 \%$ glucose feed. More research is needed to optimize processing parameters in continuous mode to produce a viable alternative to batch mode processes. 


\section{ACKNOWLEDGEMENTS}

This work was funded by USDA-CSREES \#2006-35503-17449.

I would like to thank the faculty and the staff of the Animal and Nutritional

Sciences Department for their interest in their students, their support and willingness to help. I would specifically like to thank to Sarah Beamer for her tremendous help. Thanks also to our statistician Desta Fekedulegn and Professor Erdogan Gunel for helping me with the statistical analyses.

I want to thank to my committee members Dr. Kristen E. Matak, Dr. Jacek Jaczynski and Dr. Kim Barnes for their valuable times spent teaching me, answering my questions and offering suggestions for improvement. A special thank you goes to Dr. Jacek Jaczynski for the use of his lab.

Thank you very much Dr. Matak for motivation and support you gave me. I am grateful for your positive, helpful and analytical approach which always motivated and encouraged me.

I finally want thank to my husband Hakan Inan and my son Berk Inan for their patience during the times I was working on my thesis instead of being there with them. 


\title{
TABLE OF CONTENTS
}

\begin{abstract}
............................................................................................................................ii
ACKNOWLEDGEMENTS .............................................................................................iv

TABLE OF CONTENTS ............................................................................................v

CHAPTER 1 - GENERAL INTRODUCTION .......................................................1

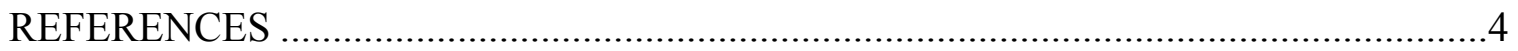

CHAPTER 2 - REVIEW OF LITERATURE ........................................................7

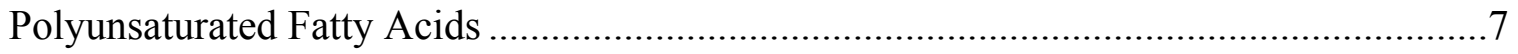

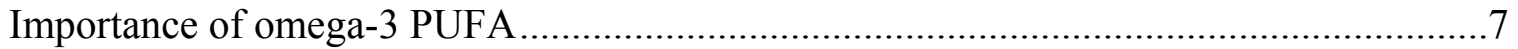

Health Effects of Omega-3 Fatty Acids ..........................................................................

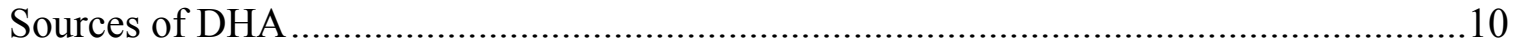

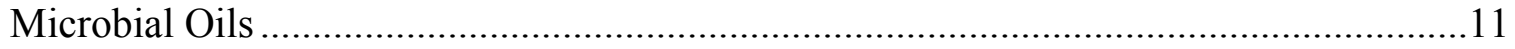

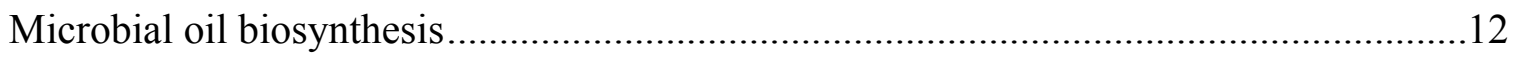

Commercial Production of DHA by Crypthecodinium cohnii .....................................14

Parameters affecting the growth of Crypthecodinium cohnii ........................................16

The effect of temperature on growth and DHA production of C. cohnii..........................16

The effect of carbon source on growth and DHA production of C. cohnii ......................19

The effect of salinity on growth and DHA production of C. cohnii ...............................23

The effect of yeast extract on growth, lipid and DHA production of C.

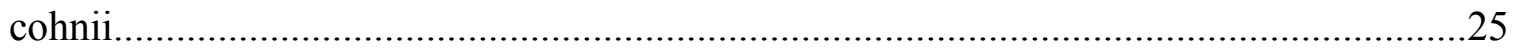

The effect of oxygen availability, agitation, culture viscosity and $\mathrm{pH}$ on

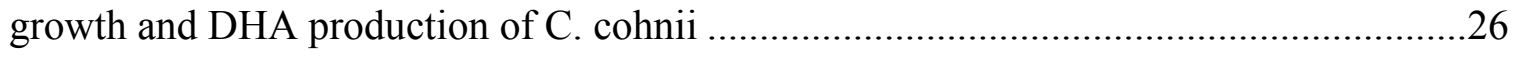

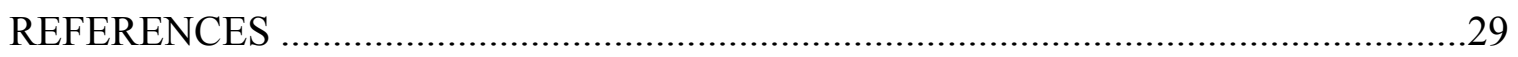

CHAPTER 3 - FED-BATCH CULTIVATION OF C. COHNII .................................33

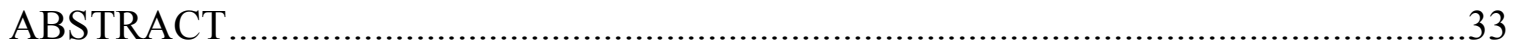

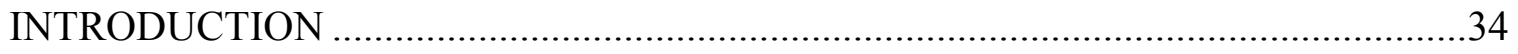

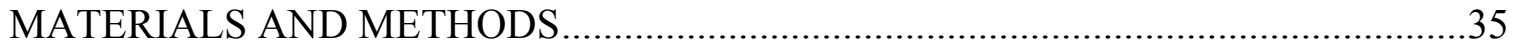

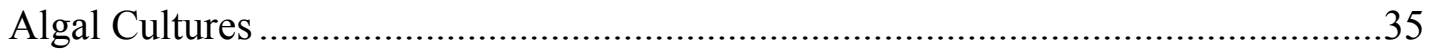

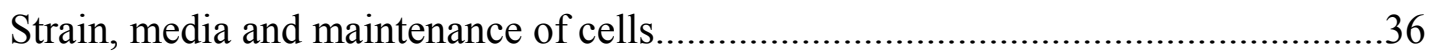




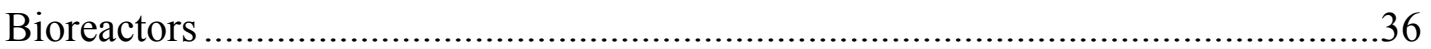

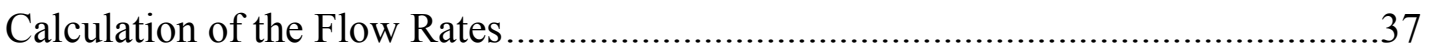

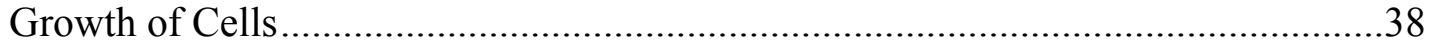

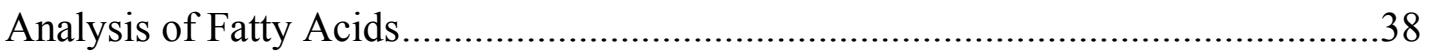

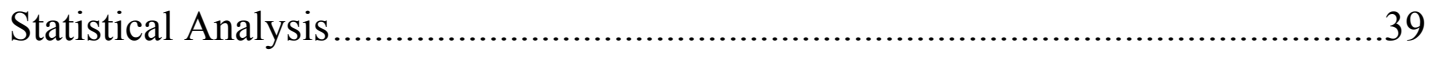

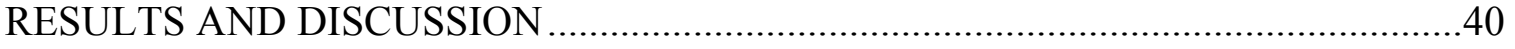

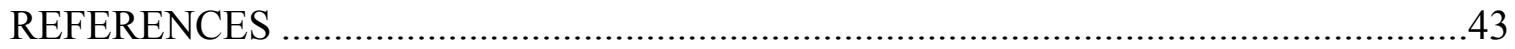

CHAPTER 4 - CONTINUOUS CULTIVATION OF C. COHNII ..................................47

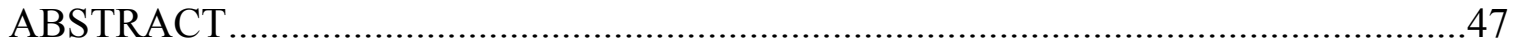

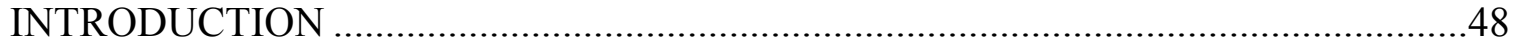

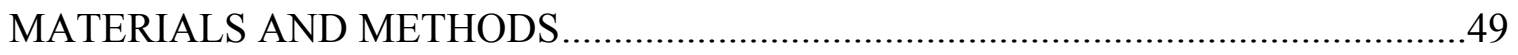

Strain, media and maintenance of cells............................................................49

Strain, media and maintenance of cells...........................................................50

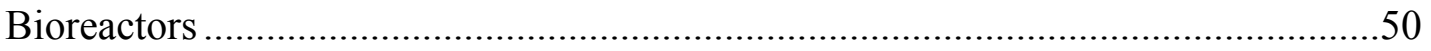

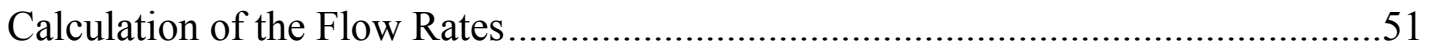

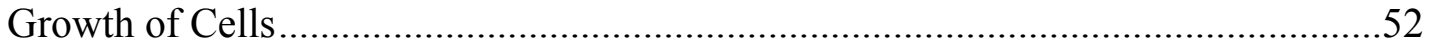

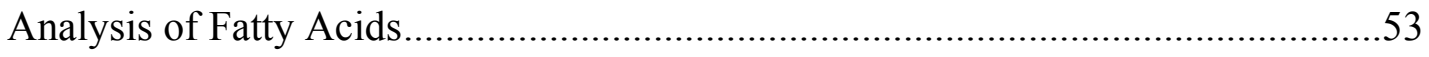

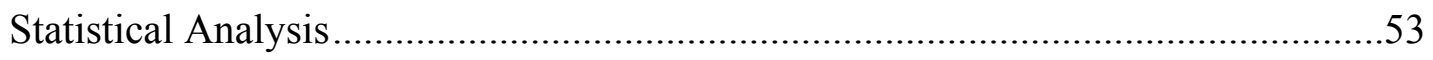

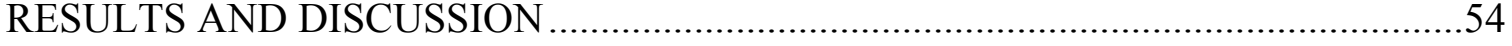

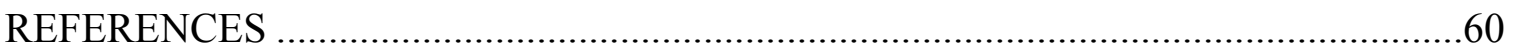

APPENDIX A. Fatty Acid Analysis ..................................................................69

APPENDIX B. Fatty Acid Profile.............................................................................................71

APPENDIX C. Calculation of the Flow Rates................................................................76

APPENDIX D. Statistical Analysis.......................................................................................78 


\section{LIST OF TABLES}

Table 1. Fat (\%) and fatty acid profile of $C$. cohnii over time in a batch mode

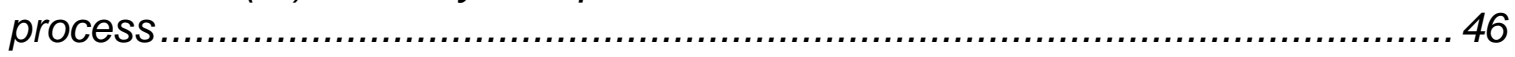
Table 2. Fat (\%) and Fatty acid profile of C. cohnii over time in the continuous

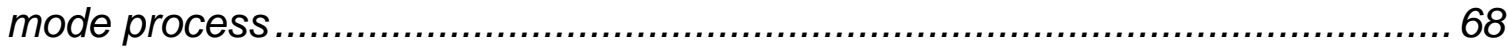




\section{LIST OF FIGURES}

Figure 1. PUFA synthesis pathways of microorganisms using FAS route 13 Figure 2.Optical density of Crypthecodinium cohnii over time in batch mode process

Figure 3. Biomass concentration (BC), Lipid content of dry biomass (lipid \%) and

DHA content of lipid (DHA \%) over time in batch mode process.... 45

Figure 4. Lipid concentration, volumetric productivity of DHA (rDHA) and DHA concentration change over time in a batch mode process.

Figure 5 . Flow chart of the continuous process

Figure 6. Growth of $C$. cohnii over time in a continuous mode process.

Figure 7. Biomass concentration of cooling vessel over time in the continuous mode process.

Figure 8. Lipid percentages of cooling vessel over time in the continuous mode process

Figure 9. DHA percentages of cooling vessel over time in the continuous mode process.

Figure 10. Lipid concentrations of cooling vessel over time in the continuous mode process. 66

Figure 11. DHA mass flow rate (DHA productivity) of cooling vessel over time in continuous mode process.... 67 Figure 12. DHA concentration of cooling vessel over time in continuous mode process 


\section{CHAPTER 1 - GENERAL INTRODUCTION}

The omega-3 fatty acids, eicosapentaenoic acid (EPA) and docosahexaenoic acid (DHA), are polyunsaturated fatty acids (PUFA) that are commonly found in fish. a-Linolenic acid (ALA, 18:3) is the other common member of the omega-3 family of fatty acids and is the parent compound of EPA and DHA. In the human body, a-Linolenic acid (ALA, 18:3) is converted into both EPA and DHA, but the conversion rate is very slow (Al et al., 2000).

DHA is an important PUFA in human breast milk and has positive health benefits. Health benefits of polyunsaturated fatty acids are well documented (Marszalek et al., 2005; Whelan et al., 2006; Ward et al., 2005; Simopoulos, 1991, 1999, 2000 \& 2001). Throughout gestation, the PUFA requirement of pregnant women is high and the fetus is dependent on maternal fatty acid intake (Al et al., 2000). Late gestation (last trimester) and early postnatal periods are critical times for neurological development; therefore, adequate maternal consumption of PUFAs, especially DHA, are important for the proper brain and retina developments of fetuses and infants during these periods (Marszalek et al., 2005).

The most widely available source of EPA and DHA is cold water fatty fish types such as salmon, herring, mackerel, anchovies and sardines (Yongmanitchai et al., 1989). While the suggested amount of $220 \mathrm{mg} / \mathrm{day}$ DHA for adults may be attained by consuming fish, this may increase exposure to environmental pollutants. Furthermore, the use of fish oil in value added food products is limited because of its strong odor and distinct taste. Fish and fish oil 
contain DHA and EPA together. The presence of EPA in fish oil is not desirable for infant food applications because EPA suppresses the endogenous ARA synthesis of infants resulting in their decreased growth rate (Carlson, 1996). Therefore, it is necessary to identify alternative sources that are safe, reliable and contain DHA as the primary PUFA.

Microorganisms have long been known to be a source of "valuable" lipids because they are free of cholesterol, heavy metals, and pesticides; they are also high in PUFAs (Gunstone, 2001). Although fish is a very good source of DHA, they do not synthesize it but ingest it from sources in the marine food chain, primarily algae (Yongmanitchai \& Ward, 1989). Commercial interest in the unicellular, heterotrophic, non-photosynthetic marine dinoflagellate Crypthecodinium cohnii is due to their capability to generate high amounts of lipid (>20\% of their biomass) with a DHA proportion between $30-50 \%$ and the absence of other PUFAs above 1\% (Beach et al., 1973, 1974). Commercially, DHA production by $C$. cohnii is conducted in large bioreactors ( $100 \mathrm{~m}^{3}$ capacity) using a batch-mode process. There are a limited number of studies about the growth of C. cohnii, lipid and DHA production, and capability of C. cohnii in batch mode cultivation (Beach et al., 1973, 1974; Ratledge et al., 1989, 2001, 2004; Kyle 1996; Swaaf et al., 1999, 2001, 2003a, 2003b). In these studies different carbon sources like glucose, ethanol and acetate; different growth temperatures; different substrate and salt concentrations have been investigated.

Volumetric productivity of DHA (rDHA) is an important parameter to determine cost effectiveness of DHA production by algae. An increase in DHA 
productivity will decrease product cost. The maximum rDHA reported to date for batch cultivation of $C$. cohnii in a standard medium containing glucose as the carbon source was $19 \mathrm{mg} / \mathrm{L} . \mathrm{h}$ (Swaaf et al. 1999), with a $50 \%$ glucose feed was $14 \mathrm{mg} / \mathrm{L} . \mathrm{h}$ (Swaaf et al. 2003a), with a pure acetic acid feed was $48 \mathrm{mg} / \mathrm{L} . \mathrm{h}$ (Swaaf et al. 2003a), and with a pure ethanol feed was $53 \mathrm{mg} / \mathrm{L} . \mathrm{h}$ (Swaaf et al. 2003b). The objective of the first study is to cultivate marine algae $C$. cohnii successfully with lipid and DHA production using a batch-mode cultivation strategy in larger bioreactor vessels using a $25 \%$ glucose feed.

At the time of this publication, there was no published work dealing with DHA and lipid production by C. cohnii in a continuous cultivation system; therefore, the purpose of the second study was to investigate growth, lipid and DHA production of $C$. cohnii using a novel, continuous-mode process. 


\section{REFERENCES}

Al MDM. Houwelingen AC. Hornstra G. 2000. Long chain polyunsaturated fatty acids, pregnancy, and pregnancy outcome. Am J Clin Nutr 71: 285-291

Beach DH. Holz GG. 1973. Environmental influences on the docosahexaenoate content of the triacylglycerols and phosphatidylcholine of a heterotrophic, marine dinoflagellate, Crypthecodinium cohni., Biochimica et Biophysica Acta 316: 56-65.

Beach DH. Harrington GW. Gellerman JL. Schlenk H. Holz GG. 1974. Biosynthesis of oleic acid and docosahexaenoic acid by a heterotrophic marine dinoflagellate Crypthecodinium cohni. Biochimica et Biophysica Acta 369: 16-24.

Carlson SE. 1999. Arachidonic acid status human infants: influence of gestational age at birth and diets with very long chain n-3 and n-6 fatty acids. J. Nutr 126: 1092-1098.

Gunstone FD. Structured and modified lipids. Marcel Dekker, New York (2001).

Kyle DJ. 1996. Production and use of a single cell oil which is highly enriched in docosahexaenoic acid. Lipid Technology. September: 107-110.

Ratledge C. Kanagachandran K. Anderson AJ. Grantham DJ. Stephenson JC. 2001. Production of docosahexaenoic acid by Crypthecodinium cohnii grown in a $\mathrm{pH}$-auxostat culture with acetic acid as principal carbon source. Lipids 36 : 1241-1246.

Ratledge C, Evans CT.1989. Lipids and their metabolism. The Yeasts. Academic Press London. Ed 2. Vol. 3. 368-446. 
Ratledge C. 2004. Fatty acid biosynthesis in microorganisms being used for single cell oil production. Biochimie 86: 807-815.

Simopoulos AP. 1991. Omega 3 fatty acids in health and disease and in growth and development. Am J Clin Nutr 54: 438-463

Simopoulos AP. 1999. Essential fatty acids in health and chronic disease. Am J Clin Nutr 70: 560-569..

Simopoulos AP. 2000. Human requirement for N-3 polyunsaturated fatty acids. Poultry Science 79: 961-970.

Swaaf ME. Rijk TC. Eggink G. Sijtsma L. 1999. Optimisation of docosahexaenoic acid production in batch cultivations by Crypthecodinium cohnii. Journal of Biotechnology 70 185-192.

Swaaf ME. Grobben GJ. Eggink G. Rijk TC. Meer P, Sijtsma L. 2001. Characterization of extracellular polysaccharides produced by Crypthecodinium cohnii. App Microbiol Biotechnol 57: 395-400.

Swaaf ME. Sijtsma L. Pronk JT. 2003a. High cell density fed batch cultivation of the docosahexaenoic acid producing marine alga Crypthecodinium cohnii. Biotechnol Bioeng 81: 666-672.

Swaaf ME. Pronk JT. Sijtsma L. 2003b. Fed-batch cultivation of the docosahexaenoic acid producing marine alga Crypthecodinium Cohnii., App Microbiol Biotechnol 61: 40-43.

Swaaf ME. Rijk TC. Meer P. Eggink G. Sijtsma L. 2003c. Analysis of docosahexaenoic acid biosynthesis in Crypthecodinium cohnii by ${ }^{13} \mathrm{C}$ labeling and desaturase inhibitor experiments. Journal of Biotechnol 103: 21-29. 
Ward OP, Singh A. 2005. Omega-3/6 fatty acids: Alternative sources of production. Process Biochemistry 40: 3627-3652.

Whelan J. Rust C. 2006. Innovative Dietary Sources of N-3 Fatty Acids. Annu. Rev. Nutr. 26:75-103.

Yongmanitchai W. Ward OP. 1989. Omega-3 fatty acids: alternative sources of production. Proc Biochem: 117-125. 


\section{CHAPTER 2 - REVIEW OF LITERATURE Polyunsaturated Fatty Acids}

Fatty acids having more than 18 carbon atoms with multiple double bonds are defined as long chain polyunsaturated fatty acids (PUFA). Depending on the location of the first double bond from the methyl end of the fatty acid, the unsaturated fatty acids are divided into three groups; omega-3 (n-3), omega-6 (n6) and omega-9 (n-9) with their first double bonds at the third, sixth and ninth carbon atoms from their methyl end, respectively.

a-Linolenic acid (ALA, 18:3), the parent compound of eicosapentaenoic acid (EPA, 20:5) and docosahexaenoic acid (DHA, 22:6), are members of the omega-3 family of fatty acids. Omega-3 fatty acids are considered essential fatty acids because mammals are not able to add double bonds between carbons before the ninth carbon from the methyl end because they lack the desaturase enzymes responsible for this desaturation. Since DHA cannot be synthesized (de novo) by mammals, ALA must be ingested from dietary sources. In the human body, ALA can be converted to both EPA and DHA, but the conversion rate is very low (Al et al., 2000, Yongmanitchai et. al., 1989).

\section{Importance of omega-3 PUFA}

Health benefits of polyunsaturated fatty acids are well documented (Marszalek et al., 2005, Whelan et al., 2006 and Ward et al., 2005). Omega-3 EPA and DHA support heart health, cognitive health and development, mental health and eye health \& development. Interest in PUFAs began when it was 
reported that populations obtaining a substantial proportion of their fat intake from fish had a lower incidence of heart disease than other populations (Ward et al., 2005). The best source of omega-3 EPA and DHA is from oily fish like mackerel, anchovies and sardines (Yongmanitchai et al.1989; Ward et al., 2005) and is associated with a lower risk of fatal heart disease and stroke (Whelan et al., 2006). DHA is a major structural component of the gray matter of the brain, the eye retina, and heart tissue (Marszalek et al., 2005). The brain is $65 \%$ lipid and DHA is a significant proportion of that (Whelan et al., 2006). Compared to other body tissues, the nervous system has been reported as having the highest concentration of PUFA, especially DHA (Marszalek et al., 2005).

PUFAs contribute to fluidity, flexibility and selective permeability properties of membranes and so contribute important roles in membrane functioning (Ward et al., 2005). Furthermore, PUFAs contained in the phospholipid layer of the membranes are precursors for the synthesis of eicosanoids; like prostaglandins, leukotrienes and thromboxanes. Eicosanoids, hormone like substances, signal cellular responses to inflammation, vasodilation, blood pressure and fever. The eicosanoids from omega-6 arachidonic acid (ARA, 20:4) and EPA are different in terms of structure and function, and are even reported as antagonists (Ward et al., 2005).

\section{Health Effects of Omega-3 Fatty Acids}

The health effects of omega-3 fatty acids are anti-inflammatory, antithrombotic, anti-arrhythmic, hypolipidemic and vasodilatory, whereas omega-6 
fatty acids function as prothrombotic and proaggregatory (Simopoulos, 1999). Omega-3 fatty acids have a role in the secondary prevention of coronary heart disease, hypertension, type 2 diabetes, and, in some patients with renal disease, rheumatoid arthritis, ulcerative colitis, Crohn's disease, and chronic obstructive pulmonary disease (Simopoulos, 1999). Omega-3 \& omega-6 fatty acids are not inter-convertible in the human body (Simopoulos, 1991). Therefore, a balanced $\mathrm{n}-6 / \mathrm{n}-3$ ratio in the diet would optimize growth and development, improve mental health, and decrease the risk for cardiovascular diseases and other chronic diseases (Simopoulos, 2000).

PUFAs, particularly DHA and ARA, are highly concentrated in the cell membranes of the retina and brain. Late gestation (last trimester) and early postnatal periods are critical times for neurological development; therefore, adequate maternal consumption of PUFAs, especially DHA, are important for the proper brain and retina developments of infants during these periods (Marszalek et al., 2005). In the last trimester of gestation, ARA and DHA are transferred through the placenta, and supplied to the infant in breast milk during the first year of life (Marszalek et al., 2005). Greater levels of ARA and DHA are found in the phospholipids of erythrocytes of breast-fed babies relative to formula fed not supplemented with these PUFAs. It was concluded that infants had a limited capacity to convert linoleic acid (18:2) to ARA and ALA to DHA (Jensen \& Heird, 2002).

The relationship between the sleep patterns of infants and maternal plasma PUFA concentrations were investigated (Cheruka et al., 2002). Plasma 
phospholipid fatty acid concentrations of 17 women were measured at parturition while infants' sleep and wake states were measured at postpartum day 1 and day 2. The infants of mothers with high-serum DHA had a significantly lower ratio of active sleep (AS) to quiet sleep (QS) and less AS than the infants of mothers with low-serum DHA. Infant sleep patterns are an expression of central integrative control; therefore, sleep and wake states of newborns were reported as providing a tool for assessing the functional integrity of their CNS. Infants born from mothers with higher plasma phospholipid DHA had a greater CNS maturity (Cheruku et al., 2002).

\section{Sources of DHA}

Fish, fish oil supplements, human milk, certain microbial oils and enriched products (oils, bakery products, fruit juice, infant formula, eggs, milk, mayonnaise and margarines) are dietary sources of DHA (Ward et al., 2005). Human milk is a good source of DHA, and since 2002 DHA has been added to infant formulas (Marszalek et al., 2005).

Fish are a major source of EPA and DHA with the PUFA content depending on the species and the geographic location of catching sites (Yongmanitchai et al., 1989). The most widely available source of EPA and DHA is cold water fatty fish types such as salmon, herring, mackerel, anchovies and sardines (Yongmanitchai et al., 1989). Fish and fish oil are thought to have some disadvantages. The first disadvantage linked with fish and fish oil is the cooccurrence of EPA and DHA. EPA suppresses the endogenous ARA synthesis of 
infants resulting in their decreased growth rate (Carlson, 1996). Furthermore, fish and fish oils may contain health threatening environmental contaminants such as heavy metals and fat-soluble pollutants like PCBs and dioxins (Ratledge, 2004). Some manufacturers remove heavy metals and other contaminants from fish oil through various means, such as molecular distillation. The use of fish oil in manufactured foods has sensory consequences due to the fishy odor. The disadvantages with fish and fish oils accelerated the studies for alternative sources of PUFA and economical methods for PUFA production.

\section{Microbial Oils}

Animals and plants are the most common and traditional sources of lipids; however, animal sources may contain some environmental man-made pollutants and plants do not produce PUFA longer than 18 carbons (Ratladege, 2004). In order to get PUFA longer than 18 carbons from plant sources, genetic manipulation would be needed (Ratledge, 2004). Genetic manipulation includes the transfer of genes between different species. Genetic engineering is currently applied to oilseed plants for increased resistance to herbicides and pests, thus to increase yield (Gunstone, 2001). With genetic engineering the fatty acid composition of seed oil, chain length of fatty acids and level of unsaturation could be manipulated (Gunstone, 2001). However, genetically modified (GM) oils are not popular from the consumer perspective.

Microorganisms have long been known to be a source of "valuable" lipids because they are free of cholesterol, heavy metals, and pesticides; they are also 
high in PUFAs (Gunstone, 2001). The fatty acid profile of microbial oil depends on genetics of the species (Ratladege, 2004). Microbial oils have been given GRAS (Generally Regarded As Safe) status by Food and Drug Administration. This has helped the single cell oils (SCO) industry in the market place, for example: ARA and DHA from microbial oils are added to preterm and term infant formula. It is also recommended that pregnant and nursing women increase consumption of DHA-containing microbial oil (Ward et al., 2005) and DHA-rich oils are added to animal feed to increase the PUFA content of the meat (Simopoulos, 2000).

A well known SCO producer company, Martek Biosciences Corporation (Columbia, MD, USA), has two patented products, $\mathrm{DHASCO} \otimes$ and ARASCO $\circledast$, which are permitted to be added to infant formula in the US. DHA in DHASCO ${ }^{8}$ and ARA in ARASCO ${ }^{2}$ were produced by Crypthecodinium cohnii and Mortieralla alpine respectively (Ratledge, 2004). The benefits of these PUFAs and their use in some disease treatments will probably accelerate the production of microbial oils by variety of companies.

\section{Microbial oil biosynthesis}

Oleaginous microorganisms are defined as eukaryotic microorganisms capable of accumulating more than $20 \%$ of their biomass as lipid (Ratledge et al., 1989). In some oleaginous microorganisms, the content of oil could even exceed $70 \%$ of the biomass (Ratledge, 2004). 


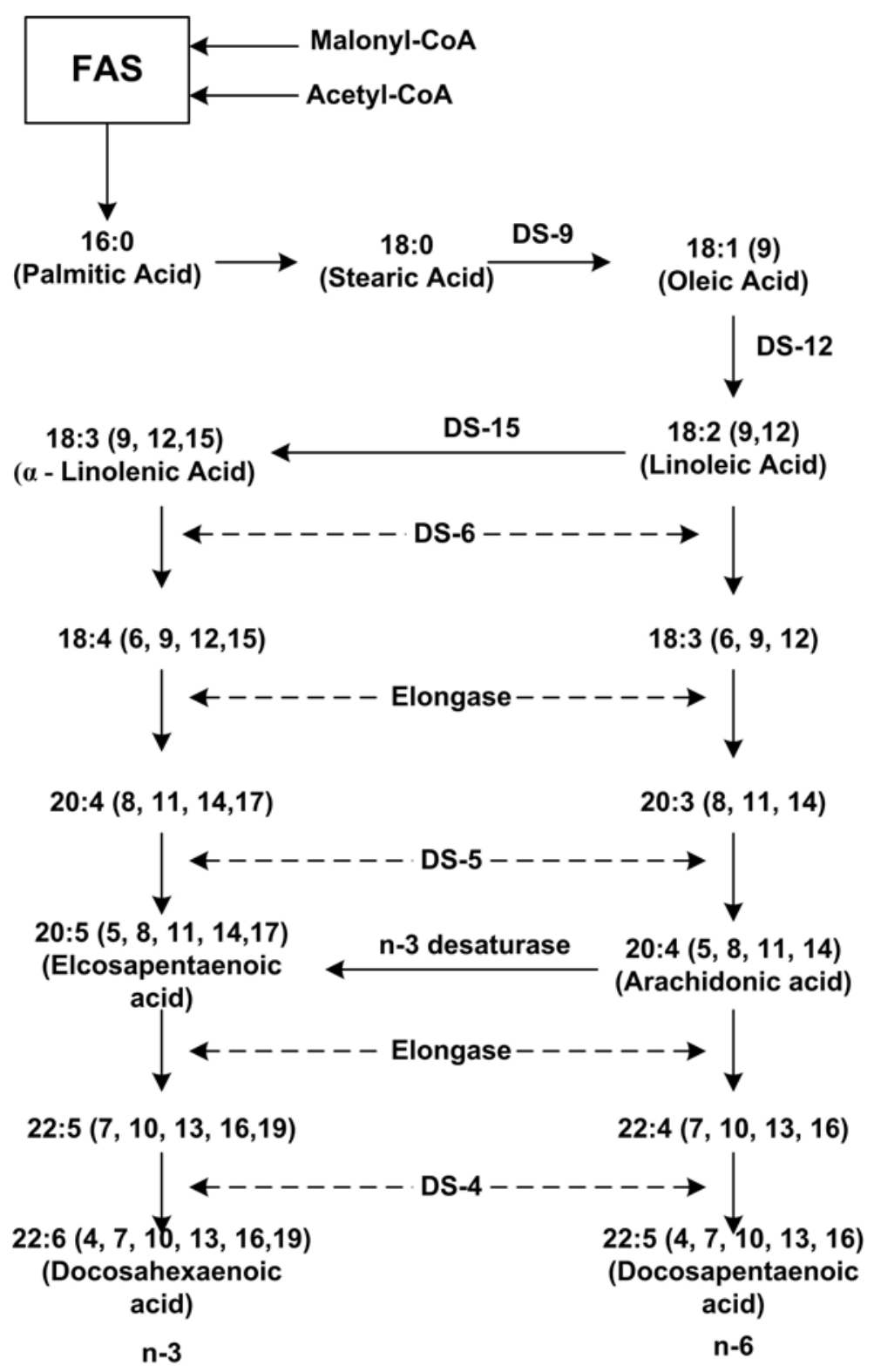

Figure 1. PUFA synthesis pathways of microorganisms using FAS route

In mammals the synthesis DHA starts with the precursor $\alpha$ - linolenic acid. In the DHA (also other PUFAs) synthesis pathway, some specific desaturase and elongase enzymes are employed for desaturation and elongation reactions. In the PUFA synthesis pathway of microorganisms using the fatty acid synthase (FAS) route, palmitic acid (16:0) is produced from acetyl CoA and malony CoA by 
using FAS enzyme complex. The saturated fatty acid is then converted to various PUFAs through a series of elongation and desaturation reactions. Besides this pathway, another PUFA biosynthesis mechanism called polyketide synthase (PKS) route has been reported for some marine prokaryotic and eukaryotic micro-organisms (Ratledge, 2004; Ward et al., 2005). Ratledge (2004) reported the synthesis of PUFA in Schizochytrium sp. and other related thraustochytrid marine protists via PKS. For each microbial PUFA producer, identification of the oil accumulation pathways and key enzymes involved in these pathways is necessary to increase productivity and reduce product cost. Currently, there is no scientific work on the mechanism of DHA production as the primary PUFA in the biosynthesis pathway of $C$. cohnii. A better understanding of the lipid biosynthesis pathway of $C$. cohnii may result in increased productivity and decreased cost of this beneficial PUFA.

Microbial lipid accumulation is a biphasic process which requires an excess of carbon source over other nutrients especially nitrogen. Rapid cell growth occurs in the first phase while the second phase shows decreased growth and increased lipid synthesis and accumulation (Leman, 1997). Lipid accumulation is encouraged by growing the microorganism in a culture medium high in carbon and low in nitrogen (Ratledge, 2004).

\section{Commercial Production of DHA by Crypthecodinium cohnii}

Fish are a good dietary source of DHA; however, they do not synthesize it. It is ingested from sources in the marine food chain, primarily by algae 
(Yongmanitchai \& Ward, 1989). Marine microorganisms such as heterotrophic dinoflagellates contribute significant amounts of DHA into the marine food chain because they can accumulate a high proportion of their lipid components as DHA. C. cohnii and strains from Traustochytrium (marine protists) are used commercially for DHA production. C. cohnii was the first microbial strain used for commercial production of DHA for infant formula (Ward et al., 2005). Commercial interest in the unicellular, heterotrophic, non-photosynthetic marine dinoflagellate C. cohnii has been stimulated by their capability to generate high amounts of lipid with a DHA proportion between $30-50 \%$ and the absence of other PUFA above 1\% (Beach et al., 1973, 1974).

Commercially, DHA production by $C$. cohnii is conducted in large bioreactors or fermenters $\left(\sim 100 \mathrm{~m}^{3}\right.$ capacity) using a batch-mode process. Commercial batch-mode production of DHA using C.cohnii was described by Kyle (1996). The sequence of processing steps was described as:

"The pure cultures of one species are first grown in test tubes and they are systematically transferred to larger vessels where their temperature, $\mathrm{pH}$, dissolved oxygen, pressure and agitation rate are monitored and controlled. When the culture reaches a determined cell density and fatty acid content, it is harvested by centrifugation and then spray-dried producing dry biomass. The purity of cultures are observed by inoculating culture broth samples onto agar plates at each transfer stage and also observed under microscope" Kyle (1996).

Kyle (1996) also described the method of DHASCO® (Martek Biosciences Corporation, Columbia, MD, USA) production which is the registered trade name 
for the DHA rich oil, incorporated into infant formula. According to their process, the oil is extracted from the biomass by blending it with hexane, separated from the solids, separated from the solvent under vacuum and winterized to remove more highly saturated oil fractions. The winterized oil is refined, bleached, deodorized and finally diluted with high oleic sunflower oil to bring the DHA levels to an industry standard of $40 \%$ (Kyle, 1996).

Specifications for different microbial strains for oil production include being non-pathogenic and non-toxin forming (Ward et al, 2005). C. cohnii has not demonstrated pathogenicity or toxigenicity (Kyle, 1996). Furthermore, commercial strains must be stable so that they do not lose the desirable oil producing characteristics over time to maintain consistency from batch to batch (Ward et al, 2005).

\section{Parameters affecting the growth of Crypthecodinium cohnii}

Environmental conditions such as temperature, media composition, aeration, agitation and culture age influence fatty acid biosynthesis and fatty acid composition of microalgae both qualitatively and quantitatively.

\section{The effect of temperature on growth and DHA production of C. cohnii}

Temperature is one of the most important environmental factors affecting the growth of $C$. cohnii and formation of DHA. The inhibition of cell growth of $C$. cohnii occurs at temperatures below $14^{\circ} \mathrm{C}$ or above $31^{\circ} \mathrm{C}$ with the optimum growth temperature of C. cohnii at $27^{\circ} \mathrm{C}$ (Beach et al., 1973). 
Growth of $C$. cohnii in the temperature range of $20-35^{\circ} \mathrm{C}$ was investigated by Tuttle and others (1975). At $20-30^{\circ} \mathrm{C}$, division cysts yield two cells; whereas, between $30-34^{\circ} \mathrm{C}$ an abnormal division where $30-40 \%$ of the division cysts yield four cells, and a longer generation time of the cells were observed (Tuttle et al., 1975).

Jiang and Chen (2000) investigated the growth of C. cohnii over the temperature range of $15-30^{\circ} \mathrm{C}$ and reported the highest specific growth rate at $30^{\circ} \mathrm{C}$ while the highest $\mathrm{DHA}$ content was obtained at $15^{\circ} \mathrm{C}$ at $72^{\text {nd }}$ hour of cultivation. According to their study:

"Culture of C. cohnii 30556 was maintained in liquid porphyridium with 5 g/L glucose at $20^{\circ} \mathrm{C}$ and sub-cultured every 7 days. This culture was used to inoculate the $100 \mathrm{~mL}$ flasks containing $20 \mathrm{~mL}$ porphyridium medium (with $5 \mathrm{~g} / \mathrm{L}$ glucose) and incubated at $25{ }^{\circ} \mathrm{C}, 150 \mathrm{rpm}$ for $48 \mathrm{~h}$. The $100 \mathrm{~mL}$ flask were used to inoculate ( $5 \% \mathrm{vol} / \mathrm{vol}) 250 \mathrm{~mL}$ flask containing $50 \mathrm{~mL}$ porphyridium medium and incubated at various temperatures $\left(15{ }^{\circ} \mathrm{C}, 20^{\circ} \mathrm{C}, 25^{\circ} \mathrm{C}, 30{ }^{\circ} \mathrm{C}\right)$ \& at 200 rpm. The specific growth rates were determined by plotting the logarithm of culture optical density or dry weight concentration against time. The specific growth rate and biomass concentration of $C$. cohnii increased as the temperature increased while DHA proportion decreased" (Jiang and Chen, 2000). These results show that $C$. cohnii cultures grown at higher temperatures adapt themselves to the growth temperature by producing more saturated fatty acids; in contrast, they adapt themselves to the lower temperatures by increasing the degree of unsaturation and DHA proportions. The physiological adaptations of 
microalgae to the growth temperature are considered to be regulated by enzyme reactions, cell permeability and cell composition which in turn affect the content of unsaturated fatty acids (Jiang and Chen, 2000).

The growth of $C$. cohnii and lipid accumulation were compared at incubation temperatures of $27^{\circ} \mathrm{C}$ and $30^{\circ} \mathrm{C}$ by measuring optical density at 470 $\mathrm{nm}$ (de Swaaf et al.,1998). At the $50^{\text {th }}$ hour of the growth, the optical densities of the cultures grown at $27^{\circ} \mathrm{C}$ and $30^{\circ} \mathrm{C}$ were 4.7 and 5.8 , respectively, indicating that growth was more stimulated at the higher incubation temperatures. At $27^{\circ} \mathrm{C}$ the DHA proportion of total lipid was $35.9 \%$ compared to $40.4 \%$ at $30^{\circ} \mathrm{C}$; the greater proportion of DHA at increased incubation temperatures does not fit with the findings of Jiang and Chen (2000).

Jiang and Chen (2000) investigated the effect of temperature shift on biomass concentrations and DHA production by using two temperature shift experiments in which algae grown at $30^{\circ} \mathrm{C}$ or $25^{\circ} \mathrm{C}$ for $48 \mathrm{~h}$ were transferred to a lower temperature $\left(15^{\circ} \mathrm{C}\right)$ environment and maintained there for another $24 \mathrm{~h}$. They compared DHA contents and DHA productivity (volumetric productivity of DHA), of these two temperature shift cultures with cultures grown at the constant temperatures of $15^{\circ} \mathrm{C}, 20^{\circ} \mathrm{C}, 25^{\circ} \mathrm{C}$ or $30^{\circ} \mathrm{C}$ for $72 \mathrm{~h}$. The DHA content (\%DHA) and productivity $(\mathrm{rDHA})$ of cultures grown at the static temperatures of $15^{\circ} \mathrm{C}$, $20^{\circ} \mathrm{C}$ and $25^{\circ} \mathrm{C}$, as well as cultures grown with a temperature shift from $25^{\circ} \mathrm{C}$ to $15^{\circ} \mathrm{C}$, were all greater than those grown at $30^{\circ} \mathrm{C}$ or with temperature shift from $30^{\circ} \mathrm{C}$ to $15^{\circ} \mathrm{C}$. A temperature shift from $25^{\circ} \mathrm{C}$ to $15^{\circ} \mathrm{C}$ resulted in an increase in DHA content by $19.9 \%$ and DHA productivity by $6.5 \%$ as compared to that 
maintained at $25^{\circ} \mathrm{C}$ for $72 \mathrm{~h}$. DHA productivity (rDHA) of the culture grown with temperature shift from $30^{\circ} \mathrm{C}$ to $15^{\circ} \mathrm{C}$ was $0.79 \mathrm{mg} / \mathrm{L} . \mathrm{h}$ while the culture grown at $30^{\circ} \mathrm{C}$ for $72 \mathrm{~h}$ was $0.39 \mathrm{mg} / \mathrm{L} . \mathrm{h}$ (Jiang and Chen, 2000). At $15^{\circ} \mathrm{C}(72 \mathrm{~h}), \mathrm{C}$. cohnii had a higher DHA proportion ( $57.64 \%$ of total fatty acids) but a lower biomass concentration than the cultures grown at $20^{\circ} \mathrm{C}, 25^{\circ} \mathrm{C}$ and $30^{\circ} \mathrm{C}$. DHA productivities were similar for all cultures grown at $15^{\circ} \mathrm{C}, 20^{\circ} \mathrm{C}$ and $25^{\circ} \mathrm{C}$, but was highest $(1.47 \mathrm{mg} / \mathrm{L} . \mathrm{h})$ with the temperature shift from $25^{\circ} \mathrm{C}$ to $15^{\circ} \mathrm{C}$. In this study, temperature shift from $25^{\circ} \mathrm{C}$ to $15^{\circ} \mathrm{C}$ was indicated as an advantage in terms of DHA production (Jiang and Chen, 2000).

\section{The effect of carbon source on growth and DHA production of C.}

\section{cohnii}

The effect of initial glucose concentration $(25 \mathrm{~g} / \mathrm{L} 50 \mathrm{~g} / \mathrm{L}$ and $75 \mathrm{~g} / \mathrm{L})$ of media on batch growth of C. cohnii was tested (Swaaf et al., 1999). All three media had the same yeast extract $(5 \mathrm{~g} / \mathrm{L})$ and sea salt concentrations $(17.8 \mathrm{~g} / \mathrm{L})$. Biomass concentrations were determined by optical density. The highest optical densities were reached with $75 \mathrm{~g} / \mathrm{L}$ glucose; however, initial growth rate decreased at concentrations above $25 \mathrm{~g} / \mathrm{L}$. The average doubling times between the $16^{\text {th }}$ and $40^{\text {th }}$ hour of growth were $10 \mathrm{~h}, 12.5 \mathrm{~h}$ and $13.8 \mathrm{~h}$ for $25 \mathrm{~g} / \mathrm{L}, 50 \mathrm{~g} / \mathrm{L}$ and $75 \mathrm{~g} / \mathrm{L}$ glucose concentrations respectively (Swaaf et al., 1999). A $25 \mathrm{~g} / \mathrm{L}$ glucose concentration showed highest growth rate for $C$. cohnii between 16-40 h as a result of lowest doubling time at this concentration. The initial growth rate decreased at concentrations above $25 \mathrm{~g} / \mathrm{L}$. 
Glucose and galactose were compared as carbon sources in batch cultivation of C. cohnii (Swaaf et al., 1999). C. cohnii cultures were grown in both glucose and galactose containing media resulting in similar DHA contents of 35.2 $\%$ and $36.2 \%$ of total lipid respectively. After $50 \mathrm{~h}$ of incubation, C. cohnii cultures grown in glucose media had reached optical density of 4.0 with $13.4 \%$ cell lipid content, while the cultures grown in galactose media reached optical density of 3.8 with $11.4 \%$ cell lipid content (Swaaf et al., 1999).

C. cohnii can also be grown using acetic acid as the carbon source resulting in high cell densities with high DHA productivities (Ratledge et al.2001, Swaaf et al. 2003a). When microorganisms are grown in sodium acetate, a rise in $\mathrm{pH}$ is observed. The $\mathrm{Na}^{+}$from sodium acetate remains in the growth medium and forms sodium hydroxide when combined with $\mathrm{OH}^{-}$. This rise in $\mathrm{pH}$ results in poor cell yield and is prevented in a $\mathrm{pH}$ auxostat culture system. In these systems, a low concentration of sodium acetate is included in the initial growth medium and acetic acid is used to maintain a constant $\mathrm{pH}$ value and to supply a further carbon source for growth. Ratledge et al., (2001) studied C. cohnii (ATTC 30772) growth in a $\mathrm{pH}$ auxostat culture system with initial sodium acetate concentrations ranging from $1 \mathrm{~g} / \mathrm{L}$ to $16 \mathrm{~g} / \mathrm{L}$. The strains were grown at $27^{\circ} \mathrm{C}$ for 4-5 days in ATCC medium 460 and then used to inoculate $100 \mathrm{~mL}$ of medium (9 g/L glucose, $2 \mathrm{~g} / \mathrm{L}$ yeast extract and $25 \mathrm{~g} / \mathrm{L}$ sea salt) to be used as starter cultures. Shake flask cultures grown in $100 \mathrm{~mL}$ media containing $27 \mathrm{~g} / \mathrm{L}$ glucose, $3.8 \mathrm{~g} / \mathrm{L}$ yeast extract and $25 \mathrm{~g} / \mathrm{L}$ sea salt were inoculated with static cultures at 10 $\%$ inoculation value. The shake flask cultures were used to inoculate $1 \mathrm{~L}$ 
fermenter containing $800 \mathrm{~mL}$ media composed of $7.5 \mathrm{~g} / \mathrm{L}$ yeast extract, $25 \mathrm{~g} / \mathrm{L}$ sea salt and different concentrations of sodium acetate changing between 1-16 $\mathrm{g} / \mathrm{L}$. Small $(1 \mathrm{~L}) \mathrm{pH}$-auxostat cultures grown at $27 \mathrm{C}$ for 3 days were used to inoculate $(5 \% \mathrm{vol} / \mathrm{vol})$ larger $(5 \mathrm{~L})$ fermenter containing $3.5 \mathrm{~L}$ the same media of $1 \mathrm{~L}$ fermenter. The $\mathrm{pH}$ and dissolved oxygen concentration was maintained at 6.5 and $30 \%$ respectively. For growth with glucose as principal carbon source, shake flask cultures were used to inoculate $1 \mathrm{~L}$ fermenter and then $5 \mathrm{~L}$ fermenter containing the same media of shake flasks. After $140 \mathrm{~h}$ of growth, the growth rate and cell density were greatest at $8 \mathrm{~g} / \mathrm{L}$ sodium acetate concentration. This concentration resulted in the highest lipid content in the cell; however, the sodium acetate concentration in the medium had no significant effect on the proportion of DHA (Ratledge et al., 2001). The accumulation of lipid by C. cohnii in pH auxostat batch culture with acetic acid as the principal carbon source was also compared with batch cultures grown in glucose as principal carbon source. Both lipid and DHA production were greater in the acetic acid culture than the glucose culture (Ratledge et al., 2001). Ratledge et al., (2001) were also compared six strains of $C$. cohnii cultures at $8 \mathrm{~g} / \mathrm{L}$ sodium acetate concentration. The strains investigated were ATCC 30772, ATCC 30541, ATCC 50298, ATCC 40750, ATCC 30555 \& ATCC 3055. C. cohnii ATCC 30772 was the best of six cultures tested because it had the greatest DHA yield between the $98^{\text {th }}$ and $144^{\text {th }}$ hour of cultivation. This strain reached $20-30 \mathrm{~g} / \mathrm{L}$ dry biomass and contained more than $40 \%$ total lipid with DHA accounting half of the total fatty acids. 
Fed-batch cultures refer to a batch culture fed continuously or with an intermittent manner with media. Glucose and acetate were compared as carbon sources in the fed batch cultivation of $C$. cohnii (Swaaf et al., 2003a). In glucose grown cultures, the feed rate was manually adjusted to maintain a residual glucose concentration between 5 and $20 \mathrm{~g} / \mathrm{L}$ throughout the fermentation; in acetic acid grown cultures the feed rate was controlled via culture $\mathrm{pH}$. Between $90 \mathrm{~h}$ and $120 \mathrm{~h}$ cultivation with $50 \%$ glucose, the final volumetric production rate was $14 \mathrm{mg} / \mathrm{L} . \mathrm{h}$ while cultivation with $50 \%$ acetic acid resulted in a maximum value of $38 \mathrm{mg} / \mathrm{L} . \mathrm{h}$ at $210^{\text {th }}$ hour. When the cultures were fed with pure acetic acid instead of $50 \%$ solution in water, a further increase in volumetric productivity was observed: between $150 \mathrm{~h}$ and $400^{\text {th }} \mathrm{h}$ cultivation, the final volumetric production rate was $48 \mathrm{mg} / \mathrm{L}$.h. With pure acetic acid feed, the final biomass, lipid and DHA concentrations reached were $109 \mathrm{~g} / \mathrm{L}, 61 \mathrm{~g} / \mathrm{L}$ and $19 \mathrm{~g} / \mathrm{L}$ respectively, and these were the highest values reported to the date for heterotrophic alga (Swaaf et al., 2003a).

The potential of ethanol as a carbon source was also investigated by Swaaf et al. (2003b). In shake flask cultures, growth did not occur at concentrations above $15 \mathrm{~g} / \mathrm{L}$ but occurred at the concentrations of 5 and $10 \mathrm{~g} / \mathrm{L}$. The specific growth rate was optimal at $5 \mathrm{~g} / \mathrm{L}$ ethanol (Swaaf et al. 2003b). In an ethanol grown fed batch cultivation of C. cohnii, $300 \mathrm{~g}$ pure ethanol was added over a total fermentation time of $220 \mathrm{~h}$. The volumetric production rate (rDHA) reached a maximum of $53 \mathrm{mg} / \mathrm{L}$ and the final concentrations of biomass dry weight, lipid and DHA were $83 \mathrm{~g} / \mathrm{L}, 35 \mathrm{~g} / \mathrm{L}$ and $11.7 \mathrm{~g} / \mathrm{L}$ respectively. The results 
of these studies showed that the volumetric production rate for DHA (rDHA) in ethanol grown (fed-batch) cultures was higher than the highest rDHA values of the cultures grown in glucose $(19 \mathrm{mg} / \mathrm{L} . \mathrm{h})$ and in acetic acid (48 mg/L.h) (Swaaf et al. 2003b). Although DHA content of the lipid produced by C. cohnii was the same in both acetic acid and ethanol grown cultures and the total lipid content was higher in the acetic acid than ethanol grown cultures, the ethanol grown cultures resulted in a considerably higher DHA because of the faster biomass production (Swaaf et al. 2003b).

\section{The effect of salinity on growth and DHA production of C. cohnii}

Growth of $C$. cohnii is favored by supplementing $\mathrm{NaCl}$ to the culture medium. Marine microalgae require $\mathrm{NaCl}$ to maintain the osmotic balance of the cells. Cells respond to salinity changes by adjusting their specific growth rates and cellular fatty acid composition. The reduced polyunsaturated fatty acids at increased salinities results in a reduction in membrane fluidity and permeability. The reduced membrane fluidity and permeability was reported as an improvement of the performance of the algae at high salinity to prevent leakage of compatible solutes out of the cell and diffusion of potential growth inhibitory ions into the cell (Jiang and Chen, 1999).

The effect of salt on the growth of C. cohnii was tested with $\mathrm{NaCl}$ concentrations ranging from 0.3 to $5 \%$. Growth was inhibited at 0.3 and $5 \%$ and failed in the absence of $\mathrm{NaCl}$ (Beach et al., 1973). 
Swaaf et al. (1999) studied the effect of sea salt on growth and lipid accumulation of $C$. cohnii with $\mathrm{NaCl}$ concentrations ranging from 2.8 to $27.8 \mathrm{~g} / \mathrm{L}$ in media containing $9 \mathrm{~g} / \mathrm{L}$ glucose and $2 \mathrm{~g} / \mathrm{L}$ yeast extract. Both growth and lipid accumulation were stimulated by increasing salinity. For optimal growth and lipid accumulation the minimal required sea salt concentration was $17.8 \mathrm{~g} / \mathrm{L}$, which is about half of the average sea water salinity. Similar growth and lipid accumulation was observed at both 27.8 and $17.8 \mathrm{~g} / \mathrm{L}$ sea salt concentrations (Swaaf et al., 1999).

Jiang and Chen (1999) investigated the effects of salt concentrations on cell growth and DHA content of C. cohnii ATCC 30556, C. cohnii ATCC 50051 and C. cohnii RJH. NaCl concentrations were in the range of $0-35 \mathrm{~g} / \mathrm{L}$. No growth was observed when the medium did not contain $\mathrm{NaCl}$ and at $\mathrm{NaCl}$ concentrations above $30 \mathrm{~g} / \mathrm{L}$. The specific growth rate of C. cohnii ATCC 30556 was greatest at $9 \mathrm{~g} / \mathrm{L} \mathrm{NaCl}$, while the other two strains were greatest at $5 \mathrm{~g} / \mathrm{L}$. The highest biomass concentration was achieved at $9 \mathrm{~g} / \mathrm{L} \mathrm{NaCl}$ yielding $2.51 \mathrm{~g} / \mathrm{L}$ for C. cohnii ATCC 30556 and $1.56 \mathrm{~g} / \mathrm{L}$ for C. cohnii ATCC 50051. The highest biomass concentration was achieved at $5 \mathrm{~g} / \mathrm{L} \mathrm{NaCl}$ yielding $2.49 \mathrm{~g} / \mathrm{L}$ for $C$. cohnii RJH. At $9 \mathrm{~g} / \mathrm{L} \mathrm{NaCl}$, C. cohnii ATCC 30556 had the highest DHA proportion (56.9 $\%$ of total fatty acids) while C. cohnii ATCC 50051 and C. cohnii RJH reached their highest DHA contents (54.6\% and $55.7 \%$ respectively) at $5 \mathrm{~g} / \mathrm{L} \mathrm{NaCl}$. At $\mathrm{NaCl}$ concentrations above the optimum value of $C$. cohnii, a decrease in specific growth rate due to the salinity adaptation was also reported. The reported modification of cellular fatty acid composition and changes in specific growth 
rates in response to the salinity changes for all three cells indicated that salinity was an important factor influencing the growth and chemical composition of the C. cohnii (Jiang and Chen, 1999).

\section{The effect of yeast extract on growth, lipid and DHA production of C. cohnii}

Yeast extract concentration of media is another important parameter affecting growth and DHA productivity of $C$. cohnii. The effect of yeast extract with concentrations ranging from $0 \mathrm{~g} / \mathrm{L}$ to $10 \mathrm{~g} / \mathrm{L}$ was studied in a medium composed of $9 \mathrm{~g} / \mathrm{L}$ glucose and $27.8 \mathrm{~g} / \mathrm{L}$ sea salt (Swaaf et al., 1999). At a yeast extract concentration of $1 \mathrm{~g} / \mathrm{L}$, optical density (OD) and lipid content of the biomass was 3.8 and $20 \%$, respectively. At a yeast extract concentration of 5 $\mathrm{g} / \mathrm{L}$ these values were 5.8 and $6 \%$, respectively.

When Swaaf et al. (2001) studied the effect of yeast extract on viscosity the yeast extract concentration was increased from $7.5 \mathrm{~g} / \mathrm{L}$ to $15 \mathrm{~g} / \mathrm{L}$. By doubling the yeast extract concentration, the biomass increased from $17.1 \mathrm{~g} / \mathrm{L}$ to $21.4 \mathrm{~g} / \mathrm{L}$, while the lipid content of the cells decreased from $13.8 \%$ to $5.1 \%$ (Swaaf et al., 2001). These results indicated that increasing amounts of yeast extract stimulated growth however lipid accumulation was negatively affected (Swaaf et al., 1999, 2001).

Ratledge et al. (2001) tested the effects of independently varying concentrations of yeast extract and sea salt in growth medium of $C$. cohnii in a $\mathrm{pH}$-auxostat culture with acetic acid and found no significant improvement in lipid 
accumulation or DHA production by modest increases or decreases in yeast and sea salt concentrations.

\section{The effect of oxygen availability, agitation, culture viscosity and pH on growth and DHA production of C. cohnii}

Oxygen tension is another important parameter affecting the growth of $C$. cohnii. Cells with an enhanced supply of $\mathrm{O}_{2}$, from flask or fermentor cultures, multiply more rapidly than cells grown with a restricted supply of oxygen (Beach \& Holz, 1973).

Tutle \& Loeblich (1975) investigated the importance of aeration and reported that rotary agitation in flask at 40 and $80 \mathrm{rev} / \mathrm{min}$ exponentially killed $C$. cohnii cells. Microscopic examination showed disintegration of the cells caused by this agitation. They also reported that aeration by bubbling sterile air at the rate of $1.8 \mathrm{l} / \mathrm{min}$ and agitation by stirring the culture with Teflon coated magnet at the rate of $200 \mathrm{rev} / \mathrm{min}$ did not increase the growth significantly. It was decided that oxygen supply was not a limiting factor in their culture conditions. In contrast to Tutle \& Loeblich's (1975) findings, Swaaf et al. (1999) reported a significant improvement in the growth of $C$. cohnii by increasing the agitation speed from 50 to $100 \mathrm{rpm}$ in shaken flask cultivations. According to their study, optical density (OD) reached at $100 \mathrm{rpm}$ was more than four times higher than the OD found for the culture grown at $50 \mathrm{rpm}$ at the $50^{\text {th }}$ hour of cultivation. This increase was thought due to the enhanced oxygen supply. In addition, microscopic 
examination of the cells revealed absence of any detrimental effects by agitation at 50-100 rpm (Swaaf et al.,1999).

Viscosity is especially important in high scale industrial cultivations, affecting both volumetric productivity of $\mathrm{DHA}(\mathrm{rDHA})$ and cost of the high cell density cultivation process. An increase in viscosity increases the need for heavy stirring which then increases the energy cost component of productions. In addition, an increase in agitation will produce more heat, which in turn will cause an increased need for cooling, resulting in higher energy costs. Swaaf et al. (2001) investigated the effects of culture viscosity on oxygen availability and the possible causes of this viscosity. Extra-cellular polysaccharides were produced by $C$. cohnii (batch growth) in a media composed of glucose, yeast extract and sea salt. The presence of these extra-cellular polysaccharides increased viscosity and decreased the oxygen transfer by decreasing oxygen transfer coefficient (Swaaf et al., 2001). Increased viscosity complicates the high cell density cultivation and thus DHA production. The effect of yeast extract on culture viscosity was tested and found that by doubling yeast extract concentration from $7.5 \mathrm{~g} / \mathrm{L}$ to $15 \mathrm{~g} / \mathrm{L}$, the biomass increased from $17.1 \mathrm{~g} / \mathrm{L}$ to 21.4 $\mathrm{g} / \mathrm{L}$. The viscosity of the supernatant also increased from $4.0 \mathrm{~mm} / \mathrm{s}^{2}$ to $5.6 \mathrm{~mm} / \mathrm{s}^{2}$ (Swaaf et al., 2001). Culture viscosity affects the oxygen transfer from the gas phase to the culture broth in a negative manner, as the culture viscosity increases it becomes difficult to supply cultures with sufficient dissolved oxygen. Efficient gas transfer is more difficult to achieve in large scale bioreactors than small scale bioreactors because large scale bioreactors have a lower maximal 
oxygen transfer coefficient $\left(k_{1} A\right)$ than small scale laboratory bioreactors (Swaaf et al., 2001).

Swaaf et al (2003 a) tested the effect of a polysaccharide hydrolyzing enzyme preparation Glucanex® (Novo Nordisk, Neumatt, Switzerland) on C. cohnii culture supernatant viscosity. The addition of $1 \mathrm{~g} / \mathrm{L}$ Glucanex led to an immediate increase in dissolved oxygen concentration and automatic reduction of the stirrer speed without a change in metabolic activity. The addition of $0.5 \mathrm{~g} / \mathrm{L}$ Glucanex was also found to reduce viscosity compared to media without Glucanex (Swaaf et al., 2003 a).

Tuttle and Loeblich (1975) examined the growth of C. cohnii at the range of $\mathrm{pH}$ (5.2-7.0). The $\mathrm{pH}$ for optimum growth was found as 6.6. Most published studies (Ratledge et al. 2001, Swaaf et al. 1999, 2001, 2003a, 2003b and 2003c) maintained $\mathrm{pH}$ at 6.5 which is very close to the optimum $\mathrm{pH}$ found by Tuttle and Loeblich in 1975. Furthermore, limited growth was reported below pH 5.2 (Tuttle and Loeblich, 1975).

The objective of this study is the successful cultivation of the marine alga C. cohnii with lipid and DHA production using a continuous cultivation strategy rather than batch. The long term objectives are to maximize DHA production from microbial sources. This research is expected to develop methodologies that will improve current process techniques to maximize DHA production from a safe and reliable source. 


\section{REFERENCES}

Al MD. Houwelingen AC. Hornstra G. 2000. Long chain polyunsaturated fatty acids, pregnancy, and pregnancy outcome. Am J Clin Nutr 71: 285-291

Beach DH. Holz GG. 1973. Environmental influences on the docosahexaenoate content of the triacylglycerols and phosphatidylcholine of a heterotrophic, marine dinoflagellate, Crypthecodinium cohni., Biochimica et Biophysica Acta 316: 56-65.

Beach DH. Harrington GW. Gellerman JL. Schlenk H. Holz GG. 1974. Biosynthesis of oleic acid and docosahexaenoic acid by a heterotrophic marine dinoflagellate Crypthecodinium cohni. Biochimica et Biophysica Acta 369: 16-24.

Bell MV. Henderson RJ. 1990. Molecular species composition of phosphatidylcholine from Crypthecodinium cohnii in relation to growth temperature. Lipids 25: 115-118.

Carlson SE. 1999. Arachidonic acid status human infants: influence of gestational age at birth and diets with very long chain n-3 and n-6 fatty acids. J. Nutr 126: 1092-1098.

Cheruku SR. Downs HE. Farkas SL. Thoman EB. Lammi-Keefe CJ. 2002. Higher maternal plasma docosahexaenoic acid during pregnancy is associated with more mature neonatal sleep-state patterning. American Journal of Clinical Nutrition 76: 608-613.

Gunstone FD. Structured and modified lipids. Marcel Dekker, New York (2001). 
Henderson RJ. Mackinlay EE. 1991. Polyunsaturated fatty acid metabolism in the marine dinoflagellate Crypthecodinium cohni . Phytochemistry 30: 1781-1787. Henderson RJ. Leftley JW. Sargent RJ. 1988. Lipid composition and biosynthesis in the marine dinoflagellate Crypthecodinium cohni. Phytochemistry 27: 16791683.

Huang YS. Pereira SL. Leonard AE. 2004. Enzymes for transgenic biosynthesis of long chain polyunsaturated fatty acids. Biochimie $86: 793-798$

Jiang Y. Cheng F. 1999. Effects of salinity on cell growth and docosahexaenoic acid content of the heterotrophic marine microalga Crypthecodinium cohni. Journal of Industrial Microbiology \& Biotechnology 23: 508-513.

Jiang Y. Cheng F. 2000. Effect of Temperature and Temperature Shift on Docosahexaenoic Acid Production by the Marine Microalga Crypthecodinium cohnii. JAOCS 77: 613-617.

Jiang Y. Cheng F. Liang SZ. 1999. Production potential of docosahexaenoic acid by the heterotrophic marine dinoflagellate Crypthecodinium cohnii. Process Biochemistry 34: 633-637.

Kyle DJ. 1996. Production and use of a single cell oil which is highly enriched in docosahexaenoic acid. Lipid Technology. September: 107-110.

Leman J. 1997. Oleaginous microorganisms: an assessment of the potential. Adv Appl Microbiol 43: 195-243.

Marszalek JR. Lodish HF. 2005. Docosahexaenoic acid, fatty acid- interacting proteins, and neuronal function: Breastmilk and fish are good for you. Annu. Rev. Cell Dev. Biol. 21: 633-657. 
Ratledge C. Kanagachandran K. Anderson AJ. Grantham DJ. Stephenson JC. 2001. Production of docosahexaenoic acid by Crypthecodinium cohnii grown in a pH-auxostat culture with acetic acid as principal carbon source. Lipids 36 : $1241-1246$.

Ratledge C, Evans CT.1989. Lipids and their metabolism. The Yeasts. Academic Press London. Ed 2. Vol. 3. 368-446.

Ratledge C. 2004. Fatty acid biosynthesis in microorganisms being used for single cell oil production. Biochimie 86: 807-815.

Schrooyen PMM. Meer R. Kruif De CG. 2001. Microencapsulation: its application in nutrition. Proceedings of the Nutrition Society 60: 475-479.

Simopoulos AP. 1991. Omega 3 fatty acids in health and disease and in growth and development. Am J Clin Nutr 54: 438-463

Simopoulos AP. 1999. Essential fatty acids in health and chronic disease. Am J Clin Nutr 70: 560-569..

Simopoulos AP. 2000. Human requirement for N-3 polyunsaturated fatty acids. Poultry Science 79: 961-970.

Swaaf ME. Rijk TC. Eggink G. Sijtsma L. 1999. Optimisation of docosahexaenoic acid production in batch cultivations by Crypthecodinium cohnii. Journal of Biotechnology 70 185-192.

Swaaf ME. Grobben GJ. Eggink G. Rijk TC. Meer P, Sijtsma L. 2001. Characterization of extracellular polysaccharides produced by Crypthecodinium cohnii. App Microbiol Biotechnol 57: 395-400. 
Swaaf ME. Sijtsma L. Pronk JT. 2003a. High cell density fed batch cultivation of the docosahexaenoic acid producing marine alga Crypthecodinium cohnii. Biotechnol Bioeng 81: 666-672.

Swaaf ME. Pronk JT. Sijtsma L. 2003b. Fed-batch cultivation of the docosahexaenoic acid producing marine alga Crypthecodinium cohn., App Microbiol Biotechnol 61: 40-43.

Swaaf ME. Rijk TC. Meer P. Eggink G. Sijtsma L. 2003c. Analysis of docosahexaenoic acid biosynthesis in Crypthecodinium cohnii by ${ }^{13} \mathrm{C}$ labeling and desaturase inhibitor experiments. Journal of Biotechnol 103: 21-29.

Tuttle RC. Loeblich AR. 1975. An optimal growth medium for the dinoflagellate Crypthecodinium cohnii. Phycologia 14: 1-8.

Ursin VM. 2003. Modification of plant lipids for human health: Development of functional land based omega-3 fatty acids. J. Nutr. 133: 4271-4274.

Vazhappilly R. Cheng F. 1998. Eicosapentaenoic acid and docosahexaenoic acid production potential of microalgae and their heterotrophic growth. JAOCS 75: 393-397.

Ward OP, Singh A. 2005. Omega-3/6 fatty acids: Alternative sources of production. Process Biochemistry 40: 3627-3652.

Whelan J. Rust C. 2006. Innovative Dietary Sources of N-3 Fatty Acids. Annu. Rev. Nutr. 26:75-103.

Yongmanitchai W. Ward OP. 1989. Omega-3 fatty acids: alternative sources of production. Proc Biochem: 117-125. 


\section{CHAPTER 3 - FED-BATCH CULTIVATION OF C. COHNII}

\section{ABSTRACT}

Crypthecodinium cohnii (ATCC 30772) was revived and grown in ATCC complex media 460 for 10 days at $25{ }^{\circ} \mathrm{C}$, transferred to simple media $(9 \mathrm{~g} / \mathrm{L}$ glucose, $2 \mathrm{~g} / \mathrm{L}$ yeast, and $25 \mathrm{~g} / \mathrm{L}$ salt) and incubated statically for 8 days at $25^{\circ} \mathrm{C}$. Cultures were subsequently transferred to larger volumes of simple media and incubated at $25{ }^{\circ} \mathrm{C}$ in an orbital shaker incubator at $100 \mathrm{rpm}$. At each transfer, a $10 \%(\mathrm{v} / \mathrm{v})$ inoculum level was maintained. Batch cultivation of C. cohnii was conducted in a $15 \mathrm{~L}$ computer controlled bioreactor vessel. Temperature of bioreactor was maintained at $27^{\circ} \mathrm{C}$ by a computer controlled heating jacket. A $25 \%$ glucose solution was administered continuously at a rate of $0.78 \mathrm{~mL} / \mathrm{min}$. Algal growth was monitored spectrophotometrically and measured every $12 \mathrm{~h}$ at $470 \mathrm{~nm}$. The biomass concentration, lipid content and fatty acid profile were determined by harvesting samples from the vessel every $24 \mathrm{~h}$. Results of the study showed that $C$. cohnii growth was achieved in batch-mode cultivation with lipid and DHA production. Maximum volumetric DHA productivity (3.61 mg/L.h) was achieved at the 71st hour of the cultivation. Maximum biomass, fat and DHA concentrations achieved were $8.35 \mathrm{~g} / \mathrm{L}, 0.89 \mathrm{~g} / \mathrm{L}$ and $0.32 \mathrm{~g} / \mathrm{L}$, respectively. These values did not exceed the reported values of other batch processes that used a $50 \%$ glucose feed. With fed-batch and continuous cultures dilution rate is an important parameter affecting the growth because the substrate concentration in the culture broth is dependent on the dilution rate. The use of $25 \%$ glucose 
solution versus $50 \%$ or inappropriate feed rate may cause the growth inhibition by the substrate. In order to exceed the previous reported values the feed (media) rate, the composition of the feed and the concentration of the glucose solution should be optimized.

\section{INTRODUCTION}

Docosahexaenoic acid (DHA) is a long chain poly unsaturated fatty acid with 22 carbons and 6 double bonds. DHA belongs to the omega- 3 group of fatty acids and is an important structural fatty acid found in neural tissue and in heart tissue. The phospholipids of the brain and retina are characterized by high contents of omega-3 fatty acids, particularly by DHA (Cheruku at al. 2002). Thus, DHA is important for the normal brain and retina development of fetuses and infants (Marszalek et al. 2005). Maternal DHA status is significantly influenced by dietary DHA and it is associated with maturity of the central nervous systems of infants at birth (Al et al. 2000, Cheruku at al. 2002).

The most widely available source of DHA is cold water fatty fish. Although fish is a very good source of DHA, they do not synthesize it but ingest it from sources in the marine food chain, primarily by algae (Yongmanitchai \& Ward, 1989). Two groups of marine organisms, Crypthecodinium cohnii and thraustochytrid group, are used for the commercial production of DHA rich oil (Ward et al., 2005). Marine algae C.cohnii is capable of synthesizing lipid with a high proportion of DHA (30-50\%) with the absence of other PUFAs above $1 \%$ (Beach et al., 1973\&1974). Commercial production of DHA is conducted by a 
very limited number of companies, in large bioreactors using a batch-mode cultivation process.

The purpose of this study was to achieve successful cultivation of $C$. cohnii with a batch mode process and to investigate biomass, lipid and DHA accumulation during the cultivation period. The experience gained by this study will help lead to the successful continuous cultivation of C.cohnii. The long term objective of this research is to maximize DHA production from a safe and reliable marine source.

\section{MATERIALS AND METHODS}

\section{Algal Cultures}

A Crypthecodinium cohnii (ATCC 30772 ) ampoule was stored at $-80^{\circ} \mathrm{C}$ in an Ultra low temperature freezer (U535, New Brunswick Scientific, Edison, NJ). The ampoule was thawed at room temperature and aseptically transferred to 5 $\mathrm{mL}$ ATCC growth medium 460 in a screw-capped test tube. ATCC growth medium 460 was composed of: $23.48 \mathrm{~g} / \mathrm{L} \mathrm{NaCl} ; 10.63 \mathrm{~g} / \mathrm{L} \mathrm{MgCl}{ }_{2} 6 \mathrm{H}_{2} \mathrm{O} ; 3.92 \mathrm{~g} / \mathrm{L}$ $\mathrm{Na}_{2} \mathrm{SO}_{4} ; 1.11 \mathrm{~g} / \mathrm{L} \mathrm{CaCl} 2 ; 0.66 \mathrm{~g} / \mathrm{L} \mathrm{KCl} ; 0.19 \mathrm{~g} / \mathrm{L} \mathrm{NaHCO}{ }_{3} ; 0.1 \mathrm{~g} / \mathrm{L} \mathrm{KBr} ; 0.03 \mathrm{~g} / \mathrm{L}$ $\mathrm{H}_{3} \mathrm{BO}_{3} ; 0.04 \mathrm{~g} / \mathrm{L} \mathrm{SrCl}{ }_{2} 6 \mathrm{H}_{2} \mathrm{O} ; 3.0 \mathrm{ml}$ Metal Mixture (0.03 g/L EDTA; $0.05 \mathrm{~g} / \mathrm{L} \mathrm{FeCl}$ $6 \mathrm{H}_{2} \mathrm{O} ; 1.0 \mathrm{~g} / \mathrm{L} \mathrm{H}_{3} \mathrm{BO}_{3} ; 0.15 \mathrm{~g} / \mathrm{L} \mathrm{MnCl} \mathrm{Mn}_{2} 4 \mathrm{H}_{2} \mathrm{O} ; 0.1 \mathrm{~g} / \mathrm{L} \mathrm{ZnCl} 2 ; 0.005 \mathrm{~g} / \mathrm{L} \mathrm{CoCl} 26 \mathrm{H}_{2} \mathrm{O}$; $100.0 \mathrm{ml}$ distilled deionized water $\left.\left(\mathrm{ddH}_{2} \mathrm{O}\right)\right) ; 0.01 \mathrm{~g} / \mathrm{L} \mathrm{FeCl}_{3} 6 \mathrm{H}_{2} \mathrm{O} ; 0.15 \mathrm{~g} / \mathrm{L}$ sodium glycerophosphate; $0.05 \mathrm{~g} / \mathrm{L}\left(\mathrm{NH}_{4}\right)_{2} \mathrm{SO}_{4} ; 3.0 \mathrm{~g} / \mathrm{L}$ TRIS buffer, $1.0 \mathrm{~mL}$

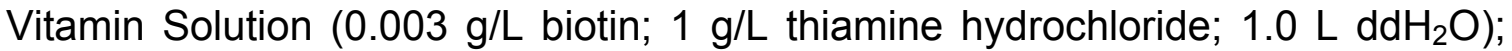

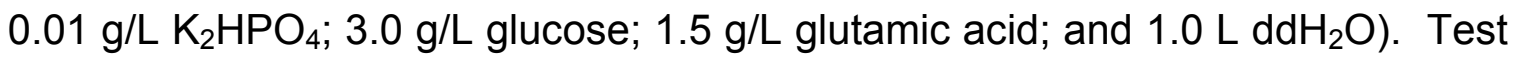


tube caps were screwed on tightly and then loosened one half turn. Cultures were statically incubated upright at $25^{\circ} \mathrm{C}$ for $10-14$ days (as the manufacturer suggested) in a Fisher Scientific Isotemp Economy Incubator (537D, Hampton, $\mathrm{NH}$ ). The cultures were sub-cultured by screwing the cap on tightly, inverting the culture 5 times, and aseptically transferring a $0.1 \mathrm{~mL}$ to $5 \mathrm{~mL}$ ATCC growth medium 460 in screw-capped test tubes. The sub-culturing process was repeated every 10-14 days.

\section{Strain, media and maintenance of cells}

Static sub-cultures $(0.1 \mathrm{~mL})$ were aseptically transferred to test tubes containing $5 \mathrm{~mL}$ media (9 g/L glucose, $2 \mathrm{~g} / \mathrm{L}$ yeast extract and $25 \mathrm{~g} / \mathrm{L}$ sea salt) and incubated statically at $25{ }^{\circ} \mathrm{C}$ for 8 days. Cultures were aseptically transferred to a $250 \mathrm{~mL}$ flask containing $50 \mathrm{~mL}$ media $(9 \mathrm{~g} / \mathrm{L}$ glucose, $2 \mathrm{~g} / \mathrm{L}$ yeast extract and

$25 \mathrm{~g} / \mathrm{L}$ sea salt) at an inoculation level of $10 \% \mathrm{v} / \mathrm{v}$ and incubated at $25{ }^{\circ} \mathrm{C}$ for 3 days in a shaker incubator (C24, New Brunswick Scientific, Edison, NJ) at 100 rpm. The contents of the flask were then transferred to $500 \mathrm{~mL}$ flasks each containing $100 \mathrm{~mL}$ media $(25 \mathrm{~g} / \mathrm{L}$ glucose, $5.5 \mathrm{~g} / \mathrm{L}$ yeast extract and $25 \mathrm{~g} / \mathrm{L}$ sea salt) and incubated in a shaker incubator $(100 \mathrm{rpm})$ at $25^{\circ} \mathrm{C}$ for 3 days. These cultures were used for inoculation of the bioreactors at an initial inoculation level of $10 \% \mathrm{v} / \mathrm{v}$.

\section{Bioreactors}

Fed-batch cultivation was performed in a computer controlled (Biostat $\AA$ Twin Controller, Sartorius BBI Systems, Bethlehem, PA, USA) 15 L bioreactor 
vessel. Temperature of the vessel was maintained at $27^{\circ} \mathrm{C}$ using a computer controlled heating jacket (Sartorius BBI Systems, Bethlehem, PA, USA). The initial medium in the bioreactor was composed of $5 \mathrm{~g} / \mathrm{L}$ glucose, $10 \mathrm{~g} / \mathrm{L}$ yeast

extract, $25 \mathrm{~g} / \mathrm{L}$ sea salt and $0.5 \mathrm{~g} / \mathrm{L}$ commercial polysaccharide hydrolyzing enzyme (Lysing Enzymes from Trichoderma, Sigma Aldrich Inc, St. Louis, MO). The $\mathrm{pH}$ was maintained at 6.5 by automatic addition of $2.5 \mathrm{M} \mathrm{NaOH}$ and $3 \mathrm{M}$ $\mathrm{HCl}$. A $25 \%$ glucose solution was administered continuously at a rate of 0.78 $\mathrm{mL} / \mathrm{min}$. Foam production was suppressed by addition of antifoam B (AstoriaPacific, Clackmas, OR, USA) 1 drop/L as needed. Dissolved oxygen was maintained at $30 \%$ by computer controlled flushing with filter sterilized air and by stirring.

\section{Calculation of the Flow Rates}

In the study done by Swaaf et al. (1999), average glucose feed rate was $1.06 \mathrm{~g}$ glucose $/ \mathrm{h}$ for the first 75 hours. This value of feed rate was used as the basis for flow rate calculations. Accordingly, the feed rate for a $50 \%$ glucose solution in water was calculated as:

$(1.06 \mathrm{~g}$ glucose $/ \mathrm{h}) \times(100 \mathrm{~mL}$ soln $/ 50 \mathrm{~g}$ glucose $) \times(\mathrm{h} / 60 \mathrm{~min})=0.035 \mathrm{~mL} / \mathrm{min}$ (for $1 \mathrm{~L}$ start up volume)

Since thin fluids have lower viscosity than thick fluids, $25 \%$ solution was preferred in place of $50 \%$ to decrease the resistance of fluid to flow. With $25 \%$ glucose feed the flow rate was doubled (multiplied by 2) to supply culture the same amount of glucose as with $50 \%$. 
Accordingly, the feed rate for a $25 \%$ glucose solution and $11 \mathrm{~L}$ start up volume was calculated as:

$(0.035 \mathrm{~mL} / \mathrm{min}) \times 2 \times(11 \mathrm{~L})=0.78 \mathrm{~mL} / \mathrm{min}$

\section{Growth of Cells}

Optical density and biomass concentration were used to evaluate growth over time. Samples $(3-5 \mathrm{~mL})$ were aseptically removed from the bioreactor vessel twice a day over the course of the cultivation period. Optical density was measured spectrophotometrically at $470 \mathrm{~nm}$ (Swaaf, 1999). Approximately $1 \mathrm{~L}$ of culture was harvested each day from the bioreactor vessel so that biomass concentration could be ascertained. The sample was centrifuged $(10,000 \mathrm{~g}$ at $5^{\circ} \mathrm{C}$ for $10 \mathrm{~min}$ ) and the pellet was rinsed once with $50 \mathrm{ml} \mathrm{dH} 2 \mathrm{O}$, lyophilized, and weighed. Biomass concentration was calculated by dividing the weight of freeze dried sample to the volume of sample solution centrifuged for that freeze dried sample quantity.

\section{Analysis of Fatty Acids}

Fat and fatty acids were extracted from biomass by the acidic hydrolysis method (AOAC Official Method 996.06). Pyrogallic acid was added to minimize oxidative degradation of fatty acids during analysis. Triglyceride, triundecanoin (C11:0), was used as internal standard. Fat was extracted into ether, then methylated to fatty acid methyl esters (FAMEs) using boron trifluoride (BF3) in methanol (Appendix A). FAMEs were quantitatively measured by capillary gas chromatography against the $\mathrm{C} 11: 0$ internal standard. All samples were analyzed 
on a gas-liquid chromatography (Agilent Technologies, Model 7890A) equipped with a 7683B series Injector. Helium was used as the carrier gas with a 0.75 $\mathrm{mL} / \mathrm{min}$ flow rate. The temperature program for separations began at $100^{\circ} \mathrm{C}$, held for $4 \mathrm{~min}$, increased to $240^{\circ} \mathrm{C}$ at $3^{\circ} \mathrm{C} / \mathrm{min}$ and held for $15^{\circ} \mathrm{C}$. Temperatures for injector and detector were 225 and $285^{\circ} \mathrm{C}$ respectively. Peaks were identified by comparing their retention times with references.

Total fat was calculated as sum of individual fatty acids expressed as triglyceride equivalents.

\section{Statistical Analysis}

The batch cultivation experiment was conducted once with observations in duplicate. Data were analyzed by multiple linear regressions using MS Office 2003. 


\section{RESULTS AND DISCUSSION}

Growth of C. cohni, with lipid and DHA production, was achieved in batchmode cultivation. Optical density was used to evaluate growth over time, C. cohnii reached homeostasis by $50^{\text {th }} \mathrm{h}$ of cultivation (Figure 2). Optical density $(470 \mathrm{~nm})$ at the $17^{\text {th }} \mathrm{h}$ of cultivation was 1.3 and reached maximum value of 2.41 .

Maximum biomass concentration was achieved by $45 \mathrm{~h}$ cultivation, followed by a gradual reduction until the $89^{\text {th }}$ hour of cultivation (Figure 3 ). Maximum biomass concentration was $8.35 \mathrm{~g} / \mathrm{L}$ (at $45^{\text {th }}$ hour of bioreactor cultivation). Swaaf et al. (2003a) reported a final maximum biomass concentration of $26 \mathrm{~g} / \mathrm{L}$ over a cultivation period of $120 \mathrm{~h}$ with $50 \%$ glucose solution feed.

Fat content of biomass increased steadily between $24^{\text {th }}$ and $137^{\text {th }}$ hours of the bioreactor cultivation. An increase from $3.60 \%$ to $14.0 \%$ was observed during this period of time (Figure 3 and Table 1). This shows a positive relationship between the fat content and cultivation time. Swaaf et al. (2003a) reported a maximum lipid content of $15 \%$ (at $90^{\text {th }}$ hour of cultivation) with $50 \%$ glucose feed which is very close to our maximum value reached (14\%) with $25 \%$ glucose feed.

The proportion of DHA in the lipid also increased steadily between $24^{\text {th }}$ and $137^{\text {th }}$ hours of the bioreactor cultivation. An increase from $15.4 \%$ to $36.60 \%$ was observed during this period of time (Figure 3 and Table 1). Like the lipid 
content, a positive relationship was observed between the DHA content and age of the culture. Maximum DHA percentage achieved was $36.7 \%$ at $116^{\text {th }}$ hour of cultivation. Swaaf et al. (2003a) reported a maximum value of $46 \%$ for DHA percentage with $50 \%$ glucose feed.

Maximum lipid and DHA concentrations were $0.89 \mathrm{~g} / \mathrm{L}$ and $0.32 \mathrm{~g} / \mathrm{L}$ respectively (Figure 4). However, these values were quite low compared to the previously reported maximum values of $3.8 \mathrm{~g} / \mathrm{L}$ and $1.7 \mathrm{~g} / \mathrm{L}$ with $50 \%$ glucose fed batch process (Swaaf et al., 2003a).

The rDHA is the value of volumetric DHA productivity per liter of the harvest per hour. Maximum volumetric DHA productivity achieved at the $71^{\text {th }}$ hour of bioreactor cultivation was $3.61 \mathrm{mg} / \mathrm{L} . \mathrm{h}$ (Figure 4). Swaaf et al. (2003 a) reported maximum rDHA with $50 \%$ glucose feed culture as 14 mg/L.h. Compared to $14 \mathrm{mg} / \mathrm{L} . \mathrm{h}$, the rDHA of this study (3.61 mg/L.h) was quite low. The use of $25 \%$ glucose solution in place of $50 \%$ might account for some portion of this difference. Since of $25 \%$ glucose solution contains more water, it will dilute the culture more and so will decrease the cell density. A $25 \%$ solution was preferred in place of $50 \%$ to decrease the resistance of fluid to flow and to provide better flow. Although cultivation of $C$. cohnii with lipid and DHA production was achieved, high cell densities could not be achieved. There are a number of reasons for this result. As stated previously, $25 \%$ glucose solution used in this study diluted the culture more than $50 \%$ glucose solution used in the previous study (Swaaf et al. 2003a). By flow rate adjustment the same amount of glucose as with $50 \%$ glucose solution pumped to the bioreactor vessel with $25 \%$ 
glucose solution but more water. Also, shifts in temperature and dissolved oxygen concentrations may have had an effect on cell concentration. Initially, the temperature of bioreactor vessel was set to $27^{\circ} \mathrm{C}$; however, a rise in temperature $\left(+2.8^{\circ} \mathrm{C}\right)$ was observed. Therefore, the set temperature was reduced to $25{ }^{\circ} \mathrm{C}$. The temperature reduction was not enough to maintain the vessel at $27^{\circ} \mathrm{C}$. This may be due to a heat producing chemical reaction by the alga (biological heat) and/or heat of friction by agitation in the vessel. Swaaf et al. (2003a) pointed out cooling problems in large scale reactors due to biological heat production and power input via mixing. In an attempt to cool the contents of the growth vessel, the heating jacket was removed and the vessel was cooled by air movement. Temperature was maintained at $26.5+/-0.5{ }^{\circ} \mathrm{C}$ from the $17^{\text {th }} \mathrm{h}$ through the duration of the growth phase of cultivation $\left(41^{\text {st }} h\right)$. There were no remarkable changes in optical density during 48-65 hrs of cultivation possibly due to an interruption in oxygen flow. From the start to the end of the cultivation, lipid content of biomass \& DHA content of lipid increased steadily; however, the previously reported maximum biomass concentration (26 g/L) was not achieved (Swaaf et al. 2003a). Biomass concentration and the volumetric productivity are the most important parameters reflecting the DHA production capacity of processes. Future research will look at the ways to increase biomass concentration and volumetric DHA productivity $(\mathrm{rDHA})$. 


\section{REFERENCES}

Al MD. Houwelingen AC. Hornstra G. 2000. Long chain polyunsaturated fatty acids, pregnancy, and pregnancy outcome. Am J Clin Nutr 71: 285-291

Beach DH. Holz GG. 1973. Environmental influences on the docosahexaenoate content of the triacylglycerols and phosphatidylcholine of a heterotrophic, marine dinoflagellate, Crypthecodinium cohni., Biochimica et Biophysica Acta 316: 56-65.

Beach DH. Harrington GW. Gellerman JL. Schlenk H. Holz GG. 1974. Biosynthesis of oleic acid and docosahexaenoic acid by a heterotrophic marine dinoflagellate Crypthecodinium cohni. Biochimica et Biophysica Acta 369: 16-24.

Bell MV. Henderson RJ. 1990. Molecular species composition of phosphatidylcholine from Crypthecodinium cohnii in relation to growth temperature. Lipids 25: 115-118.

Cheruku SR. Downs HE. Farkas SL. Thoman EB. Lammi-Keefe CJ. 2002. Higher maternal plasma docosahexaenoic acid during pregnancy is associated with more mature neonatal sleep-state patterning. American Journal of Clinical Nutrition 76: 608-613.

Jiang Y. Cheng F. 1999. Effects of salinity on cell growth and docosahexaenoic acid content of the heterotrophic marine microalga

Marszalek JR. Lodish HF. 2005. Docosahexaenoic acid, fatty acid- interacting proteins, and neuronal function: Breastmilk and fish are good for you. Annu. Rev. Cell Dev. Biol. 21: 633-657. 
Swaaf ME. Rijk TC. Eggink G. Sijtsma L. 1999. Optimisation of docosahexaenoic acid production in batch cultivations by Crypthecodinium cohnii. Journal of Biotechnology 70 185-192.

Swaaf ME. Sijtsma L. Pronk JT. 2003a. High cell density fed batch cultivation of the docosahexaenoic acid producing marine alga Crypthecodinium cohnii. Biotechnol Bioeng 81: 666-672.

Swaaf ME. Pronk JT. Sijtsma L. 2003b. Fed-batch cultivation of the docosahexaenoic acid producing marine alga Crypthecodinium cohn., App Microbiol Biotechnol 61: 40-43.

Ward OP, Singh A. 2005. Omega-3/6 fatty acids: Alternative sources of production. Process Biochemistry 40: 3627-3652.

Yongmanitchai W. Ward OP. 1989. Omega-3 fatty acids: alternative sources of production. Proc Biochem: 117-125. 
Figure 2.Optical density of Crypthecodinium cohnii over time in batch mode process

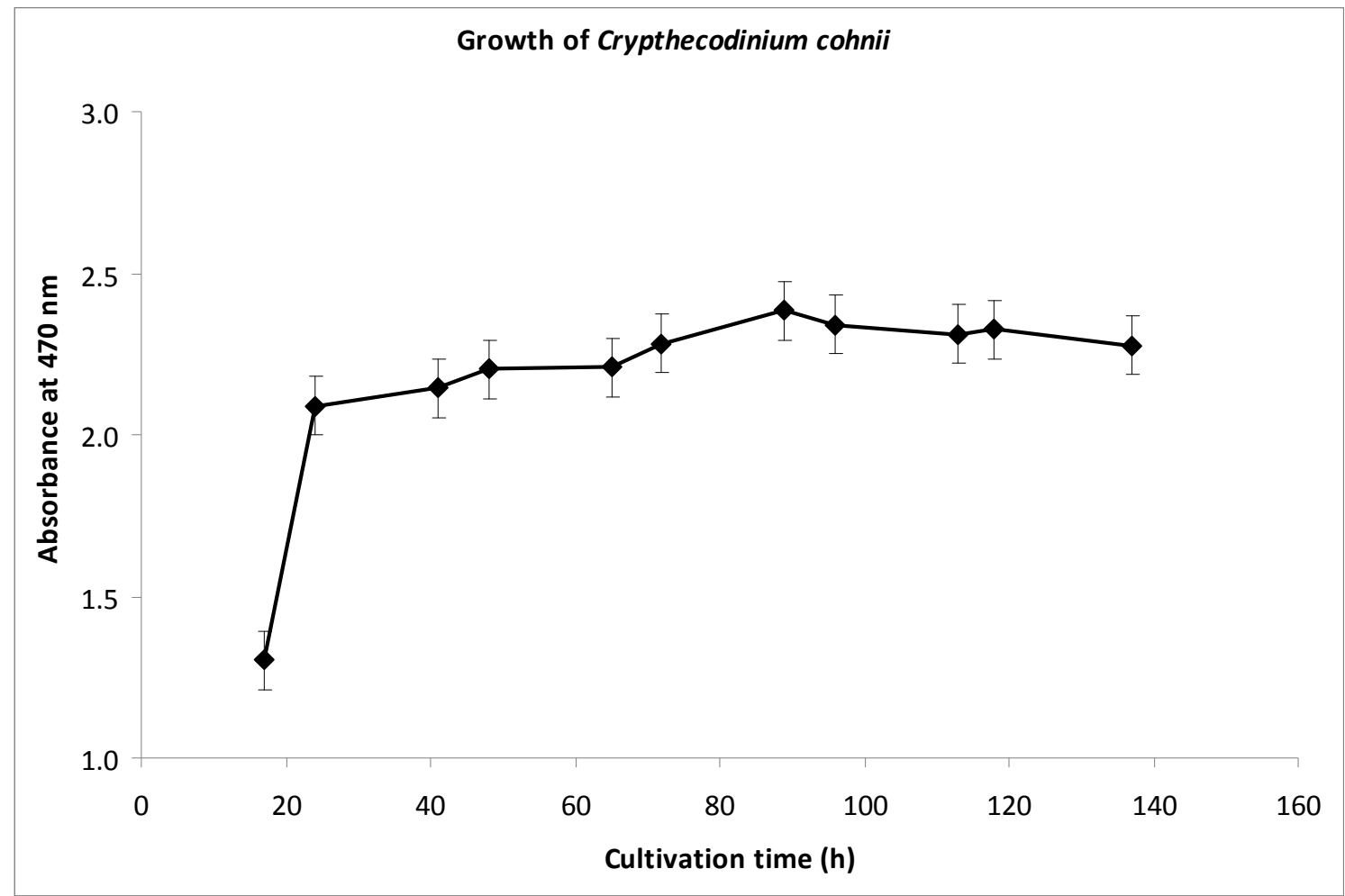

Figure 3. Biomass concentration (BC), Lipid content of dry biomass (lipid \%) and DHA content of lipid (DHA\%) over time in batch mode process

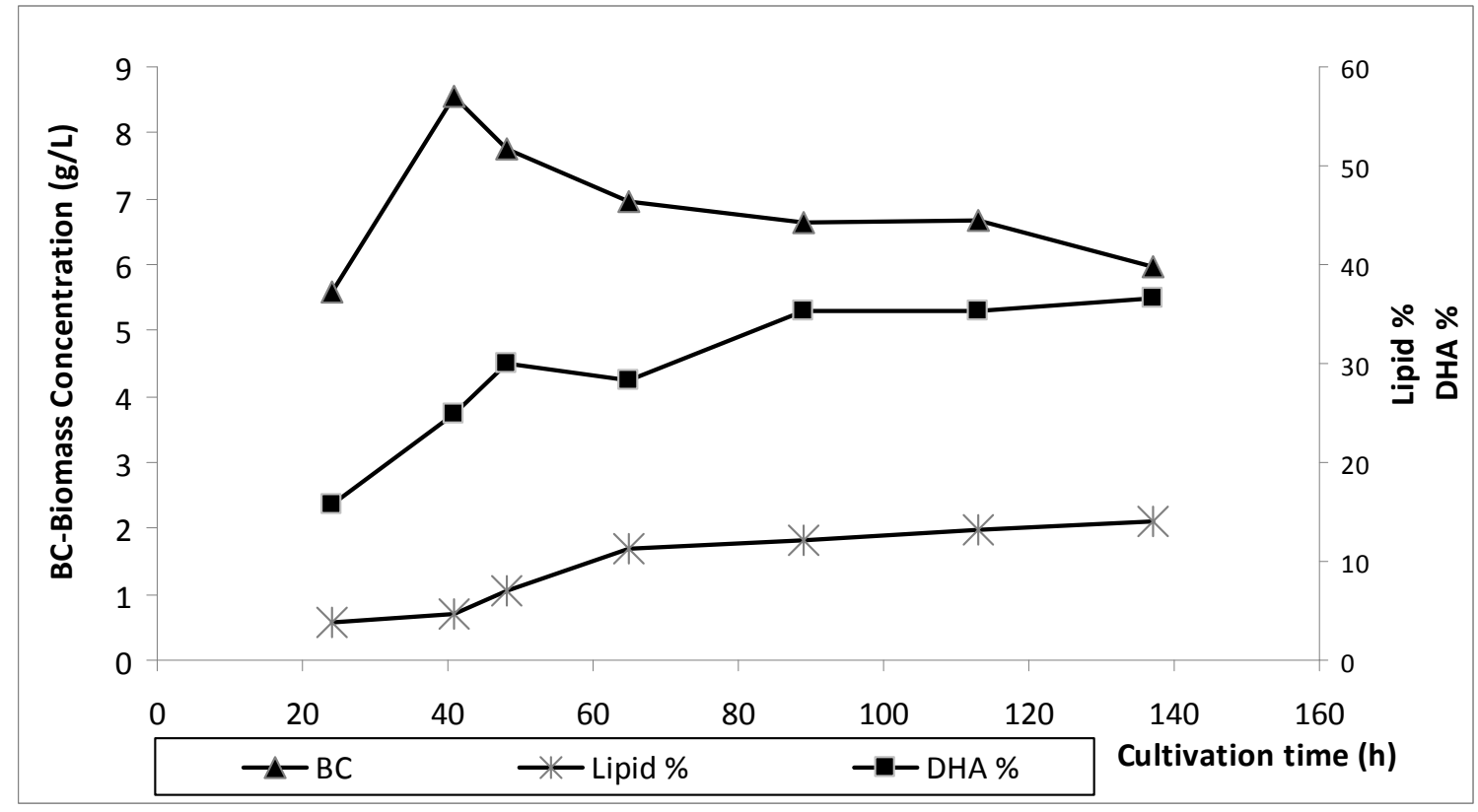


Figure 4. Lipid concentration, volumetric productivity of DHA (rDHA) and DHA concentration change over time in a batch mode process.

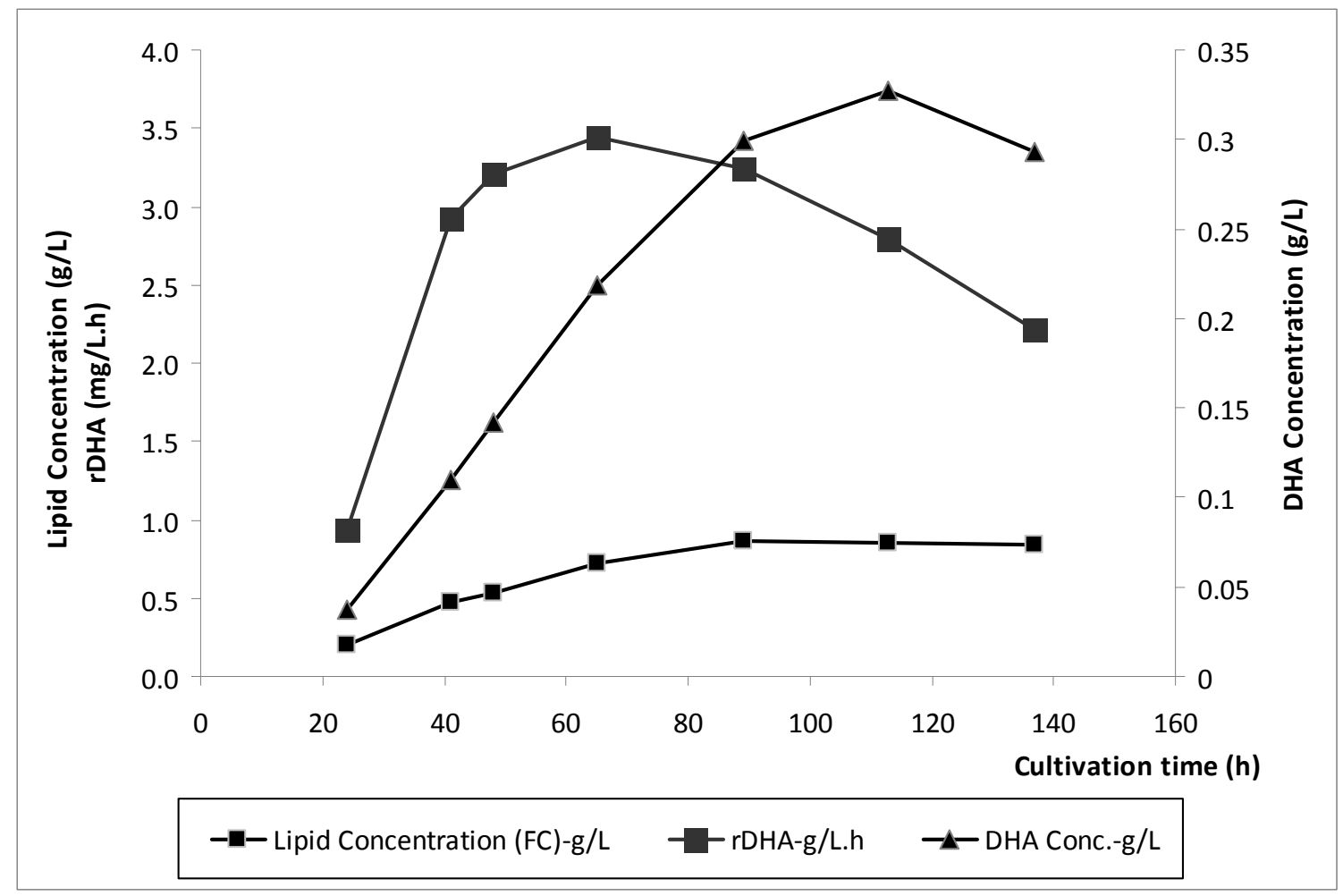

Table 1. Fat (\%) and fatty acid profile of C. cohnii over time in a batch mode process

\begin{tabular}{|l|r|r|r|r|r|r|r|}
\hline Cultivation time & $\mathbf{2 4}$ & $\mathbf{4 1}$ & $\mathbf{4 8}$ & $\mathbf{6 5}$ & $\mathbf{8 9}$ & $\mathbf{1 1 3}$ & $\mathbf{1 3 7}$ \\
\hline $\begin{array}{l}\text { Lipid \% (g Lipid/100g } \\
\text { dry Biomass) }\end{array}$ & 3.74 & 4.785 & 7.005 & 11.355 & 12.135 & 13.245 & 13.975 \\
\hline $\begin{array}{l}\text { DHA (g DHA/100g } \\
\text { Lipid) }\end{array}$ & 15.695 & 24.98 & 29.945 & 28.32 & 35.34 & 35.265 & 36.65 \\
\hline
\end{tabular}




\section{CHAPTER 4 - CONTINUOUS CULTIVATION OF C. COHNII}

\section{ABSTRACT}

Docosahexaenoic acid (DHA), an omega-3 fatty acid, has positive health benefits. The heterotrophic marine alga Crypthecodinium cohnii is an important source of DHA because C. cohnii can accumulate lipid greater than $20 \%$ of their biomass with a large fraction of DHA (30-50\%). Commercially, DHA production by $C$. cohnii is conducted in large bioreactors $\left(\sim 100 \mathrm{~m}^{3}\right.$ capacity) using a batchmode process. The purpose of this study was to investigate lipid and DHA production by $C$. cohnii using a novel, continuous-mode process.

Continuous cultivation of Crypthecodinium cohnii was conducted in two 15

$\mathrm{L}$ computer controlled bioreactor vessels. Temperature of both vessels was maintained at $27^{\circ} \mathrm{C}$ during the growth mode of the study and standard media (25g/L glucose, $5.5 \mathrm{~g} / \mathrm{L}$ yeast, and $25 \mathrm{~g} / \mathrm{L}$ salt) were administered to both bioreactors. After $40 \mathrm{~h}$, the system was switched to "continuous" mode where one vessel was maintained as a growth vessel at $27^{\circ} \mathrm{C}$, and the other as a lipid accumulation vessel at $17^{\circ} \mathrm{C}$. In continuous mode, standard media were administered to the growth vessel and a glucose $(25 \%)$ solution was administered to the lipid accumulation vessel. Results showed that C. cohnii growth was maintained in continuous production. Maximum values for DHA productivity, biomass, lipid and DHA concentrations were $4.132 \mathrm{mg} / \mathrm{L} . \mathrm{h}, 3.75 \mathrm{~g} / \mathrm{L}, 0.55 \mathrm{~g} / \mathrm{L}$ and $0.145 \mathrm{~g} / \mathrm{L}$ respectively. More research is needed to optimize processing parameters in continuous mode to produce a viable alternative to batch mode 
processes. Future research will look at the effect of different temperatures, carbon sources and feed rates on C. cohnii growth, lipid and DHA accumulation in continuous mode process.

\section{INTRODUCTION}

Long chain polyunsaturated fatty acids, especially docosahexaenoic acid (DHA) has positive health benefits. The phospholipids of the brain and retina are characterized by high contents of omega-3 fatty acids, particularly by DHA (Cheruku at al. 2002). Thus, DHA is an essential nutrient particularly during periods of rapid tissue growth and is important for the proper brain and retina development of fetuses \& infants (Marszalek et al., 2005). The most widely available source of DHA is cold water fatty fish. However, fish oil supresses the endogenous arachidonic acid (ARA) synthesis of infants resulting in decreased growth rate (Carlson, 1996). For this reason, it is banned in the USA for use in infant formula (Ratledge, 2004; Carlson, 1996). Furthermore, the use of fish oil in the food industry is limited because of its strong smell and taste. The application of DHA for human and animal nutrition is a fast growing market. Therefore, it is necessary to supply this demand and to identify safe, cost effective alternatives.

Microorganisms have long been known to be a source of "valuable" lipids because they are free of cholesterol, heavy metals, and pesticides; they are also high in polyunsaturated fatty acids (PUFAs) (Gunstone, 2001). Crypthecodinium cohnii is a very good candidate for a DHA source because it is capable of producing a high proportion (30-50\%) of lipid as DHA (Beach et al., 1973). 
Commercially, DHA production by C. cohnii is conducted in large bioreactors using a batch-mode process. There are a limited number of studies that report lipid and DHA production by C. cohnii in batch mode cultivation; no published work has been found on lipid and DHA production by $C$. cohnii in continuous cultivation. The purpose of this study was to investigate lipid and DHA production by C. cohnii using a novel, continuous-mode process. The long term objective of this research is to improve the existing cultivation methods of the marine alga $C$. cohni and to maximize production of DHA.

\section{MATERIALS AND METHODS}

\section{Strain, media and maintenance of cells}

An ampoule of $C$. cohnii (ATCC 30772) was stored at $-80^{\circ} \mathrm{C}$ in an UltraLow temperature freezer (New Brunswick Scientific, Edison, NJ, U535). The ampoule was thawed at room temperature and aseptically transferred to $5 \mathrm{~mL} \mathrm{ATCC}$ growth medium 460 in a screw-capped test tube. ATCC growth medium 460 was composed of: $23.48 \mathrm{~g} / \mathrm{L} \mathrm{NaCl} ; 10.63 \mathrm{~g} / \mathrm{L} \mathrm{MgCl}_{2} 6 \mathrm{H}_{2} \mathrm{O} ; 3.92 \mathrm{~g} / \mathrm{L} \mathrm{Na} \mathrm{SO}_{4} ; 1.11 \mathrm{~g} / \mathrm{L}$ $\mathrm{CaCl}_{2} ; 0.66 \mathrm{~g} / \mathrm{L} \mathrm{KCl} ; 0.19 \mathrm{~g} / \mathrm{L} \mathrm{NaHCO}{ }_{3} ; 0.1 \mathrm{~g} / \mathrm{L} \mathrm{KBr} ; 0.03 \mathrm{~g} / \mathrm{L} \mathrm{H}_{3} \mathrm{BO}_{3} ; 0.04 \mathrm{~g} / \mathrm{L}$ $\mathrm{SrCl}_{2} 6 \mathrm{H}_{2} \mathrm{O} ; 3.0 \mathrm{~mL}$ metal mixture $\left(0.03 \mathrm{~g} / \mathrm{L}\right.$ EDTA; $0.05 \mathrm{~g} / \mathrm{L} \mathrm{FeCl}{ }_{3} 6 \mathrm{H}_{2} \mathrm{O} ; 1.0 \mathrm{~g} / \mathrm{L}$ $\mathrm{H}_{3} \mathrm{BO}_{3} ; 0.15 \mathrm{~g} / \mathrm{L} \mathrm{MnCl}_{2} 4 \mathrm{H}_{2} \mathrm{O} ; 0.1 \mathrm{~g} / \mathrm{L} \mathrm{ZnCl} ; 0.005 \mathrm{~g} / \mathrm{L} \mathrm{CoCl}{ }_{2} 6 \mathrm{H}_{2} \mathrm{O} ; 100.0 \mathrm{ml}$ distilled deionized water $\left.\left(\mathrm{ddH}_{2} \mathrm{O}\right)\right) ; 0.01 \mathrm{~g} / \mathrm{L} \mathrm{FeCl}{ }_{3} 6 \mathrm{H}_{2} \mathrm{O} ; 0.15 \mathrm{~g} / \mathrm{L}$ sodium glycerophosphate; $0.05 \mathrm{~g} / \mathrm{L}\left(\mathrm{NH}_{4}\right)_{2} \mathrm{SO}_{4} ; 3.0 \mathrm{~g} / \mathrm{L}$ TRIS buffer, $1.0 \mathrm{~mL}$ vitamin Solution (0.003 g/L biotin; $1 \mathrm{~g} / \mathrm{L}$ thiamine hydrochloride; $\left.1.0 \mathrm{~L} \mathrm{ddH}_{2} \mathrm{O}\right) ; 0.01 \mathrm{~g} / \mathrm{L}$

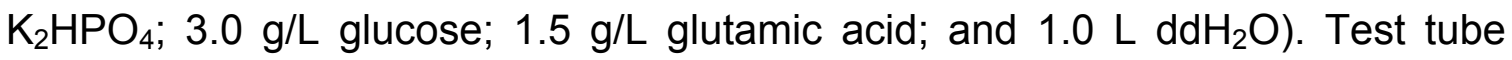


caps were screwed on tightly and then loosened one half turn. Cultures were incubated statically upright at $25^{\circ} \mathrm{C}$ for $10-14$ days (537 D, Fisher Scientific Isotemp Economy Incubator, Hampton, $\mathrm{NH}$ ). The culture was sub-cultured by screwing the cap on tightly, inverting the culture 5 times, and aseptically transferring a $0.1 \mathrm{~mL}$ to $5 \mathrm{~mL}$ ATCC growth medium 460 in screw-capped test tube. The sub-culturing process was repeated every 10-14 days so that a fresh culture was available throughout the study.

\section{Strain, media and maintenance of cells}

Static sub-cultures $(0.1 \mathrm{ml})$ were aseptically transferred to test tubes containing $5 \mathrm{~mL}$ media (9 g/L glucose, $2 \mathrm{~g} / \mathrm{L}$ yeast extract and $25 \mathrm{~g} / \mathrm{L}$ sea salt) and incubated statically at $25^{\circ} \mathrm{C}$ for 8 days. Cultures were aseptically transferred to a $250 \mathrm{~mL}$ flask containing $50 \mathrm{~mL}$ media $(9 \mathrm{~g} / \mathrm{L}$ glucose, $2 \mathrm{~g} / \mathrm{L}$ yeast extract and $25 \mathrm{~g} / \mathrm{L}$ sea salt) at $10 \%$ inoculation level (v/v) and incubated at $25{ }^{\circ} \mathrm{C}$ for 3 days in a shaker incubator at $100 \mathrm{rpm}$. The contents of the flask were then transferred to $500 \mathrm{~mL}$ flasks each containing $100 \mathrm{~mL}$ media $(25 \mathrm{~g} / \mathrm{L}$ glucose, $5.5 \mathrm{~g} / \mathrm{L}$ yeast extract and $25 \mathrm{~g} / \mathrm{L}$ sea salt) at $10 \%$ inoculation level $(\mathrm{v} / \mathrm{v})$ and incubated in a shaker incubator at $25^{\circ} \mathrm{C}$ for 3 days. These cultures were used for inoculation of the bioreactors at an initial inoculum's level of $10 \% \mathrm{v} / \mathrm{v}$.

\section{Bioreactors}

Large scale cultivation of C. cohnii was conducted in two $15 \mathrm{~L}$ computer controlled bioreactor vessels. The temperature of both vessels was maintained at $27^{\circ} \mathrm{C}$ during the batch mode of the study (the first $40 \mathrm{~h}$ ) using a computer controlled heating jacket. The initial medium was composed of $25 \mathrm{~g} / \mathrm{l}$ glucose, 
$5.5 \mathrm{~g} / \mathrm{l}$ yeast extract, $25 \mathrm{~g} / \mathrm{l}$ sea salt and $0.5 \mathrm{~g} / \mathrm{L}$ commercial polysaccharide hydrolyzing enzyme (Lysing Enzymes from Trichoderma, Sigma Aldrich Inc, St. Louis $\mathrm{MO}$ ). The $\mathrm{pH}$ was maintained at 6.5 by automatic addition of $3 \mathrm{M} \mathrm{NaOH}$ and $3 \mathrm{M} \mathrm{HCl}$. During the batch phase of continuous production (the first $40 \mathrm{~h}$ ), fresh media (25 g/l glucose, $5.5 \mathrm{~g} / \mathrm{l}$ yeast extract, $25 \mathrm{~g} / \mathrm{l}$ sea salt) was administered continuously to both bioreactors. After 40 hours, the system was switched to continuous mode where one of the bioreactor was maintained as a growth vessel at $27^{\circ} \mathrm{C}$ and the other became a cooling vessel at $17^{\circ} \mathrm{C}$. Figure 5 represents the flow chart of the system. Foam production was suppressed by the addition of antifoam B (Astoria-Pacific, Clackmas, OR, USA) 1 drop/L as needed. Dissolved oxygen was maintained at $30 \%$ by computer controlled flushing with filter sterilized air and by stirring (150-350 rpm).

\section{Calculation of the Flow Rates}

Swaaf et al. (1999) administered $19 \mathrm{~g}$ glucose to their cultures within the first 40 hours of cultivation; therefore, this value of feed rate was used as the basis of feed rate calculations for the batch mode cultivation in our current study: $(19 \mathrm{~g}$ glucose $/ 40 \mathrm{~h}) \times(1 \mathrm{~L}$ media/25 g glucose $) \times(1000 \mathrm{~mL} / \mathrm{L} \times \mathrm{h} / 60 \mathrm{~min})=0.32$ $\mathrm{mL} / \mathrm{min}$ (per each $1 \mathrm{~L}$ start up volume)

According to Swaaf's study (1999), after $40-43 \mathrm{~h}$ the growth rate decreased slowly and had ceased completely after $74 \mathrm{~h}$. Therefore, the flow rate of culture from the growth vessel to the lipid accumulation vessel for the duration of the continuous mode study was as follows: 
For $5.5 \mathrm{~L}$ initial volume, the feed rate of media was: $5.5 \times 0.32 \mathrm{~mL} / \mathrm{min}=1.76$ $\mathrm{mL} / \mathrm{min}$

The total volume in both bioreactors after $40 \mathrm{~h}$ was calculated as:

$5.5 \mathrm{~L}+(1.76 \mathrm{~mL} / \mathrm{min} \times 60 \mathrm{~min} / 1 \mathrm{~h} \times 40 \mathrm{~h} \times 1 \mathrm{~L} / 1000 \mathrm{~mL})=\sim 9.72 \mathrm{~L}$

Flow rate of culture from the growth vessel to the lipid accumulation vessel was calculated as:

$(9.72 \mathrm{~L} /(74-40 \mathrm{~h}) \times(\mathrm{h} / 60 \mathrm{~min}) \times(1000 \mathrm{~mL} / \mathrm{L})=\sim 4.75 \mathrm{~mL} / \mathrm{min}$

The flow rate of $4.75 \mathrm{~mL} / \mathrm{min}$ was also used for the feed rate of fresh media to the growth vessel. Since glucose solution (25\%) contains 10 times of glucose in media, $0.475 \mathrm{~mL} / \mathrm{min}$ was used as the glucose feed rate to the lipid accumulation vessel (Appendix C).

\section{Growth of Cells}

Optical density and biomass concentration were used to evaluate growth over time. Spectrophotometric measurements (Life Science UV/vis spectrophotometer Model DU 530, Beckman Coulter, Fullerton, CA) were read at $470 \mathrm{~nm}$ and were taken from both vessels every $12 \mathrm{~h}$ for the duration of the study. Biomass concentration was determined by harvesting a $\sim 1 \mathrm{~L}$ sample every $24 \mathrm{~h}$ from the cooling vessel. The sample was centrifuged $10,000 \times \mathrm{g}$ at $5^{\circ} \mathrm{C}$ for $10 \mathrm{~min}$, supernatant poured off, and rinsed once with $\mathrm{dH} 2 \mathrm{O}$. The pellet was then lyophilized and weighed before storage at $-80{ }^{\circ} \mathrm{C}$. Biomass concentration was calculated by dividing the weight of the freeze dried sample with the volume of sample solution centrifuged. 


\section{Analysis of Fatty Acids}

Fat and fatty acids were extracted from biomass by acidic hydrolysis method AOAC Official Method 996.06. Pyrogallic acid was added to minimize oxidative degradation of fatty acids during analysis. Triglyceride, triundecanoin (C11:0), was used as internal standard. Fat was extracted into ether, then methylated to fatty acid methyl esters (FAMEs) using boron trifluoride (BF3) in methanol (Appendix A). FAMEs were quantitatively measured by capillary gas chromatography against C11:0 internal standards. All samples were analyzed on a gas-liquid chromatography (Agilent Technologies, Model 7890A) equipped with a $7683 \mathrm{~B}$ series Injector. Helium was used as the carrier gas with a $0.75 \mathrm{~mL} / \mathrm{min}$ flow rate. The temperature program for separations began at $100^{\circ} \mathrm{C}$, held for 4 min, increased to $240^{\circ} \mathrm{C}$ at $3^{\circ} \mathrm{C} / \mathrm{min}$ and held for $15^{\circ} \mathrm{C}$. Temperatures for injector and detector were 225 and $285^{\circ} \mathrm{C}$. Peaks were identified by comparing their retention times with references. Total fat was calculated as sum of individual fatty acids expressed as triglyceride equivalents.

\section{Statistical Analysis}

The study was conducted three times with at least two observations from each. Data were analyzed using multiple linear regressions (MS Office 2003), analysis of covariance (ANCOVA) and Tukey's Honestly Significant Differences testing (JMP 7, SAS Institute, Cary, NC, USA). 


\section{RESULTS AND DISCUSSION}

Growth of C. cohnii with lipid and DHA production was achieved in this continuous study. Figure 6 represents growth, measured spectrophotometrically at $470 \mathrm{~nm}$, of $C$. cohnii over time in a continuous mode process. Growth was significantly different during the third replication of the study $(P<0.05)$ in terms of $O D$ in the growth vessel and $O D$ in cooling vessel $(P<0.05)$. The average $O D$ reached in the growth vessel at the $40^{\text {th }} \mathrm{h}$ and the cooling vessel at the $113^{\text {th }}$ hour was $2.05+/-0.05$ and $2.2+/-0.05$ respectively. These results are similar to the results of preliminary study, where all parameters were the same with this current study except that cells were cultivated and harvested in a batch mode.

Figure 7 represents the biomass concentration of harvest from the cooling vessel over in the continuous mode process. Biomass concentrations ranged from $2.0 \mathrm{~g} / \mathrm{L}$ to $4.2 \mathrm{~g} / \mathrm{L}$ over the cultivation period. Biomass concentration was significantly different during the third replication of the study $(P<0.05)$, possibly due to temperature fluctuations in the growth vessel during the other replications of the study. Temperature is one of the most important environmental factors affecting the growth of $C$. cohnii and formation of DHA. Growth of $C$. cohnii declines at temperatures below $14^{\circ} \mathrm{C}$ or above $31^{\circ} \mathrm{C}$, the optimum growth temperature of $C$. cohnii was reported to be $27^{\circ} \mathrm{C}$ (Beach et al., 1973). During the first and second repetition of the study, the temperature of the growth vessels exceeded the optimum growth temperatures reported by others. During the second repetition, a spike in biomass concentration occurred at the $160^{\text {th }} \mathrm{h}$, which corresponds to the maximum temperature of $34.2^{\circ} \mathrm{C}$. 
Maximum biomass concentration occurred during the third repetition and maintained an average of $3.70 \mathrm{~g} / \mathrm{L}$ from the $88^{\text {th }} \mathrm{h}$ through the $160^{\text {th }} \mathrm{h}$ of cultivation. In batch mode processes, the reported maximum biomass concentrations exceeded those achieved in this continuous study. Ratledge et al. (2001) reported a value of $17 \mathrm{~g} / \mathrm{L}$ (at $140 \mathrm{~h}$ ) for biomass concentration in $\mathrm{pH}$ auxostat cultures, Swaaf et al. (2003a) reported $26 \mathrm{~g} / \mathrm{L}$ in glucose solution (50 \%) fed batch culture, $51 \mathrm{~g} / \mathrm{L}$ in acetic acid solution (50\%) fed batch culture and 61 g/L in pure acetic acid fed batch culture (Swaaf et al., 2003a). High cell density was not achieved in our continuous system.

Figure 8 represents lipid percentages of cooling vessel during different cultivation time in the continuous mode process. Lipid proportion of dry biomass was significantly different during the second replication of the study $(P<0.05)$ from the other replications of the study. Lipid proportion followed an increasing trend until 112th $\mathrm{h}$ and maintained an average of $14.5 \mathrm{~g} / \mathrm{L}$ from the 112th $\mathrm{h}$ through the 160th $\mathrm{h}$ of cultivation during the third repetition. Maximum lipid proportion of dry biomass occurred during the first repetition (17.37\%) at 117 th hour of cultivation. Ratledge et al. (2001) reported a value of $44 \%$ for lipid in $\mathrm{pH}$ auxostat culture system. The other reported lipid \% values by Swaaf et al. (2003a) were $15 \%$ lipid for fed batch culture with $50 \%$ glucose, $54 \%$ lipid for fed batch culture with $50 \%$ acetic acid and $49 \%$ lipid for fed batch culture with 100 $\%$ acetic acid. According to these results it can be concluded that acetic acid as principal carbon source would yield more lipid than glucose. 
Figure 9 represents DHA yield (\% of lipid) of the cooling vessel at different cultivation times in the continuous mode process. DHA proportion of lipid was significantly different during the second replication of the study $(P<0.05)$ from the other replications of the study. DHA proportions of lipids followed an increasing trend until $112^{\text {th }} \mathrm{h}$ and maintained an average of $27 \%$ of lipid from the $112^{\text {th }} \mathrm{h}$ through the $160^{\text {th }} \mathrm{h}$ of cultivation during the first and third replication of the study. Maximum DHA percentage occurred during the first repetition $(29.90 \%)$ at $95^{\text {th }}$ hour of cultivation. Ratledge et al. (2001) reported $59 \%$ of lipid as DHA \% (\% of total fatty acids) at $140^{\text {th }} \mathrm{h}$ of cultivation in $\mathrm{pH}$-auxostat cultures with acetic acid as principal carbon source. This value is double our maximum value. Swaaf et al. (2003a) reported a maximum value of $46 \%$ DHA in a fed batch cultivation with $50 \%$ glucose solution at $120 \mathrm{~h}$ while they reported $29 \%$ for $50 \%$ acetic acid fed and $32 \%$ with $100 \%$ acetic acid fed batch cultivation at $210 \mathrm{~h}$ (Swaaf et al., 2003a).

Figure 10 represents lipid concentrations of the cooling vessel over time in the continuous mode process. Lipid concentration was significantly different during the third replication of the study $(P<0.05)$ from the other replications of the study. A state of homeostasis for lipid concentration was observed in Rep 3 between $110 \mathrm{~h}$ and $160 \mathrm{~h}$. Maximum lipid concentration occurred during the third repetition $(0.55 \mathrm{~g} / \mathrm{L})$ at $137^{\text {th }}$ hour of cultivation. This value was less than the previous reported maximum values of $3.7 \mathrm{~g} / \mathrm{L}$ in batch cultivation (Swaaf et al., 1999), $7.5 \mathrm{~g} / \mathrm{L}$ in pH auxostat culture with acetic acid as principal carbon source (Ratledge et al., 2001) and $30 \mathrm{~g} / \mathrm{L}$ with $100 \%$ acetic acid fed batch cultivation 
(Swaaf et al., 2003a). Preliminary yields in a batch study with glucose solution (25\%) feed were $0.89 \mathrm{~g} / \mathrm{L}$, exceeding the yields attained with the continuous cultivation strategy.

Figure 11 represents DHA mass flow rate (DHA productivity) of cooling vessel at different cultivation time in continuous mode process. According to the statistical analysis, DHA productivity (DHA mass flow rate) of Rep 2 was significantly less than Rep 1 and Rep 3. Maximum DHA mass productivity $(\mathrm{mDHA})$ was achieved in Rep $3(41.32 \mathrm{mg} / \mathrm{h})$. The maximum DHA volumetric productivity found in the preliminary batch study with glucose solution $(25 \%)$ fed culture was $3.61 \mathrm{mg} / \mathrm{L}$.h. The $\mathrm{rDHA}$ is the value of DHA productivity per liter of the harvest per hour while mDHA is the value of DHA productivity per hour. Therefore, the maximum mDHA from the preliminary batch mode would be 36.1 $\mathrm{mg} / \mathrm{h}$ for $10 \mathrm{~L}$ harvest while it was found $41.32 \mathrm{mg} / \mathrm{h}$ (for $10 \mathrm{~L}$ ) in the continuous mode process. Even though the maximum biomass of the continuous-mode process $(3.75 \mathrm{~g} / \mathrm{L})$ was less than the preliminary batch-mode $(8.35 \mathrm{~g} / \mathrm{L})$, the DHA mass productivity $(\mathrm{mDHA})$ of continuous-mode $(41.32 \mathrm{mg} / \mathrm{h})$ was greater than batch-mode process $(36.1 \mathrm{mg} / \mathrm{h})$. This is due to a greater product output in the continuous study. Swaaf et al. (2003 a) reported maximum rDHA in glucose solution (50\%) fed culture, acetic acid solution (50 \%) fed culture and pure acetic acid fed culture, $14 \mathrm{mg} / \mathrm{L} . \mathrm{h}, 38 \mathrm{mg} / \mathrm{L} . \mathrm{h}$ and $45 \mathrm{mg} / \mathrm{L} . \mathrm{h}$, respectively.

Figure 12 represents DHA concentrations of the cooling vessel over time in the continuous mode process. DHA concentration was significantly different during the second replication of the study $(P<0.05)$ from the other replications of 
the study. Maximum DHA concentration occurred during the third repetition $(0.145 \mathrm{~g} / \mathrm{L})$ at $127^{\text {th }}$ hour of cultivation. This value was less than the previously reported maximum values of $1.6 \mathrm{~g} / \mathrm{L}$ in batch cultivation (Swaaf et al., 1999), 4.4 $\mathrm{g} / \mathrm{L}$ in $\mathrm{pH}$-auxostat culture with acetic acid as principal carbon source (Ratledge et al., 2001) and $9.5 \mathrm{~g} / \mathrm{L}$ with $100 \%$ acetic acid fed batch cultivation (Swaaf et al., 2003a). Maximum DHA concentration was greater in the glucose solution (25\%) fed batch preliminary batch mode study $(0.32 \mathrm{~g} / \mathrm{L})$.

In conclusion, optimal media and glucose solution concentrations, feed rates, flow rates and process conditions need to be determined so that high cell densities can be achieved in a continuous mode process. Temperature is a very important factor affecting the growth of $C$. cohnii and formation of DHA. Growth of C. cohnii declines at temperatures below $14^{\circ} \mathrm{C}$ or above $31^{\circ} \mathrm{C}$. Higher incubation temperatures enhance growth but reduce DHA accumulation. So, optimum temperatures for both the growth vessel and for the cooling vessel need to be determined. In addition to feed rates, flow rates and process conditions, carbon source is also very important factor affecting the growth of $C$. cohnii and DHA productivity. For optimum growth and lipid accumulation, carbon sources (glucose vs. acetate) need to be compared in the continuous mode process. If the high cell densities of the previous batch mode studies can be achieved with the continuous mode process, the volumetric productivity could be improved significantly. Improvement in the current DHA production techniques could lead to a cost effective and reliable source of DHA for use in value added foods and 
the health benefits of DHA could be realized without the risk of exposure to the environmental pollutant and contaminants. 


\section{REFERENCES}

Beach DH. Holz GG. 1973. Environmental influences on the docosahexaenoate content of the triacylglycerols and phosphatidylcholine of a heterotrophic, marine dinoflagellate, Crypthecodinium cohni., Biochimica et Biophysica Acta 316: 56-65.

Beach DH. Harrington GW. Gellerman JL. Schlenk H. Holz GG. 1974. Biosynthesis of oleic acid and docosahexaenoic acid by a heterotrophic marine dinoflagellate Crypthecodinium cohni. Biochimica et Biophysica Acta 369: 16-24.

Carlson SE. 1999. Arachidonic acid status human infants: influence of gestational age at birth and diets with very long chain $n-3$ and $n-6$ fatty acids. J. Nutr 126: 1092-1098.

Cheruku SR. Downs HE. Farkas SL. Thoman EB. Lammi-Keefe CJ. 2002. Higher maternal plasma docosahexaenoic acid during pregnancy is associated with more mature neonatal sleep-state patterning. American Journal of Clinical Nutrition 76: 608-613.

Gunstone FD. Structured and modified lipids. Marcel Dekker, New York (2001). Jiang Y. Cheng F. 1999. Effects of salinity on cell growth and docosahexaenoic acid content of the heterotrophic marine microalga Crypthecodinium cohni. Journal of Industrial Microbiology \& Biotechnology 23: 508-513.

Jiang Y. Cheng F. 2000. Effect of Temperature and Temperature Shift on Docosahexaenoic Acid Production by the Marine Microalga Crypthecodinium cohnii. JAOCS 77: 613-617. 
Jiang Y. Cheng F. Liang SZ. 1999. Production potential of docosahexaenoic acid by the heterotrophic marine dinoflagellate Crypthecodinium cohnii. Process Biochemistry 34: 633-637.

Marszalek JR. Lodish HF. 2005. Docosahexaenoic acid, fatty acid- interacting proteins, and neuronal function: Breastmilk and fish are good for you. Annu. Rev. Cell Dev. Biol. 21: 633-657.

Ratledge C. Kanagachandran K. Anderson AJ. Grantham DJ. Stephenson JC. 2001. Production of docosahexaenoic acid by Crypthecodinium cohnii grown in a $\mathrm{pH}$-auxostat culture with acetic acid as principal carbon source. Lipids 36 : 1241-1246.

Ratledge C. 2004. Fatty acid biosynthesis in microorganisms being used for single cell oil production. Biochimie 86: 807-815.

Schrooyen PMM. Meer R. Kruif De CG. 2001. Microencapsulation: its application in nutrition. Proceedings of the Nutrition Society 60: 475-479.

Simopoulos AP. 1991. Omega 3 fatty acids in health and disease and in growth and development. Am J Clin Nutr 54: 438-463

Simopoulos AP. 1999. Essential fatty acids in health and chronic disease. Am J Clin Nutr 70: 560-569.

Simopoulos AP. 2000. Human requirement for N-3 polyunsaturated fatty acids. Poultry Science 79: 961-970.

Swaaf ME. Rijk TC. Eggink G. Sijtsma L. 1999. Optimisation of docosahexaenoic acid production in batch cultivations by Crypthecodinium cohnii. Journal of Biotechnology 70 185-192. 
Swaaf ME. Grobben GJ. Eggink G. Rijk TC. Meer P, Sijtsma L. 2001. Characterization of extracellular polysaccharides produced by Crypthecodinium cohnii. App Microbiol Biotechnol 57: 395-400.

Swaaf ME. Sijtsma L. Pronk JT. 2003a. High cell density fed batch cultivation of the docosahexaenoic acid producing marine alga Crypthecodinium cohnii. Biotechnol Bioeng 81: 666-672.

Swaaf ME. Pronk JT. Sijtsma L. 2003b. Fed-batch cultivation of the docosahexaenoic acid producing marine alga Crypthecodinium cohnii on ethanol, App Microbiol Biotechnol 61: 40-43.

Vazhappilly R. Cheng F. 1998. Eicosapentaenoic acid and docosahexaenoic acid production potential of microalgae and their heterotrophic growth. JAOCS 75: 393-397.

Ward OP, Singh A. 2005. Omega-3/6 fatty acids: Alternative sources of production. Process Biochemistry 40: 3627-3652.

Whelan J. Rust C. 2006. Innovative Dietary Sources of N-3 Fatty Acids. Annu. Rev. Nutr. 26:75-103.

Yongmanitchai W. Ward OP. 1989. Omega-3 fatty acids: alternative sources of production. Proc Biochem: 117-125. 
Figure 5 . Flow chart of the continuous process

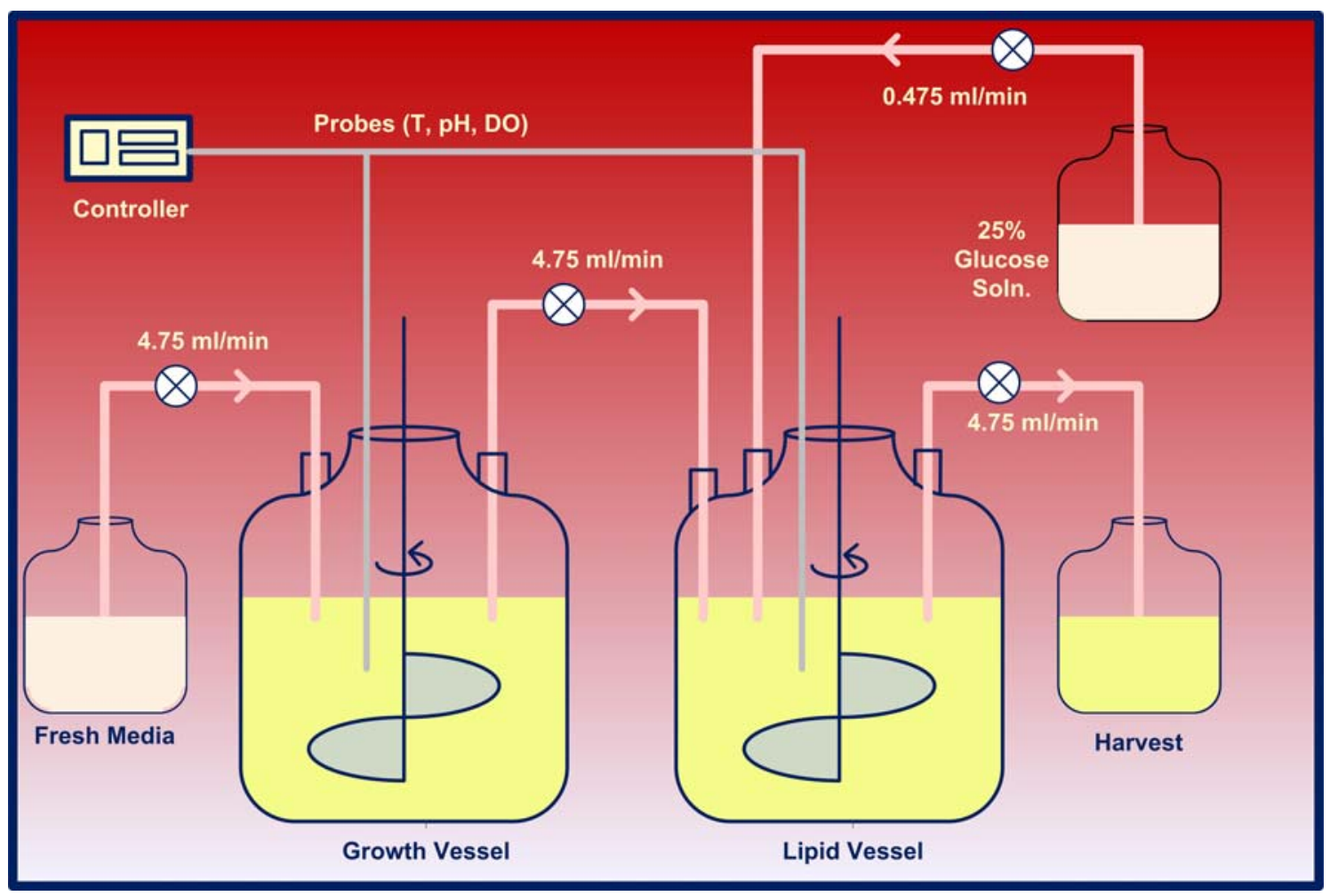


Figure 6. Growth of C. cohnii over time in a continuous mode process.

Samples were taken from a growth vessel maintained at $27^{\circ} \mathrm{C}$ and a lipid accumulation vessel where temperature was dropped to $17^{\circ} \mathrm{C}$ after $40 \mathrm{~h}$ cultivation at $27^{\circ} \mathrm{C}$. Growth was measured spectrophotometrically at $470 \mathrm{~nm}$. Straight line represents samples taken from the growth vessel and dotted line represents samples from the cooling vessel. Symbols represent $\Delta$ - Repetition 1, O - Repetition 2, - -Repetition 3

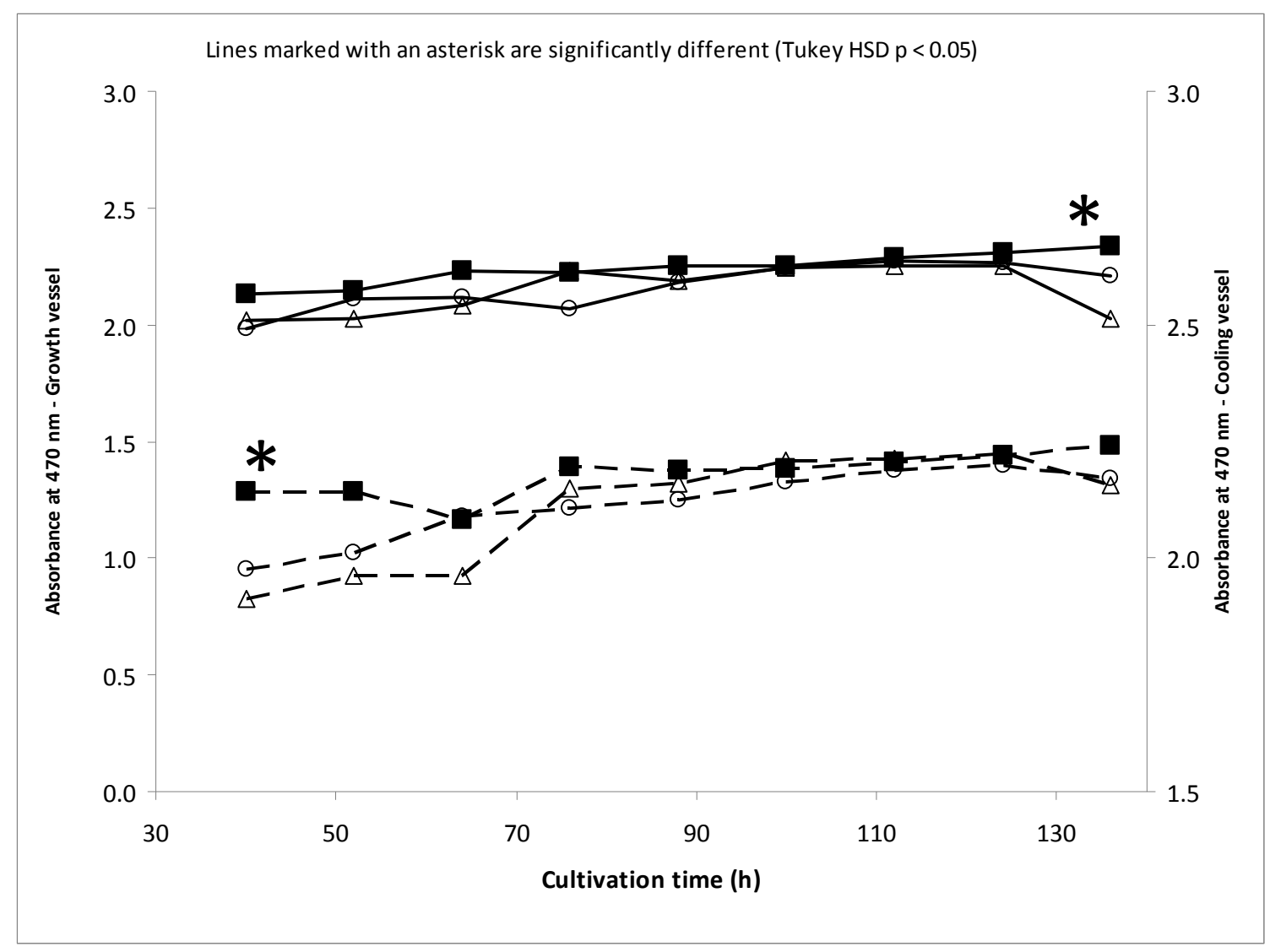


Figure 7. Biomass concentration of cooling vessel over time in the continuous mode process

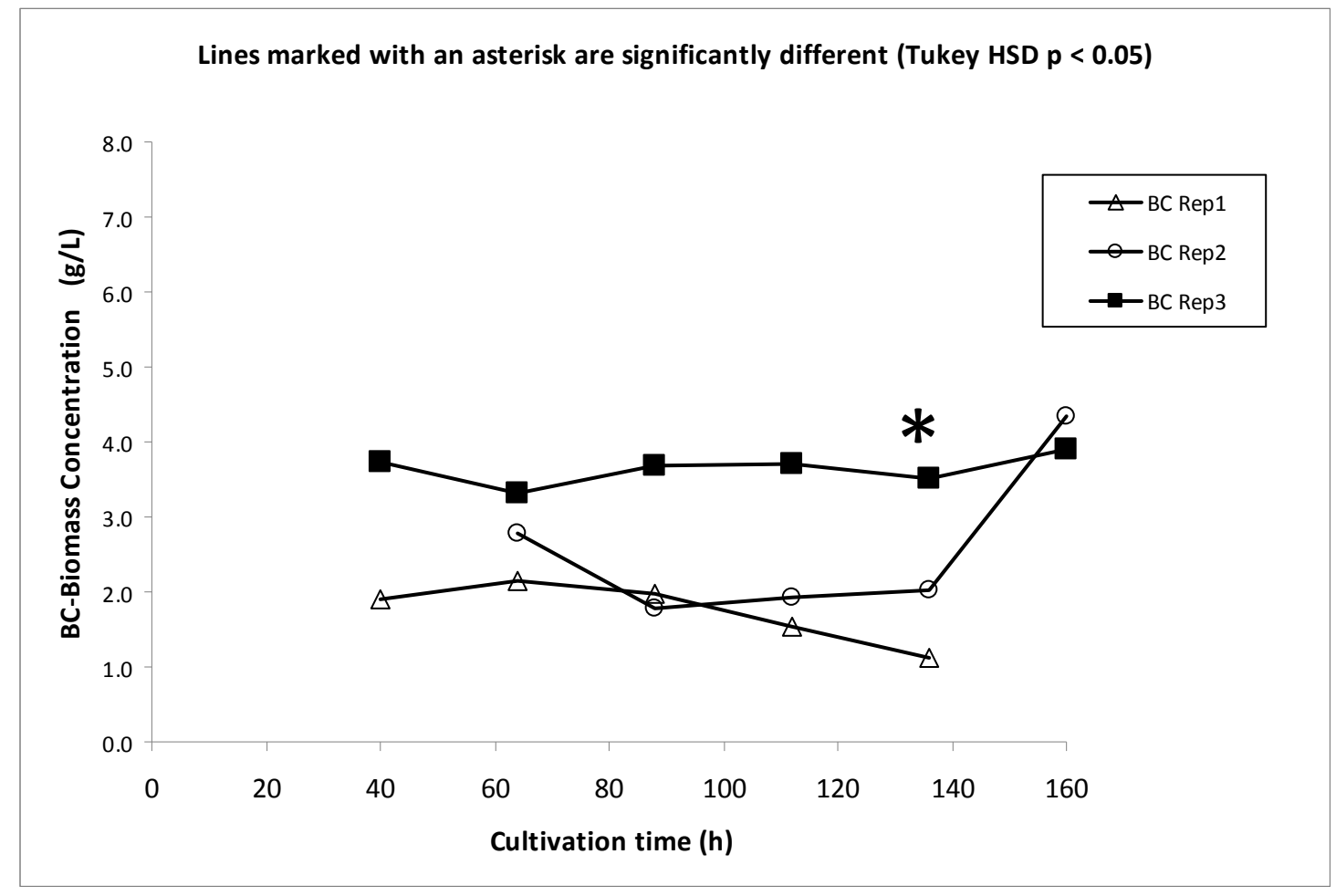

Figure 8. Lipid percentages of cooling vessel over time in the continuous mode process

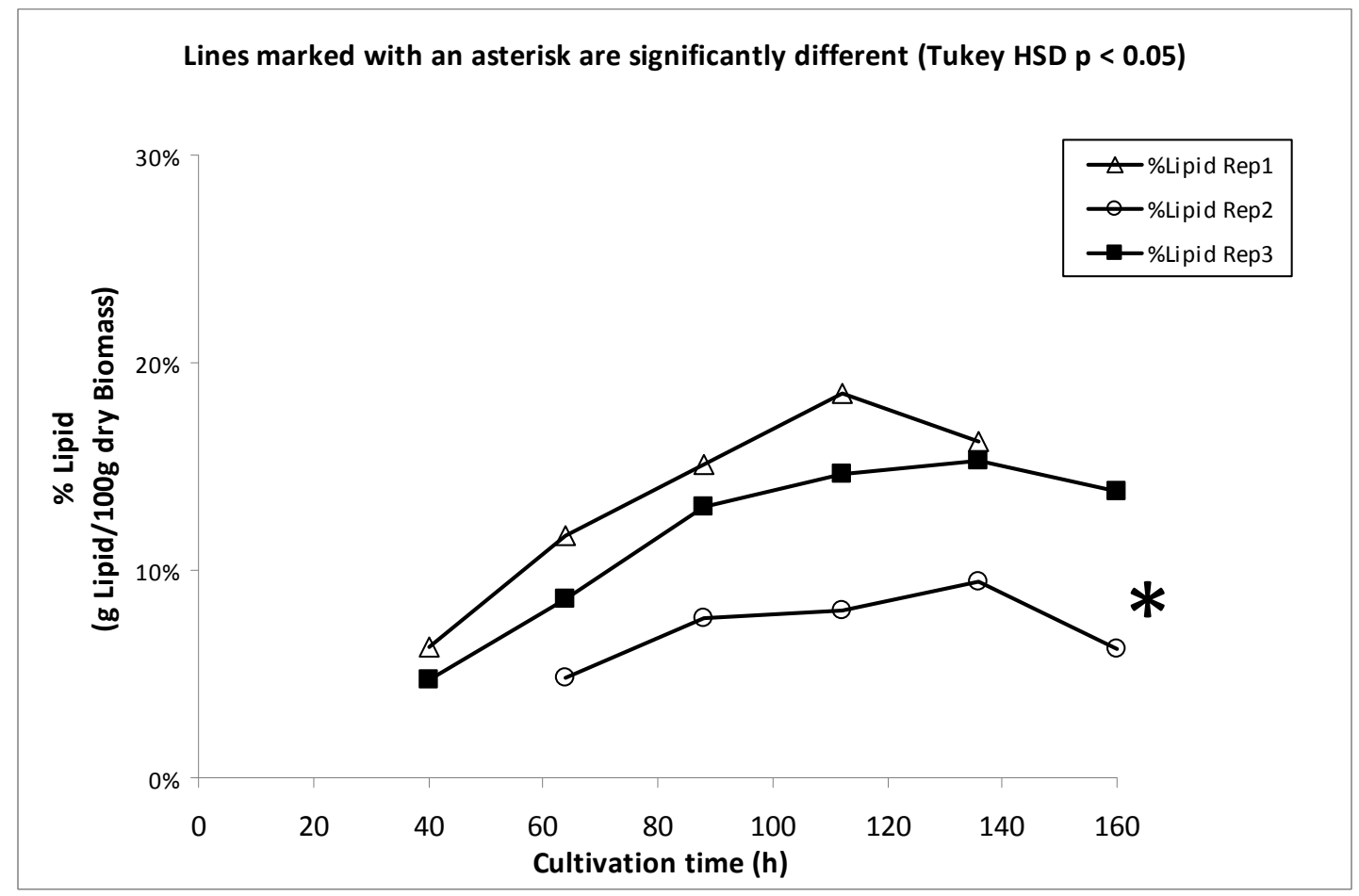


Figure 9. DHA percentages of cooling vessel over time in the continuous mode process.

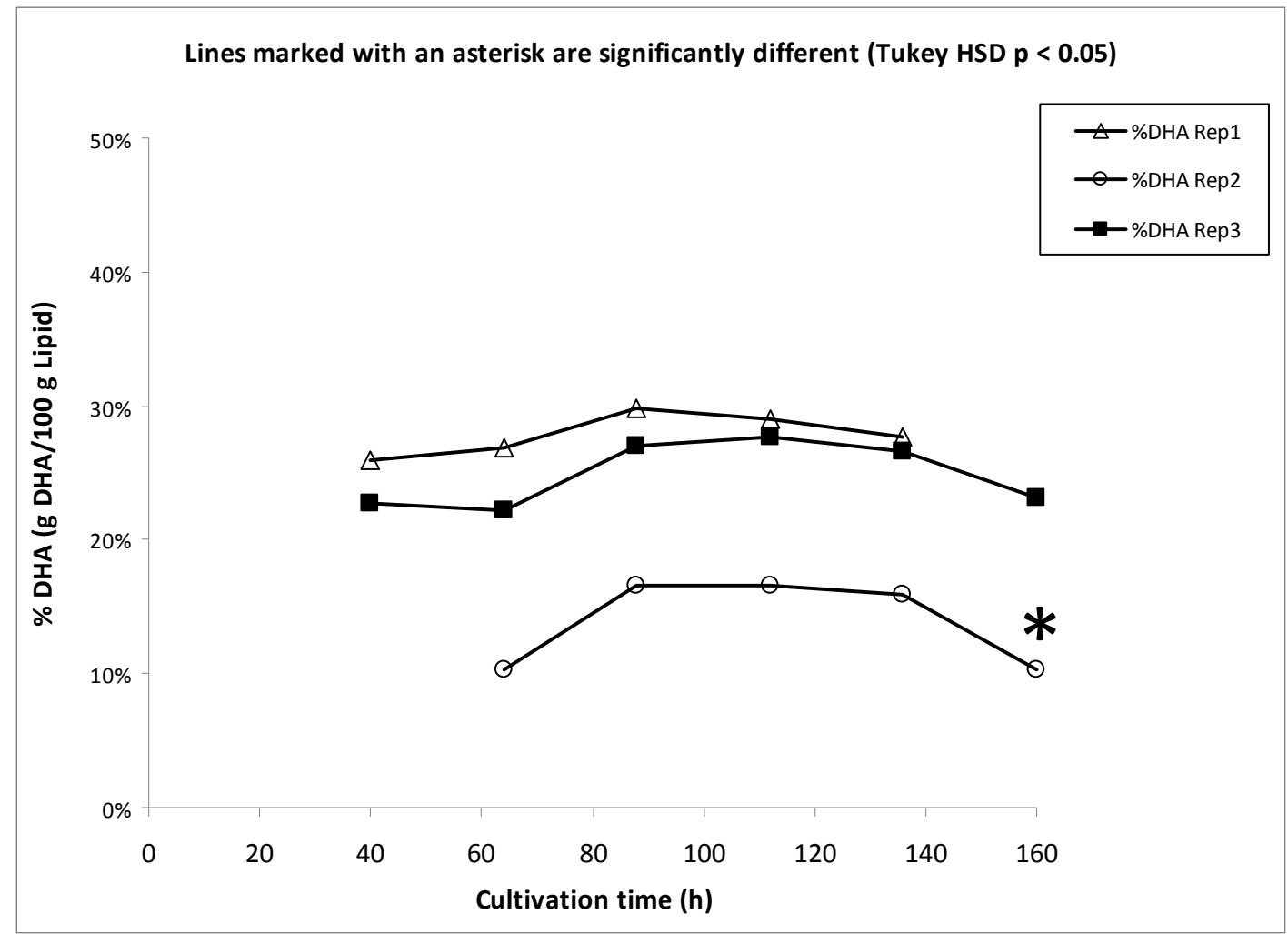

Figure 10. Lipid concentrations of cooling vessel over time in the continuous mode process.

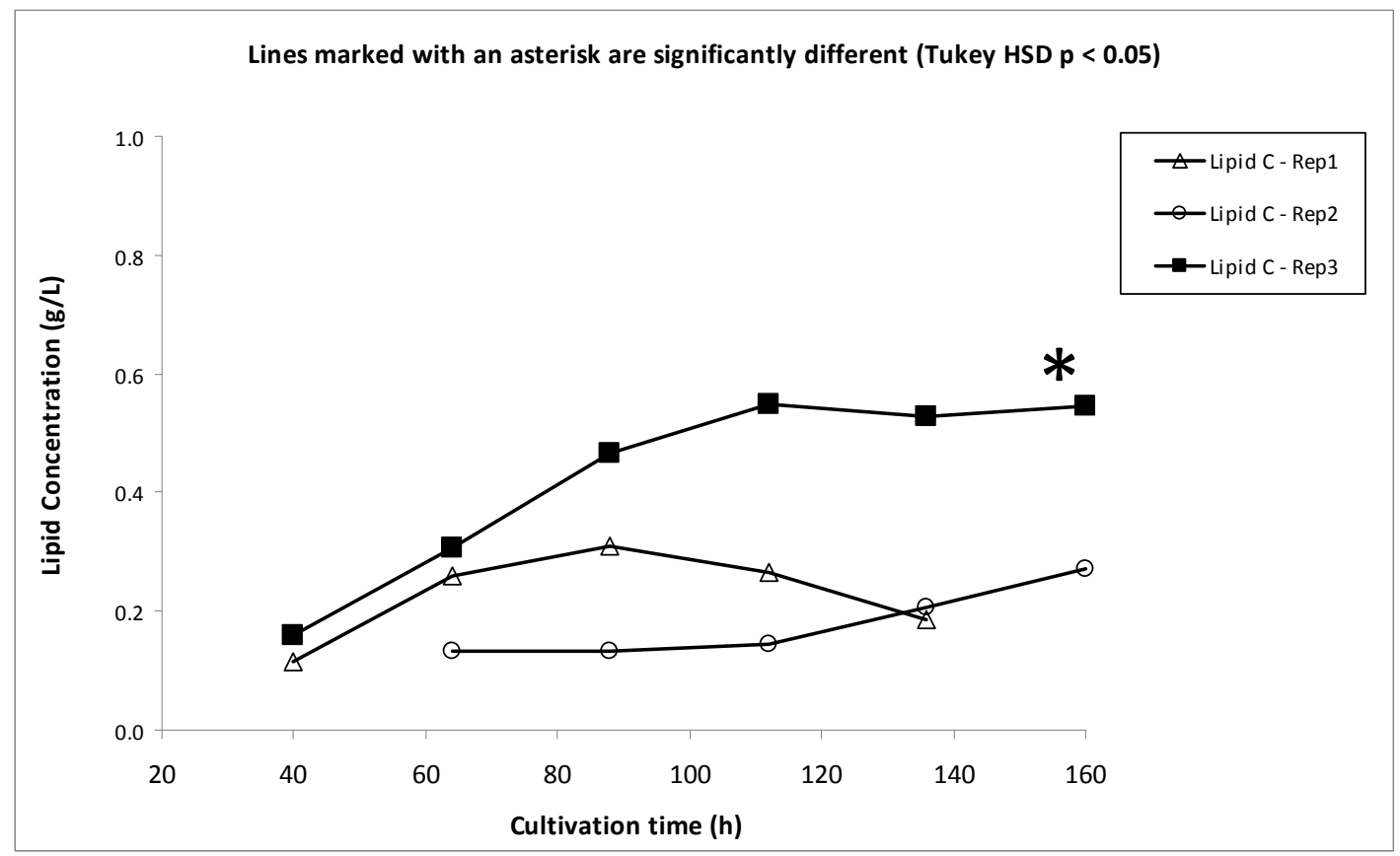


Figure 11. DHA mass flow rate (DHA productivity) of cooling vessel over time in continuous mode process

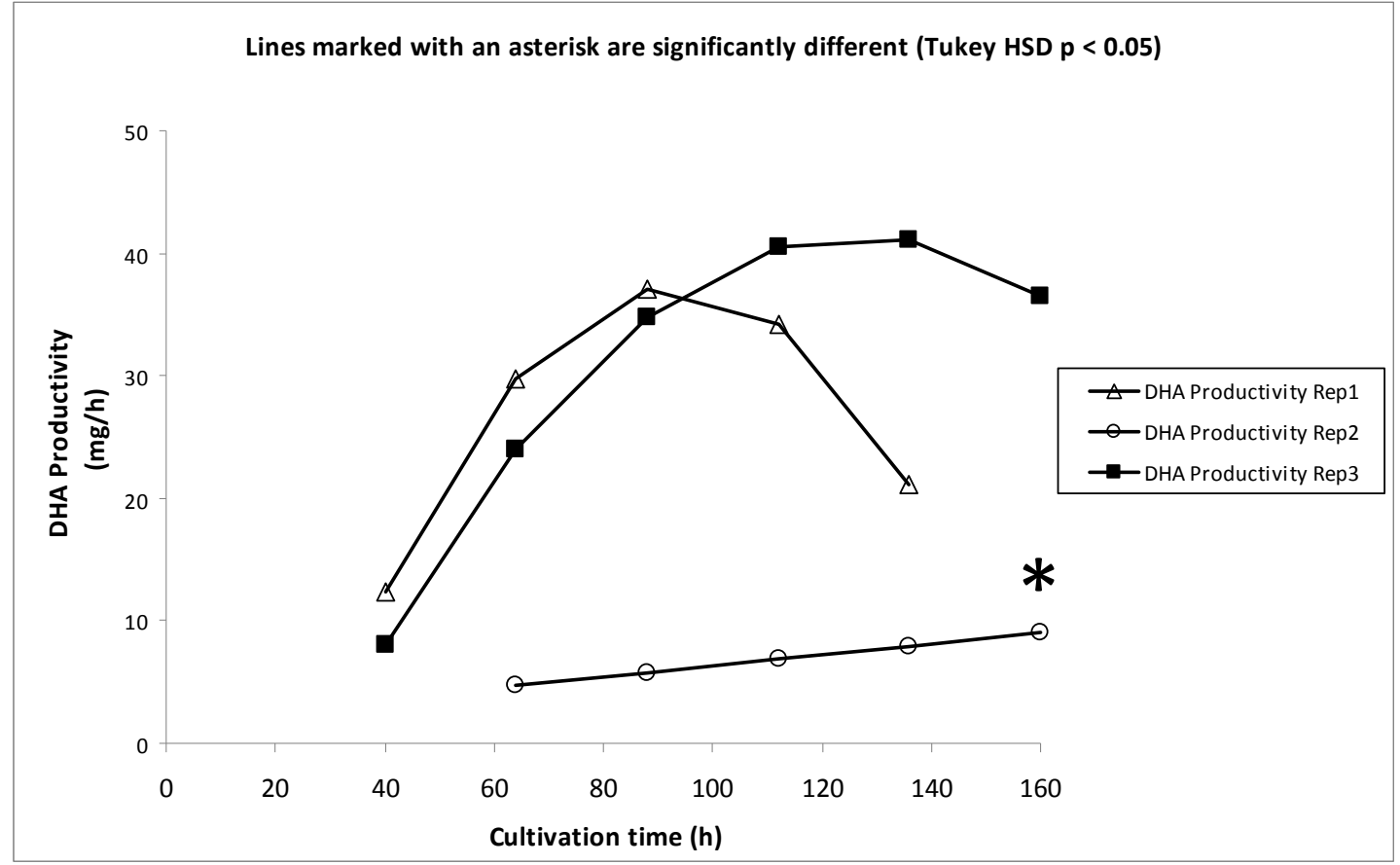

Figure 12. DHA concentration of cooling vessel over time in continuous mode process

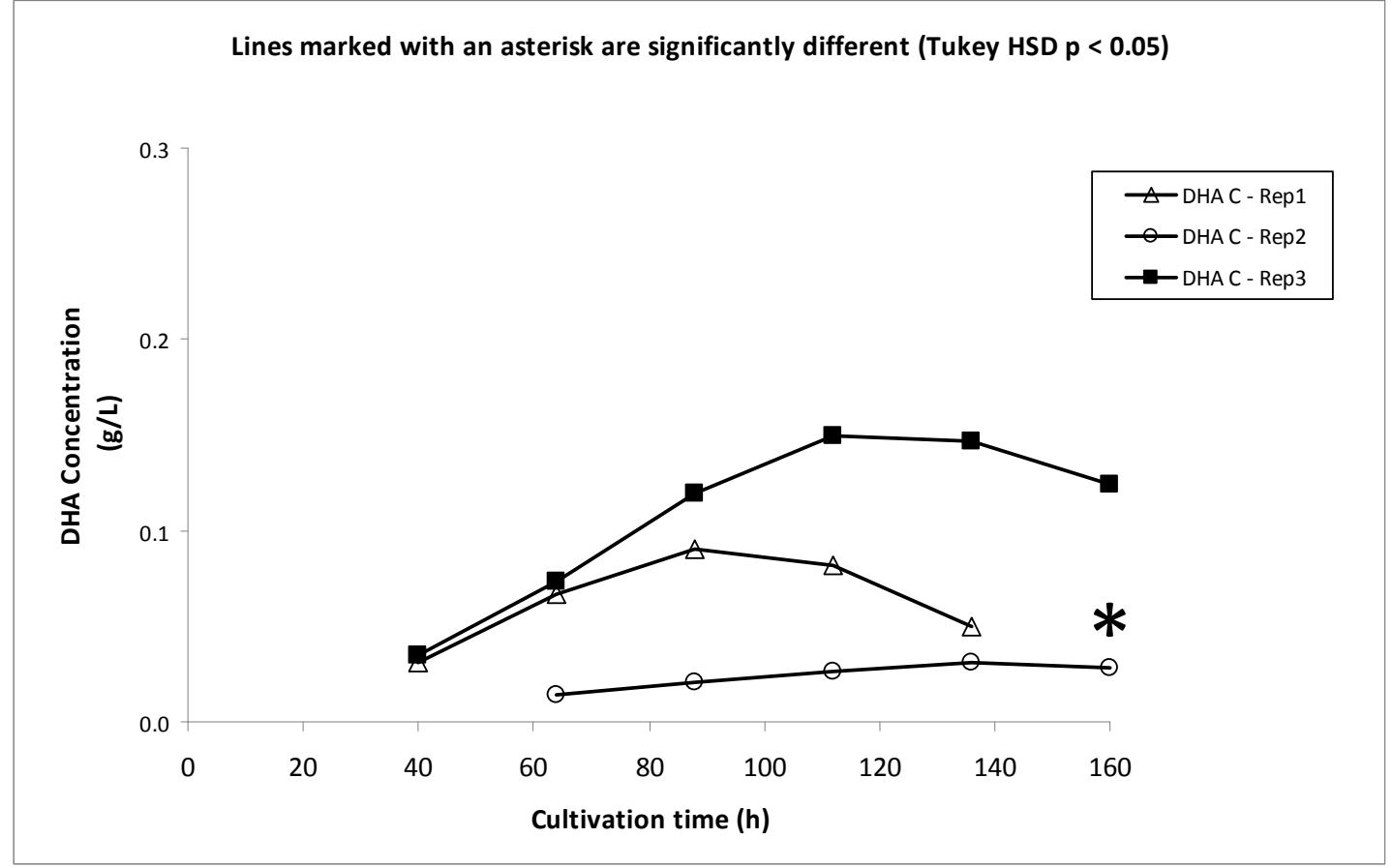


Table 2. Fat (\%) and Fatty acid profile of C. cohnii over time in the continuous mode process

\begin{tabular}{|c|c|c|c|c|c|c|c|}
\hline & Cultivation time (h) & 40 & 64 & 88 & 112 & 136 & 160 \\
\hline \multirow{2}{*}{ Rep1 } & $\begin{array}{l}\text { Lipid \% (g Lipid/100g } \\
\text { dry Biomass) }\end{array}$ & 6.29 & 11.63 & 15.06 & 18.56 & 16.21 & - \\
\hline & $\begin{array}{l}\text { DHA (g DHA/100g } \\
\text { Lipid) }\end{array}$ & 25.93 & 26.83 & 29.79 & 29.02 & 27.63 & - \\
\hline \multirow{2}{*}{ Rep2 } & $\begin{array}{l}\text { Lipid \% (g Lipid/100g } \\
\text { dry Biomass) }\end{array}$ & - & 4.76 & 7.71 & 8.07 & 9.36 & 6.17 \\
\hline & $\begin{array}{l}\text { DHA (g DHA/100g } \\
\text { Lipid) }\end{array}$ & - & 10.35 & 16.64 & 16.53 & 15.88 & 10.26 \\
\hline \multirow{2}{*}{ Rep3 } & $\begin{array}{l}\text { Lipid \% (g Lipid/100g } \\
\text { dry Biomass) }\end{array}$ & 4.65 & 8.64 & 13.13 & 14.57 & 15.27 & 13.80 \\
\hline & $\begin{array}{l}\text { DHA (g DHA/100g } \\
\text { Lipid) }\end{array}$ & 22.71 & 22.15 & 26.99 & 27.72 & 26.64 & 23.19 \\
\hline
\end{tabular}




\section{APPENDIX A. Fatty Acid Analysis}

\section{Extraction of Fats}

Homogenized freeze-dried biomass was placed in a Mojonnier flask with pyrogallic acid (100 mg), $2 \mathrm{~mL}$ triglceride internal standard (C:11, triundecanoin) solution ( $5 \mathrm{mg} / \mathrm{mL}$ in $\mathrm{CHCl}_{3}$ ) and boiling granules. Ethanol $(2 \mathrm{~mL})$ was added and mixed until entire test portion was in solution. Ten $\mathrm{mL} \mathrm{HCl}(8.3 \mathrm{M})$ was added and mixed. The flask was then placed in a shaking water bath at $70-80{ }^{\circ} \mathrm{C}$ set at moderate agitation speed and maintained for $40 \mathrm{~min}$. The contents of flask were mixed using a vortex mixer every $10 \mathrm{~min}$ to incorporate particulates adhering to the sides of flask. The flask was removed from the water bath and allowed to cool to room temperature $\left(20-25^{\circ} \mathrm{C}\right)$. Ethanol was added until it filled the bottom of the flask reservoir and mixed gently. Diethyl ether $(25 \mathrm{~mL})$ was then added to the flask. The flask was closed off with a stopper, placed in centrifuge basket in wrist action shaker and agitated for 5 min. The stopper was rinsed into flask with diethyl ether-petroleum ether mixture. Petroleum ether $(25 \mathrm{~mL})$ was added, the flask closed off and agitated for another $5 \mathrm{~min}$. The contents of the flask were separated by centrifugation ( $5 \mathrm{~min}$ at $600 \times \mathrm{g}$ ) and rest until the upper layer was clear. Again, the stopper was rinsed into flask with diethyl ether-petroleum ether mixture. The top layer (ether) was transferred into $150 \mathrm{~mL}$ beaker and ether was evaporated slowly on steam bath, using nitrogen stream to aid in evaporation. The residue remained in beaker contained extracted fat. 


\section{Methylation}

After complete drying with nitrogen gas, 2-3 mL chloroform and 2-3 mL diethyl ether were added to dissolve the extracted fat residue. This mixture was transferred to a glass vial and evaporated to dryness in $40{ }^{\circ} \mathrm{C}$ water bath under nitrogen stream. Two $\mathrm{mL}, 7 \% \mathrm{BF}_{3}$ reagent and $1 \mathrm{~mL}$ toluene were added to the vial. The vial was sealed with a screw cap top containing a Teflon/silicone septum and heated in oven $45 \mathrm{~min}$ at $100^{\circ} \mathrm{C}$. The vial was agitated gently every 10 min and allowed to cool to room temperature $\left(20-25^{\circ} \mathrm{C}\right)$. After addition of 5 $\mathrm{mL} \mathrm{H}_{2} \mathrm{O}, 1 \mathrm{~mL}$ hexane and $1 \mathrm{~g} \mathrm{Na}_{2} \mathrm{SO}_{4}$, the vial was capped and agitated $1 \mathrm{~min}$. The contents of vial were allowed to rest so that layer separation could occur. The top layer containing the FAMEs was then transferred to another vial containing $1 \mathrm{~g} \mathrm{Na}_{2} \mathrm{SO}_{4}$. Extraction of Fats 


\section{APPENDIX B. Fatty Acid Profile}

\begin{tabular}{|c|c|c|c|c|c|c|c|c|c|c|c|c|c|c|}
\hline ВАТСН MODE & 1 & 2 & 1 & 2 & 1 & 2 & 1 & 2 & 1 & 2 & 1 & 2 & 1 & 2 \\
\hline $\begin{array}{l}\text { Cultivation time } \\
\text { (h) }\end{array}$ & 17 & 17 & 24 & 24 & 48 & 48 & 65 & 65 & 89 & 89 & 113 & 113 & 137 & 137 \\
\hline $\begin{array}{l}\text { Fat (by acid } \\
\text { hydrolysis) }\end{array}$ & 3.79 & 3.69 & 4.75 & 4.82 & 6.99 & 7.02 & 11.33 & 11.38 & 12.11 & 12.16 & 13.26 & 13.23 & 14 & 13.95 \\
\hline Myristic (14:0) & 6.6 & 6.68 & 8.97 & 8.9 & 10.9 & 10.74 & 14.98 & 14.82 & 13.67 & 13.58 & 13.31 & 13.1 & 13.21 & 13.18 \\
\hline $\begin{array}{l}\text { Myristoleic } \\
(14: 1)\end{array}$ & 8.65 & 8.45 & 4.9 & 4.93 & 3 & 2.94 & 1.53 & 1.51 & 0.88 & 0.86 & 0.88 & 0.86 & 0.75 & 0.76 \\
\hline$(\mathrm{C} 15: 0)$ & 0 & 0 & 0 & 0 & 0 & 0 & 0 & 0 & 0 & 0 & 0 & 0 & 0 & 0 \\
\hline Palmitic (16:0) & 11.95 & 11.94 & 19.2 & 18.94 & 24.51 & 24.22 & 27.22 & 26.87 & 27.3 & 27.11 & 28.39 & 27.86 & 27.66 & 27.65 \\
\hline $\begin{array}{l}\text { Palmitoleic } \\
(16: 1)\end{array}$ & 11.27 & 10.93 & 6.6 & 6.49 & 3.52 & 3.47 & 1.88 & 1.84 & 1.53 & 1.52 & 1.49 & 1.45 & 1.48 & 1.49 \\
\hline$(17: 0)$ & 3.04 & 2.94 & 1.5 & 1.49 & 0.82 & 0.8 & 0.34 & 0.34 & 0.25 & 0.25 & 0.24 & 0.23 & 0.21 & 0.21 \\
\hline$(17: 1)$ & 0 & 0 & 0 & 0 & 0.94 & 0.98 & 1.15 & 1.13 & 0.89 & 0.93 & 0.84 & 0.84 & 0.74 & 0.79 \\
\hline Stearic $(18: 0)$ & 1.72 & 1.61 & 1.81 & 1.76 & 1.93 & 1.9 & 1.78 & 1.76 & 1.7 & 1.68 & 1.75 & 1.71 & 1.68 & 1.69 \\
\hline Elaidic $(18: 1 t 9)$ & 0 & 0 & 0 & 0 & 0 & 0 & 0 & 0 & 0 & 0 & 0 & 0 & 0 & 0 \\
\hline Oleic $(18: 1 n 9)$ & 3.77 & 3.62 & 5.43 & 5.19 & 5.98 & 5.87 & 6.09 & 6.04 & 8.26 & 8.19 & 8.65 & 8.46 & 8.77 & 8.79 \\
\hline $\begin{array}{l}\text { Vaccenic } \\
(18: \ln 7) \\
\end{array}$ & 0 & 0 & 2.68 & 2.6 & 2.84 & 2.85 & 1.87 & 1.82 & 0 & 0 & 0 & 0 & 0 & 0 \\
\hline Linoleic (18:2) & 0 & 0 & 0 & 0 & 0 & 0 & 0 & 0 & 0 & 0 & 0 & 0 & 0 & 0 \\
\hline $\begin{array}{l}\text { Linolenic } \\
\text { (T18:3) }\end{array}$ & $\mathbf{0}$ & $\mathbf{0}$ & $\mathbf{0}$ & $\mathbf{0}$ & $\mathbf{0}$ & $\mathbf{0}$ & $\mathbf{0}$ & $\mathbf{0}$ & $\mathbf{0}$ & $\mathbf{0}$ & $\mathbf{0}$ & $\mathbf{0}$ & $\mathbf{0}$ & $\mathbf{0}$ \\
\hline$(\mathrm{T} 18: 4)$ & $\mathbf{0}$ & 0 & $\mathbf{0}$ & $\mathbf{0}$ & $\mathbf{0}$ & $\mathbf{0}$ & 0 & $\mathbf{0}$ & $\mathbf{0}$ & $\mathbf{0}$ & $\mathbf{0}$ & $\mathbf{0}$ & $\mathbf{0}$ & $\mathbf{0}$ \\
\hline Arachidic (20:0) & 0 & 0 & 0 & 0 & 0 & 0 & 0.2 & 0.2 & 0.22 & 0.21 & 0.22 & 0.22 & 0.22 & 0.23 \\
\hline$(20: \ln 9)$ & 0 & 0 & 0 & 0 & 0 & 0 & 0 & 0 & 0 & 0 & 0 & 0 & 0 & 0 \\
\hline (20:3 T3) & $\mathbf{0}$ & $\mathbf{0}$ & $\mathbf{0}$ & $\mathbf{0}$ & $\mathbf{0}$ & $\mathbf{0}$ & $\mathbf{0}$ & $\mathbf{0}$ & $\mathbf{0}$ & $\mathbf{0}$ & $\mathbf{0}$ & $\mathbf{0}$ & $\mathbf{0}$ & $\mathbf{0}$ \\
\hline $\begin{array}{l}\text { Arachidonic } \\
(20: 4 n \sigma) \\
\end{array}$ & 0 & 0 & 0 & 0 & 0 & 0 & 0 & 0 & 0 & 0 & 0 & 0 & 0 & 0 \\
\hline $\begin{array}{l}\text { Arachidonic } \\
\text { (20:4 T3) }\end{array}$ & $\mathbf{0}$ & $\mathbf{0}$ & $\mathbf{0}$ & $\mathbf{0}$ & $\mathbf{0}$ & $\mathbf{0}$ & $\mathbf{0}$ & $\mathbf{0}$ & $\mathbf{0}$ & $\mathbf{0}$ & $\mathbf{0}$ & $\mathbf{0}$ & $\mathbf{0}$ & $\mathbf{0}$ \\
\hline $\begin{array}{l}\text { (20:5 T3; } \\
\text { EPA) }\end{array}$ & $\mathbf{0}$ & $\mathbf{0}$ & $\mathbf{0}$ & $\mathbf{0}$ & $\mathbf{0}$ & $\mathbf{0}$ & $\mathbf{0}$ & $\mathbf{0}$ & $\mathbf{0}$ & $\mathbf{0}$ & $\mathbf{0}$ & $\mathbf{0}$ & $\mathbf{0}$ & $\mathbf{0}$ \\
\hline $\begin{array}{l}\text { Docosanoic } \\
(22: 0)\end{array}$ & 0 & 0 & 0 & 0 & 0 & 0 & 0.19 & 0.19 & 0.21 & 0.2 & 0.24 & 0.24 & 0.23 & 0.25 \\
\hline Erucic $(22: 1 n 9)$ & 0 & 0 & 0 & 0 & 0 & 0 & 0 & 0 & 0 & 0 & 0 & 0 & 0 & 0 \\
\hline $\begin{array}{l}\text { (22:5 T3; } \\
\text { DPA) }\end{array}$ & 0 & 0 & 0 & 0 & 0 & 0 & 0 & 0 & 0.25 & 0.24 & 0.27 & 0.26 & 0.28 & 0.27 \\
\hline $\begin{array}{l}\text { (22:6 T3; } \\
\text { DHA) }\end{array}$ & 15.4 & 16 & 24.7 & 25.2 & 29.72 & 30.17 & 28.21 & 28.43 & 35.08 & 35.6 & 34.71 & 35.82 & 36.74 & 36.56 \\
\hline $\begin{array}{l}\text { Lignoceric } \\
(24: 0)\end{array}$ & 0 & 0 & 0 & 0 & 0 & 0 & 0 & 0 & 0.17 & 0.17 & 0.2 & 0.18 & 0.18 & 0.21 \\
\hline $\begin{array}{l}\text { Nervonic } \\
(24: 1 n 9)\end{array}$ & 0 & 0 & 0 & 0 & 0 & 0 & 0 & 0 & 0 & 0 & 0 & 0 & 0 & 0 \\
\hline
\end{tabular}




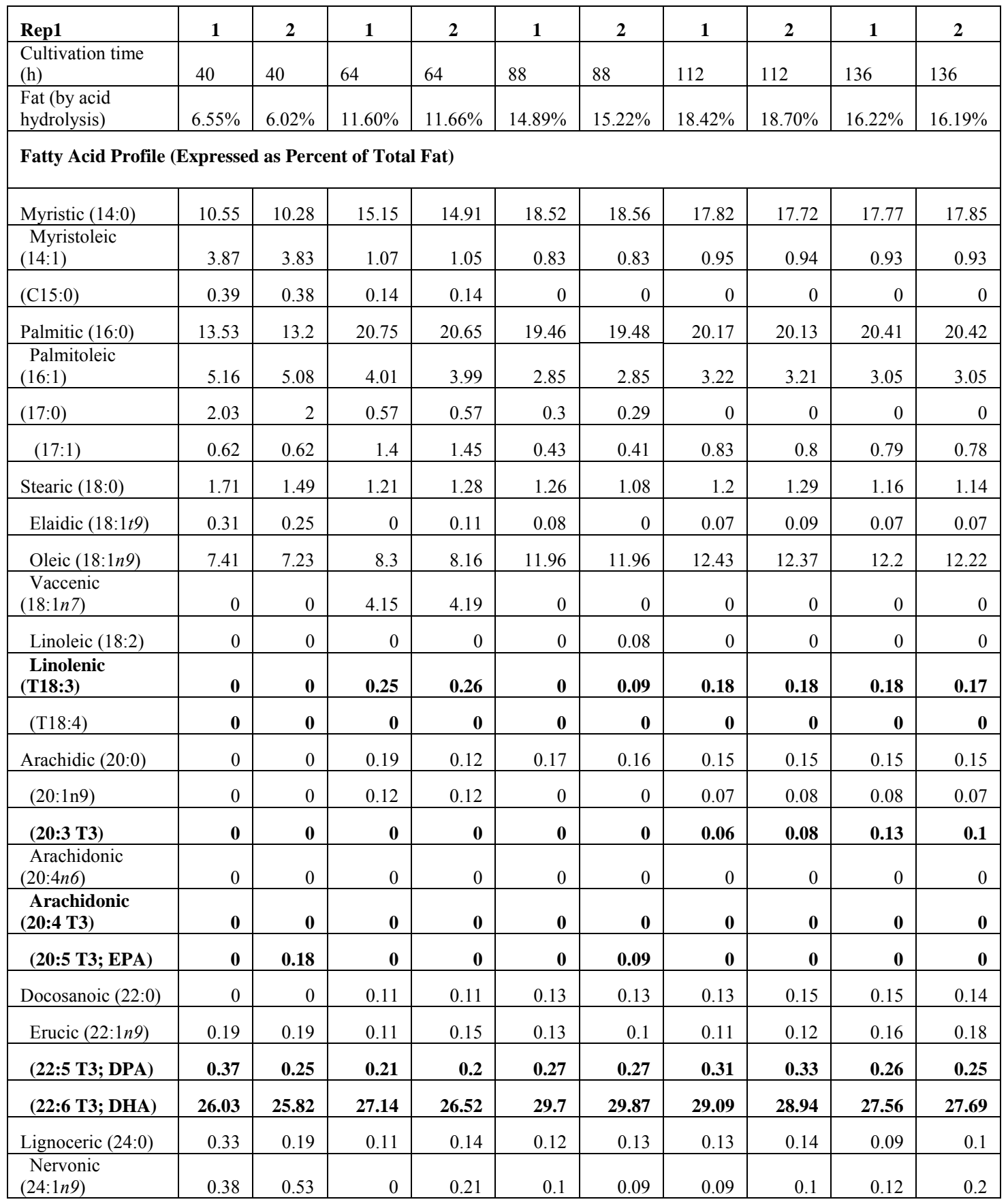




\begin{tabular}{|c|c|c|c|c|c|c|c|c|c|c|}
\hline $\operatorname{Rep} 2$ & 1 & 2 & 1 & 2 & 1 & 2 & 1 & 2 & 1 & 2 \\
\hline Cultivation time (h) & 64 & 64 & 88 & 88 & 112 & 112 & 136 & 136 & 160 & 160 \\
\hline $\begin{array}{l}\text { Fat (by acid } \\
\text { hydrolysis) }\end{array}$ & $4.39 \%$ & $5.12 \%$ & $7.95 \%$ & $7.47 \%$ & $8.36 \%$ & $7.78 \%$ & $9.26 \%$ & $9.45 \%$ & $6.28 \%$ & $6.05 \%$ \\
\hline \multicolumn{11}{|l|}{$\begin{array}{l}\text { Fatty Acid Profile } \\
\text { (Expressed as } \\
\text { Percent of Total Fat) }\end{array}$} \\
\hline Myristic (14:0) & 8.1 & 8.39 & 11.55 & 11.63 & 11.15 & 11.33 & 11.38 & 11.28 & 8.1 & 7.72 \\
\hline Myristoleic (14:1) & 5.64 & 5.78 & 5.02 & 5 & 6.02 & 5.9 & 6.63 & 6.72 & 10.58 & 11 \\
\hline$(\mathrm{C} 15: 0)$ & 0.34 & 0.32 & 0.23 & 0.23 & 0.26 & 0.26 & 0.23 & 0.23 & 0 & 0 \\
\hline Palmitic (16:0) & 20.04 & 20.52 & 19.3 & 19.41 & 14.99 & 15.02 & 14.22 & 14.3 & 13.53 & 13.24 \\
\hline Palmitoleic (16:1) & 6.22 & 6.34 & 6.13 & 6.11 & 7.33 & 7.25 & 6.65 & 6.71 & 8.94 & 9.22 \\
\hline$(17: 0)$ & 1.34 & 1.36 & 0.8 & 0.83 & 0 & 0 & 0 & 0 & 0 & 0 \\
\hline$(17: 1)$ & 4.14 & 4.39 & 3.34 & 3.08 & 3.43 & 3.35 & 3.07 & 3.3 & 3.64 & 3.68 \\
\hline Stearic (18:0) & 1.55 & 1.45 & 1.38 & 1.46 & 0.87 & 1.11 & 0.96 & 0.97 & 1.26 & 0.98 \\
\hline Elaidic $\left(18: 1 t^{9}\right)$ & 0.21 & 0.2 & 0.17 & 0.21 & 0.17 & 0.21 & 0.22 & 0.22 & 0.28 & 0.25 \\
\hline Oleic $(18: 1 n 9)$ & 2.56 & 2.69 & 6.59 & 6.67 & 7.35 & 7.63 & 7.69 & 7.68 & 4.5 & 4.25 \\
\hline Vaccenic $(18: 1 n 7)$ & 5.45 & 5.62 & 4.93 & 4.92 & 4.17 & 4.05 & 3.05 & 3.01 & 4.21 & 4.32 \\
\hline Linoleic (18:2) & 0 & 0.22 & 0 & 0 & 0 & 0 & 0 & 0 & 0 & 0.22 \\
\hline Linolenic (T18:3) & 0.99 & 0.91 & 0.65 & 0.67 & 0.73 & 0.7 & 0.65 & 0.64 & 0.68 & 0.74 \\
\hline$(\mathrm{T} 18: 4)$ & $\mathbf{0}$ & $\mathbf{0}$ & $\mathbf{0}$ & $\mathbf{0}$ & $\mathbf{0}$ & $\mathbf{0}$ & $\mathbf{0}$ & $\mathbf{0}$ & $\mathbf{0}$ & $\mathbf{0}$ \\
\hline Arachidic $(20: 0)$ & 0 & 0 & 0 & 0 & 0 & 0 & 0 & 0 & 0 & 0 \\
\hline$(20: \ln 9)$ & 0 & 0 & 0 & 0 & 0.15 & 0.14 & 0.17 & 0.16 & 0 & 0.19 \\
\hline$(20: 3$ T3) & $\mathbf{0}$ & $\mathbf{0}$ & 0.23 & 0.24 & 0.35 & 0.31 & 0.34 & 0.34 & 0.47 & 0.46 \\
\hline Arachidonic $(20: 4 n 6)$ & 0 & 0 & 0 & 0 & 0 & 0 & 0 & 0 & 0 & 0 \\
\hline $\begin{array}{l}\text { Arachidonic (20:4 } \\
\text { T3) }\end{array}$ & $\mathbf{0}$ & $\mathbf{0}$ & $\mathbf{0}$ & $\mathbf{0}$ & $\mathbf{0}$ & $\mathbf{0}$ & $\mathbf{0}$ & $\mathbf{0}$ & 0 & $\mathbf{0}$ \\
\hline (20:5 T3; EPA) & $\mathbf{0}$ & $\mathbf{0}$ & $\mathbf{0}$ & $\mathbf{0}$ & $\mathbf{0}$ & $\mathbf{0}$ & $\mathbf{0}$ & $\mathbf{0}$ & $\mathbf{0}$ & $\mathbf{0}$ \\
\hline Docosanoic $(22: 0)$ & 0 & 0 & 0 & 0 & 0 & 0 & 0 & 0 & 0 & 0 \\
\hline Erucic $(22: 1 n 9)$ & 0 & 0.2 & 0.17 & 0 & 0.17 & 0.16 & 0.14 & 0.13 & 0 & 0 \\
\hline (22:5 T3; DPA) & $\mathbf{0}$ & $\mathbf{0}$ & 0.25 & 0.28 & 0.22 & 0.2 & 0.2 & 0.18 & $\mathbf{0}$ & 0.19 \\
\hline (22:6 T3; DHA) & 10.18 & 10.52 & 16.82 & 16.46 & 16.36 & 16.7 & 15.96 & 15.79 & 10.55 & 9.96 \\
\hline Lignoceric (24:0) & 0 & 0.23 & 0 & 0 & 0 & 0 & 0 & 0 & 0 & 0 \\
\hline Nervonic $(24: 1 n 9)$ & 0.88 & 0.52 & 0.25 & 0.18 & 0 & 0 & 0.14 & 0 & 0.19 & 0 \\
\hline
\end{tabular}




\begin{tabular}{|c|c|c|c|c|c|c|c|c|c|}
\hline Rep3 -1 & 1 & 2 & 3 & 1 & 2 & 3 & 1 & 2 & 3 \\
\hline Cultivation time $(\mathrm{h})$ & 40 & 40 & 40 & 64 & 64 & 64 & 88 & 88 & 88 \\
\hline Fat (by acid hydrolysis) & $4.65 \%$ & $* *$ & $4.65 \%$ & $8.92 \%$ & $8.35 \%$ & $8.64 \%$ & $13.28 \%$ & $12.97 \%$ & $13.13 \%$ \\
\hline \multicolumn{10}{|c|}{$\begin{array}{l}\text { Fatty Acid Profile (Expressed as } \\
\text { Percent of Total Fat) }\end{array}$} \\
\hline Myristic (14:0) & 8.27 & 8.07 & 8.6 & 14.75 & 14.46 & 14.31 & 15.39 & 15.41 & 15.4 \\
\hline Myristoleic (14:1) & 8.55 & 8.6 & 0 & 1.45 & 1.46 & 0 & 1.09 & 1.09 & 0 \\
\hline$(\mathrm{C} 15: 0)$ & 0.32 & 0.31 & 0 & 0 & 0 & 0 & 0 & 0 & 0 \\
\hline Palmitic (16:0) & 11.34 & 11.16 & 11.24 & 14.52 & 14.3 & 14.16 & 15.96 & 16 & 15.62 \\
\hline Palmitoleic (16:1) & 6.97 & 6.99 & 6.88 & 7.31 & 7.26 & 7.34 & 5.29 & 5.31 & 5.26 \\
\hline$(17: 0)$ & 1.72 & 1.71 & 0 & 0.66 & 0.69 & 0.66 & 0 & 0 & 0 \\
\hline$(17: 1)$ & 0.7 & 0.67 & 0.97 & 1.05 & 1.27 & 0 & 2.06 & 2.05 & 0 \\
\hline Stearic (18:0) & 2.05 & 1.98 & 1.98 & 0.93 & 0.97 & 1.06 & 0.74 & 0.75 & 0.75 \\
\hline Elaidic $\left(18: 1 t^{9}\right)$ & 0.19 & 0.16 & 0.31 & 0 & 0 & 0 & 0.11 & 0 & 0 \\
\hline Oleic $(18: 1 n 9)$ & 6.96 & 6.68 & 6.75 & 11.39 & 11.02 & 16.45 & 13.78 & 13.92 & 13.44 \\
\hline Vaccenic $(18: 1 n 7)$ & 0 & 0 & 0 & 5.52 & 5.67 & 0 & 0 & 0 & 0 \\
\hline Linoleic (18:2) & 0 & 0 & 0 & 0 & 0 & 0 & 0.1 & 0 & 0 \\
\hline Linolenic (T18:3) & $\mathbf{0}$ & $\mathbf{0}$ & $\mathbf{0}$ & 0.21 & 0.18 & 0.22 & 0.3 & 0.3 & $\mathbf{0}$ \\
\hline$(\mathrm{T} 18: 4)$ & $\mathbf{0}$ & $\mathbf{0}$ & $\mathbf{0}$ & $\mathbf{0}$ & $\mathbf{0}$ & $\mathbf{0}$ & $\mathbf{0}$ & $\mathbf{0}$ & $\mathbf{0}$ \\
\hline Arachidic $(20: 0)$ & 0 & 0 & 0 & 0 & 0 & 0 & 0.11 & 0.11 & 0.16 \\
\hline$(20: \ln 9)$ & 0 & 0 & 0 & 0 & 0 & 0.23 & 0.09 & 0.09 & 0 \\
\hline$(20: 3$ T3) & $\mathbf{0}$ & $\mathbf{0}$ & $\mathbf{0}$ & $\mathbf{0}$ & $\mathbf{0}$ & $\mathbf{0}$ & 0.14 & 0.16 & $\mathbf{0}$ \\
\hline Arachidonic $(20: 4 n 6)$ & 0 & 0 & 0 & 0 & 0 & 0 & 0 & 0 & 0 \\
\hline Arachidonic (20:4 T3) & $\mathbf{0}$ & $\mathbf{0}$ & $\mathbf{0}$ & $\mathbf{0}$ & $\mathbf{0}$ & $\mathbf{0}$ & $\mathbf{0}$ & $\mathbf{0}$ & $\mathbf{0}$ \\
\hline (20:5 T3; EPA) & $\mathbf{0}$ & $\mathbf{0}$ & $\mathbf{0}$ & $\mathbf{0}$ & $\mathbf{0}$ & $\mathbf{0}$ & $\mathbf{0}$ & $\mathbf{0}$ & $\mathbf{0}$ \\
\hline Docosanoic (22:0) & 0 & 0 & 0 & 0 & 0 & 0 & 0.08 & 0.09 & 0 \\
\hline Erucic $(22: \ln 9)$ & 0.3 & 0.34 & 0 & 0.14 & 0.17 & 0 & 0.11 & 0.11 & 0 \\
\hline (22:5 T3; DPA) & 0.36 & 0.39 & 0.58 & 0.28 & 0.28 & 0.82 & 0.28 & 0.29 & 1.19 \\
\hline (22:6 T3; DHA) & 23.1 & 22.55 & 22.48 & 22.75 & 22.51 & 21.2 & 27.36 & 27.44 & 26.16 \\
\hline Lignoceric (24:0) & 0 & 0.17 & 0 & 0 & 0 & 0.21 & 0 & 0 & 0.18 \\
\hline Nervonic $(24: 1 n 9)$ & 0.2 & 0.37 & 0 & 0 & 0.11 & 0.34 & 0 & 0 & 0 \\
\hline
\end{tabular}




\begin{tabular}{|c|c|c|c|c|c|c|c|c|c|}
\hline Rep3-2 & 1 & 2 & 3 & 1 & 2 & 3 & 1 & 2 & 3 \\
\hline Cultivation time $(\mathrm{h})$ & 112 & 112 & 112 & 136 & 136 & 136 & 160 & 160 & 160 \\
\hline Fat (by acid hydrolysis) & $14.72 \%$ & $14.42 \%$ & $14.57 \%$ & $15.21 \%$ & $15.32 \%$ & $15.27 \%$ & $13.98 \%$ & $13.61 \%$ & $13.80 \%$ \\
\hline \multicolumn{10}{|l|}{$\begin{array}{l}\text { Fatty Acid Profile } \\
\text { (Expressed as Percent of } \\
\text { Total Fat) } \\
\end{array}$} \\
\hline Myristic (14:0) & 15.18 & 15.2 & 15.25 & 15.55 & 15.59 & 15.8 & 14.85 & 14.99 & 14.51 \\
\hline Myristoleic (14:1) & 1.05 & 1.07 & 0 & 5.44 & 5.37 & 0 & 7.08 & 6.95 & 0 \\
\hline (C15:0) & 0 & 0 & 0 & 0 & 0 & 0 & 0 & 0 & 0 \\
\hline Palmitic (16:0) & 15.59 & 15.56 & 15.54 & 15.23 & 15.23 & 15.07 & 14.43 & 14.53 & 13.64 \\
\hline Palmitoleic (16:1) & 5.53 & 5.52 & 5.59 & 6.02 & 5.97 & 5.96 & 6.77 & 6.7 & 6.54 \\
\hline$(17: 0)$ & 0 & 0 & 0 & 0 & 0 & 0 & 0 & 0 & 0 \\
\hline$(17: 1)$ & 2.02 & 2.03 & 0 & 1.85 & 1.74 & 0 & 1.71 & 1.64 & 0 \\
\hline Stearic $(18: 0)$ & 0.71 & 0.72 & 0.78 & 0.74 & 0.75 & 0.75 & 0.79 & 0.81 & 0.86 \\
\hline Elaidic $(18: 1 t 9)$ & 0.11 & 0.11 & 0 & 0.1 & 0.11 & 0 & 0.12 & 0.12 & 0 \\
\hline Oleic $(18: 1 n 9)$ & 12.49 & 12.5 & 12.39 & 12.35 & 12.36 & 12.16 & 8.75 & 8.75 & 11.3 \\
\hline Vaccenic $(18: \ln 7)$ & 0 & 0 & 0 & 0 & 0 & 0 & 3.46 & 3.49 & 0 \\
\hline Linoleic (18:2) & 0 & 0 & 0 & 0 & 0 & 0 & 0 & 0 & 0 \\
\hline Linolenic (T18:3) & 0.29 & 0.29 & $\mathbf{0}$ & 0.27 & 0.29 & $\mathbf{0}$ & 0.28 & 0.29 & $\mathbf{0}$ \\
\hline (T18:4) & $\mathbf{0}$ & $\mathbf{0}$ & $\mathbf{0}$ & $\mathbf{0}$ & $\mathbf{0}$ & $\mathbf{0}$ & $\mathbf{0}$ & $\mathbf{0}$ & $\mathbf{0}$ \\
\hline Arachidic $(20: 0)$ & 0.11 & 0.11 & 0.16 & 0.11 & 0.11 & 0.16 & 0.11 & 0.11 & 0.26 \\
\hline$(20: \ln 9)$ & 0.09 & 0.09 & 0 & 0.09 & 0.09 & 0 & 0.09 & 0.09 & 0 \\
\hline (20:3 T3) & 0.15 & 0.15 & $\mathbf{0}$ & 0.14 & 0.14 & $\mathbf{0}$ & 0.2 & 0.2 & $\mathbf{0}$ \\
\hline Arachidonic $(20: 4 n 6)$ & 0 & 0 & 0 & 0 & 0 & 0 & 0 & 0 & 0 \\
\hline Arachidonic (20:4 T3) & $\mathbf{0}$ & $\mathbf{0}$ & $\mathbf{0}$ & $\mathbf{0}$ & $\mathbf{0}$ & $\mathbf{0}$ & $\mathbf{0}$ & $\mathbf{0}$ & $\mathbf{0}$ \\
\hline (20:5 T3; EPA) & $\mathbf{0}$ & $\mathbf{0}$ & 0.19 & $\mathbf{0}$ & $\mathbf{0}$ & $\mathbf{0}$ & $\mathbf{0}$ & $\mathbf{0}$ & $\mathbf{0}$ \\
\hline Docosanoic $(22: 0)$ & 0.08 & 0.08 & 0 & 0.07 & 0.07 & 0 & 0 & 0 & 0.29 \\
\hline Erucic $(22: \ln 9)$ & 0.09 & 0.09 & 0 & 0.08 & 0.08 & 0 & 0.1 & 0.1 & 0 \\
\hline (22:5 T3; DPA) & 0.27 & 0.27 & 1.09 & 0.24 & 0.24 & 1.17 & 0.2 & 0.2 & 1.39 \\
\hline (22:6 T3; DHA) & 28.16 & 28.01 & 26.98 & 27.09 & 26.83 & 26 & 23.94 & 24.18 & 21.46 \\
\hline Lignoceric (24:0) & 0 & 0 & 0 & 0 & 0 & 0.2 & 0 & 0 & 0.26 \\
\hline Nervonic $(24: 1 n 9)$ & 0.07 & 0 & 0 & 0 & 0 & 0.26 & 0.07 & 0 & 0 \\
\hline
\end{tabular}




\section{APPENDIX C. Calculation of the Flow Rates}

\section{Repetition One}

In the study done by Swaaf et al. (1999), $19 \mathrm{~g}$ glucose was used within first 40 hours. This value of feed rate was used as the basis of feed rate calculations for the batch mode cultivation. Accordingly, our feed rate of media for the first $40 \mathrm{~h}$ cultivation period (batch- mode) was calculated as:

$(19 \mathrm{~g}$ glucose $/ 40 \mathrm{~h}) \times(1 \mathrm{~L}$ media/25 g glucose $) \times(1000 \mathrm{~mL} / \mathrm{L} \times \mathrm{h} / 60 \mathrm{~min})=0.32$ $\mathrm{mL} / \mathrm{min}$ (for $1 \mathrm{~L}$ start up volume)

For $8.8 \mathrm{~L}$ initial volume, the feed rate of media was: $8.8 \times 0.32 \mathrm{~mL} / \mathrm{min}=2.8$ $\mathrm{mL} / \mathrm{min}$

The total volume in both bioreactors after $40 \mathrm{~h}$ was calculated as:

$8.8 \mathrm{~L}+\{(2.8 \mathrm{~mL} / \mathrm{min} \times 60 \mathrm{~min} / 1 \mathrm{~h}) \times(40 \mathrm{~h} \times 1 \mathrm{~L} / 1000 \mathrm{~mL})\}=\sim 15.5 \mathrm{~L}$ According to Swaaf's study (1999), after $40-43 \mathrm{~h}$ the growth rate had started decreasing slowly and had ceased completely after $74 \mathrm{~h}$. This information was used to calculate flow rate of culture from the growth vessel to the lipid accumulation vessel for the duration of the continuous mode study:

$(15.5 \mathrm{~L} / 34 \mathrm{~h}) \times(\mathrm{h} / 60 \mathrm{~min}) \times(1000 \mathrm{~mL} / \mathrm{L})=7.58 \mathrm{~mL} / \mathrm{min}$

The same flow rate, $7.58 \mathrm{~mL} / \mathrm{min}$, was used for the feed rate of fresh media to the growth vessel. Since $25 \%$ glucose solution contains 10 times of glucose in media, $0.758 \mathrm{~mL} / \mathrm{min}$ was decided as the feed rate of $25 \%$ glucose solution to the lipid accumulation vessel. 


\section{Repetition Two and Three}

In the study done by Swaaf et al. (1999), $19 \mathrm{~g}$ glucose was used within the first $40 \mathrm{~h}$ of cultivation. This value of feed rate was used as the basis of the feed rate calculations for batch mode cultivation. Accordingly, the feed rate of media for the first $40 \mathrm{~h}$ cultivation period (batch- mode) was calculated as:

$(19 \mathrm{~g}$ glucose $/ 40 \mathrm{~h}) \times(1 \mathrm{~L}$ media/25 g glucose $) \times(1000 \mathrm{~mL} / \mathrm{L} \times \mathrm{h} / 60 \mathrm{~min})=0.32$ $\mathrm{mL} / \mathrm{min}$ (for $1 \mathrm{~L}$ start up volume)

For $5.5 \mathrm{~L}$ initial volume, the feed rate of media was: $5.5 \times 0.32 \mathrm{~mL} / \mathrm{min}=1.76$ $\mathrm{mL} / \mathrm{min}$

The total volume in both bioreactors after $40 \mathrm{~h}$ was calculated as:

$5.5 \mathrm{~L}+(1.76 \mathrm{~mL} / \mathrm{min} \times 60 \mathrm{~min} / 1 \mathrm{~h} \times 40 \mathrm{~h} \times 1 \mathrm{~L} / 1000 \mathrm{~mL})=\sim 9.72 \mathrm{~L}$

Flow rate of culture from the growth vessel to the lipid accumulation vessel was calculated:

$(9.72 \mathrm{~L} / 34 \mathrm{~h}) \times(\mathrm{h} / 60 \mathrm{~min}) \times(1000 \mathrm{~mL} / \mathrm{L})=\sim 4.75 \mathrm{~mL} / \mathrm{min}$

The flow rate of $4.75 \mathrm{~mL} / \mathrm{min}$ was also used for the feed rate of fresh media to the growth vessel. Since $25 \%$ glucose solution contains 10 times of glucose in media, $0.475 \mathrm{~mL} / \mathrm{min}$ was decided as the feed rate of $25 \%$ glucose solution to the lipid accumulation vessel. 


\section{APPENDIX D. Statistical Analysis}

Since the response variables (OD Growth, OD Cooling, ...., DHA Productivity) are linearly related to Time, Analysis of Covariance (ANCOVA) is used to compare the replications. Time is used as a covariate.

Results:

1) OD Growth.

a) There is a significant difference between Rep 1 and Rep 3

b) There is a significant difference between Rep 2 and Rep 3

c) There is no significant difference between Rep 1 and Rep 2 .

2) OD Cooling.

a) There is a significant difference between Rep 1 and Rep 3

b) There is a significant difference between $\operatorname{Rep} 2$ and $\operatorname{Rep} 3$

c) There is no significant difference between Rep 1 and Rep 2 .

3) Biomass Concentration

a) There is a significant difference between Rep 1 and Rep 3

b) There is a significant difference between Rep 2 and Rep 3

c) There is no significant difference between Rep 1 and Rep 2 .

4) \%Fat

a) There is a significant difference between Rep 1 and Rep 2

b) There is a significant difference between Rep 2 and Rep 3

c) There is no significant difference between Rep 1 and Rep 3.

5) \%DHA

a) There is a significant difference between Rep 1 and Rep 2

b) There is a significant difference between Rep 2 and Rep 3

c) There is no significant difference between Rep 1 and Rep 3.

6) Fat Concentration

a) There is a significant difference between Rep 1 and Rep 3

b) There is a significant difference between Rep 2 and Rep 3

c) There is no significant difference between Rep 1 and Rep 2 .

7) DHA Concentration

a) There is a significant difference between Rep 1 and Rep 2

b) There is a significant difference between Rep 2 and Rep 3

c) There is no significant difference between Rep 1 and Rep 3. 
8) DHA Productivity

a) There is a significant difference between Rep 1 and Rep 2

b) There is a significant difference between Rep 2 and Rep 3

c) There is no significant difference between Rep 1 and Rep 3 . 
Response OD Growth

Whole Model

Regression Plot

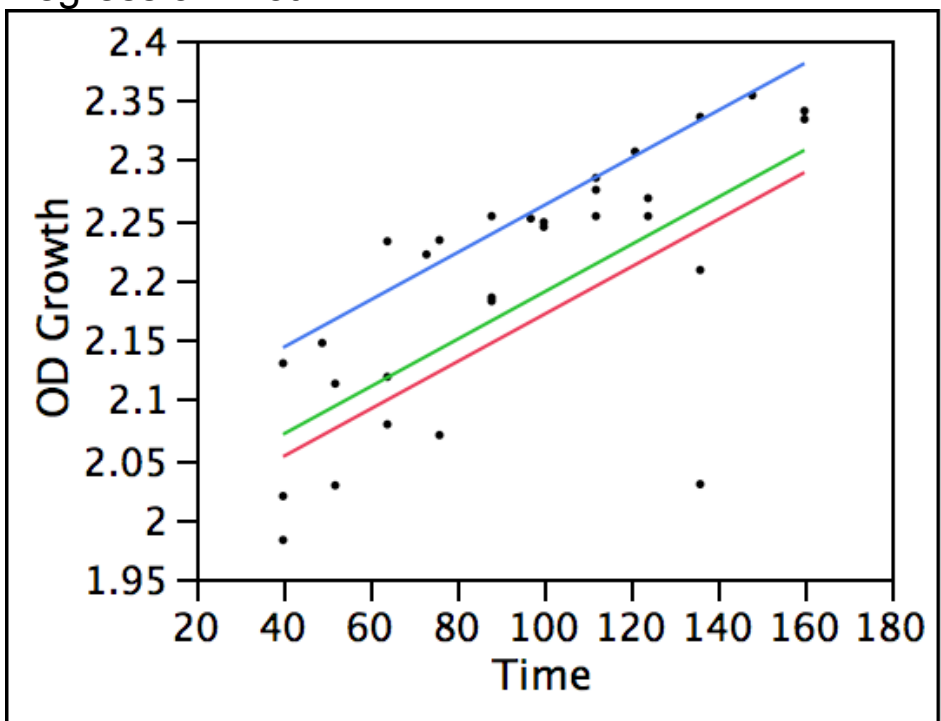

Rep 1

Rep 2 -

Rep 3 -

Summary of Fit

RSquare

0.681122

RSquare Adj

0.644329

Root Mean Square Error

0.062627

Mean of Response

2.1993

Observations (or Sum Wgts)

30

Analysis of Variance

$\begin{array}{lrrrr}\text { Source } & \text { DF } & \text { Sum of Squares } & \text { Mean Square } & \text { F Ratio } \\ \text { Model } & 3 & 0.21781693 & 0.072606 & 18.5120 \\ \text { Error } & 26 & 0.10197420 & 0.003922 & \text { Prob }>\text { F } \\ \text { C. Total } & 29 & 0.31979114 & & <.0001\end{array}$

Parameter Estimates

Term

Intercept

Time

Replication[Rep 1]

Replication[Rep 2]

$\begin{array}{rrrr}\text { Estimate } & \text { Std Error } & \text { t Ratio } & \text { Prob }>|t| \\ 2.0094027 & 0.03228 & 62.25 & <.0001 \\ 0.0019794 & 0.000321 & 6.17 & <.0001 \\ -0.036594 & 0.016752 & -2.18 & 0.0381 \\ -0.017946 & 0.016202 & -1.11 & 0.2782\end{array}$




$\begin{array}{lrrrrr}\text { Effect Tests } & & & & & \\ \text { Source } & \text { Nparm } & \text { DF } & \text { Sum of Squares } & \text { F Ratio } & \text { Prob > F } \\ \text { Time } & 1 & 1 & 0.14926973 & 38.0588 & <.0001 \\ \text { Replication } & 2 & 2 & 0.04715233 & 6.0111 & 0.0071\end{array}$

Time

Replication

Least Squares Means Table Level Least Sq Mean

Rep $1 \quad 2.1596684$

$\begin{array}{rr}\text { Std Error } & \text { Mean } \\ 0.02097627 & 2.14700 \\ 0.01980592 & 2.17990 \\ 0.01893796 & 2.25973\end{array}$

$\begin{array}{llll}\text { Rep 2 } & 2.1783165 & 0.01980592 & 2.17990 \\ \text { Rep 3 } & 2.2508018 & 0.01893796 & 2.25973\end{array}$

LS Means Plot

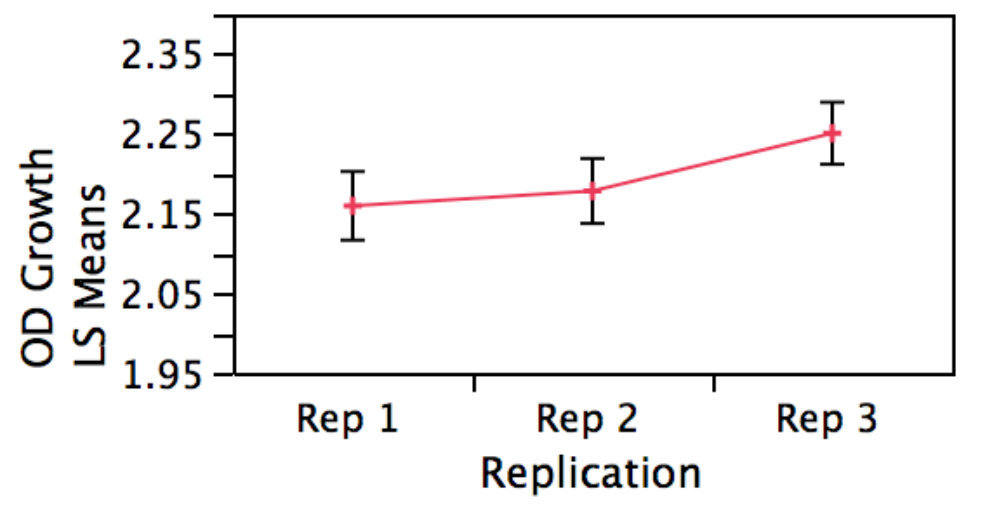

LSMeans Differences Tukey HSD

$\alpha=$ $0.050 \mathrm{Q}=$

2.48489

Level Least Sq Mean

Rep 3 A $\quad 2.2508018$

Rep $2 \quad$ B $\quad 2.1783165$

Rep $1 \quad$ B $\quad 2.1596684$

Levels not connected by same letter are significantly different. 
Response OD Cooling

Whole Model

Regression Plot

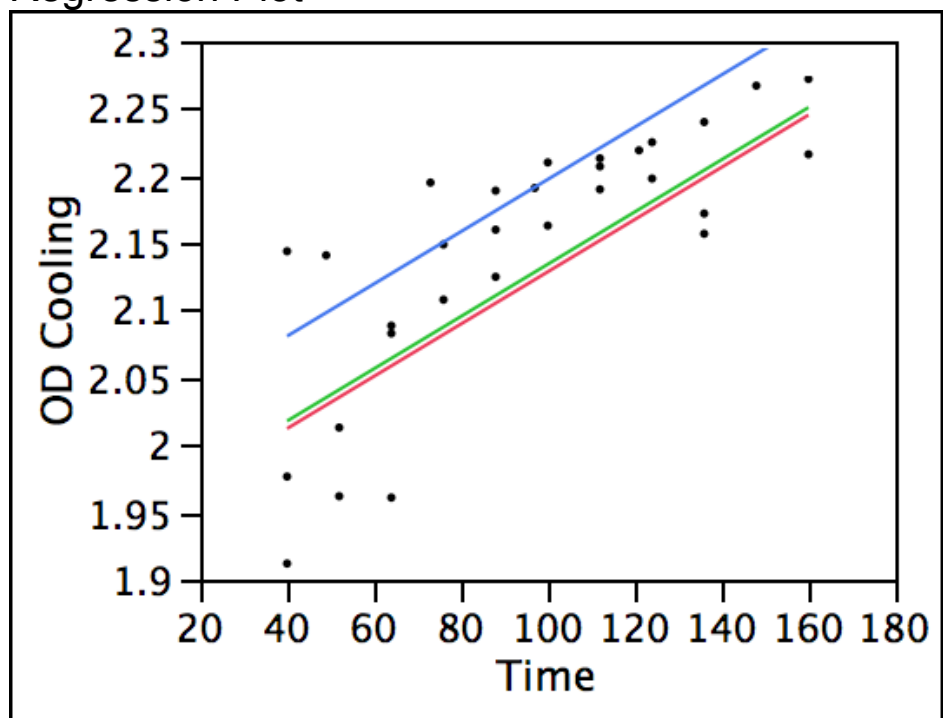

Rep 1 -

Rep 2 -

Rep 3 -

Summary of Fit

RSquare

0.732462

RSquare Adj

0.701593

Root Mean Square Error

0.051594

Mean of Response

2.144909

Observations (or Sum Wgts)

30

Analysis of Variance

Source

Model

Error

C. Total

DF Sum of Squares

$3 \quad 0.18948193$

$26 \quad 0.06920979$

29

0.25869172
Mean Square

0.063161

0.002662
F Ratio

23.7275

Prob $>$ F

$<.0001$

Parameter Estimates

Term

Intercept

Time

Replication[Rep 1]

Replication[Rep 2]

$\begin{array}{rrrr}\text { Estimate } & \text { Std Error } & \mathrm{t} \text { Ratio } & \text { Prob }>|\mathrm{t}| \\ 1.9593377 & 0.026593 & 73.68 & <.0001 \\ 0.0019416 & 0.000264 & 7.35 & <.0001 \\ -0.02475 & 0.013801 & -1.79 & 0.0846 \\ -0.019147 & 0.013347 & -1.43 & 0.1633\end{array}$




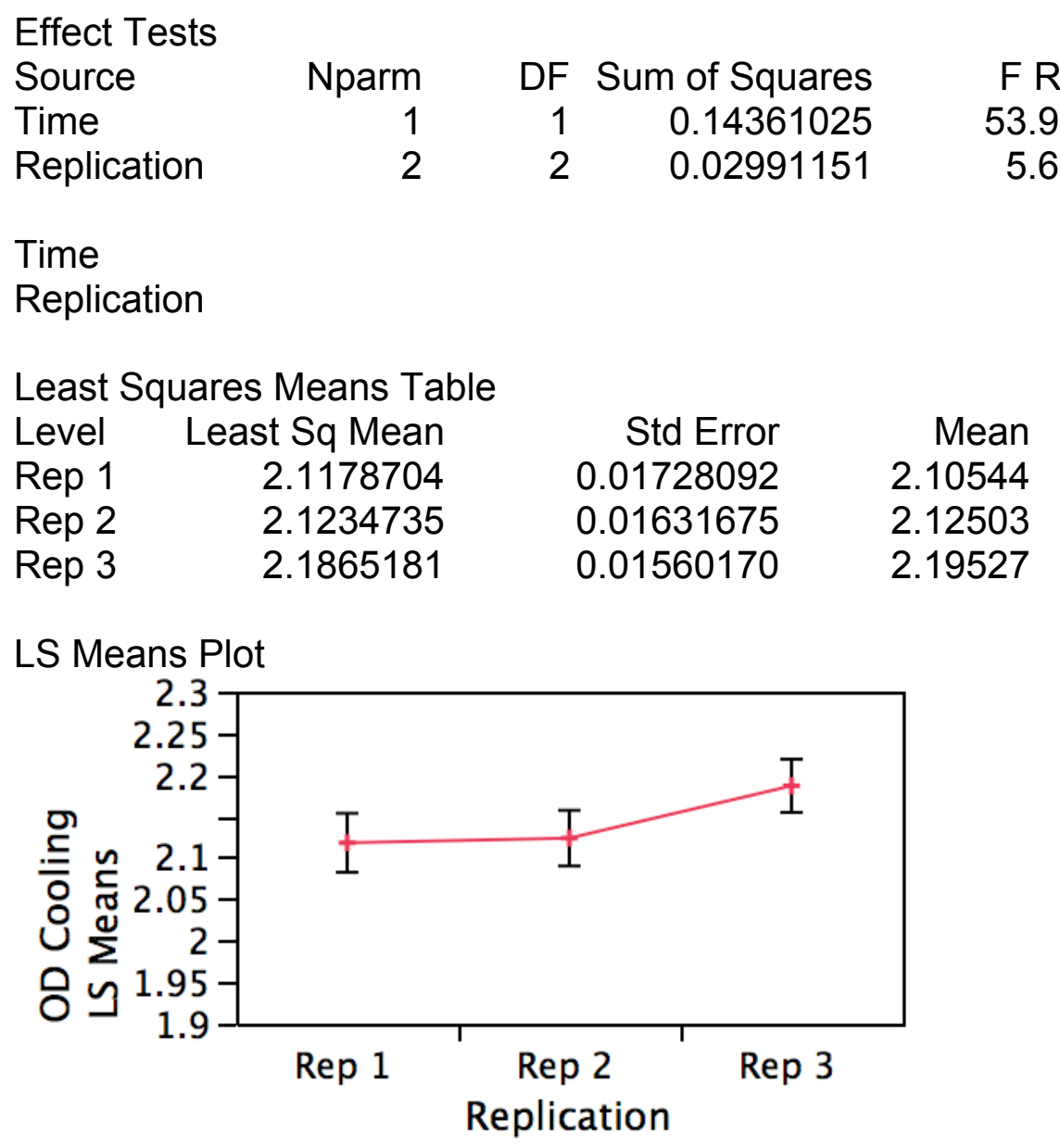

LSMeans Differences Tukey HSD

$\alpha=$ $0.050 \mathrm{Q}=$

2.48489

Level Least Sq Mean

Rep 3 A $\quad 2.1865181$

Rep $2 \quad$ B $\quad 2.1234735$

Rep $1 \quad$ B $\quad 2.1178704$

Levels not connected by same letter are significantly different. 
Response Biomass Concentration

Whole Model

Regression Plot

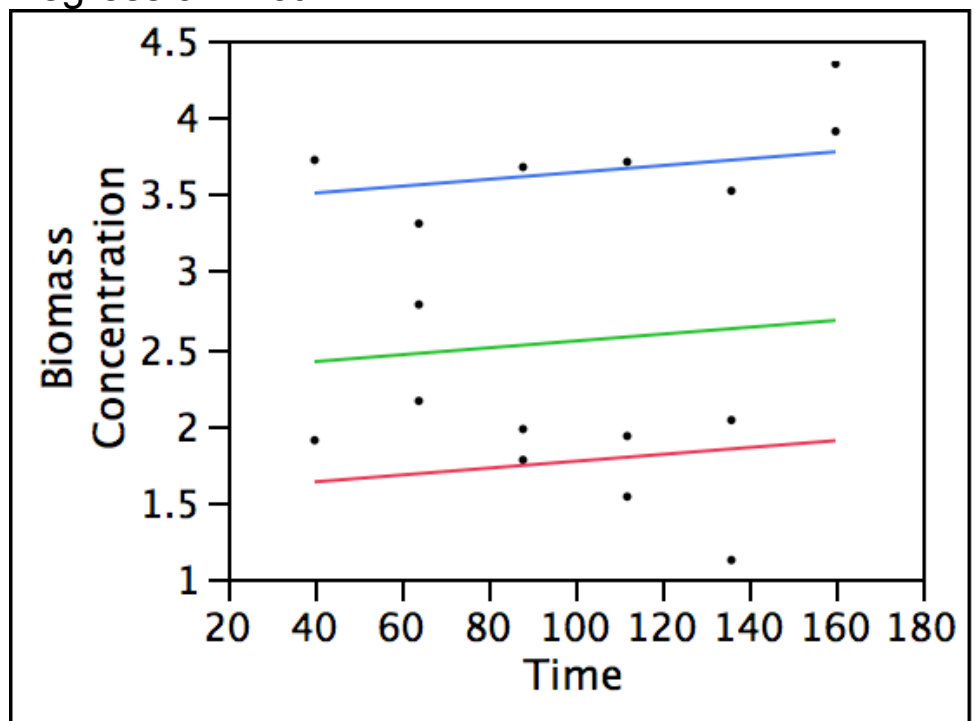

Rep 1

Rep 2 -

Rep 3 -

Summary of Fit

RSquare

0.655813

RSquare Adj

0.569767

Root Mean Square Error

0.66595

Mean of Response

2.711622

Observations (or Sum Wgts)

16

Analysis of Variance

Source

Model

Error

C. Total

DF Sum of Squares

$3 \quad 10.140291$

12

15

5.321871

15.462162
Mean Square

3.38010

0.44349
F Ratio

7.6216

Prob $>\mathrm{F}$

0.0041

Parameter Estimates

Term

Intercept

Time

Replication[Rep 1]

Replication[Rep 2]
Estimate

2.4261001

0.0022358

$-0.886385$

$-0.104708$
Std Error

0.482952

0.004531

0.245858

0.245858 t Ratio

5.02

0.49

$-3.61$

$-0.43$
Prob $>|t|$

0.0003

0.6306

0.0036

0.6777 


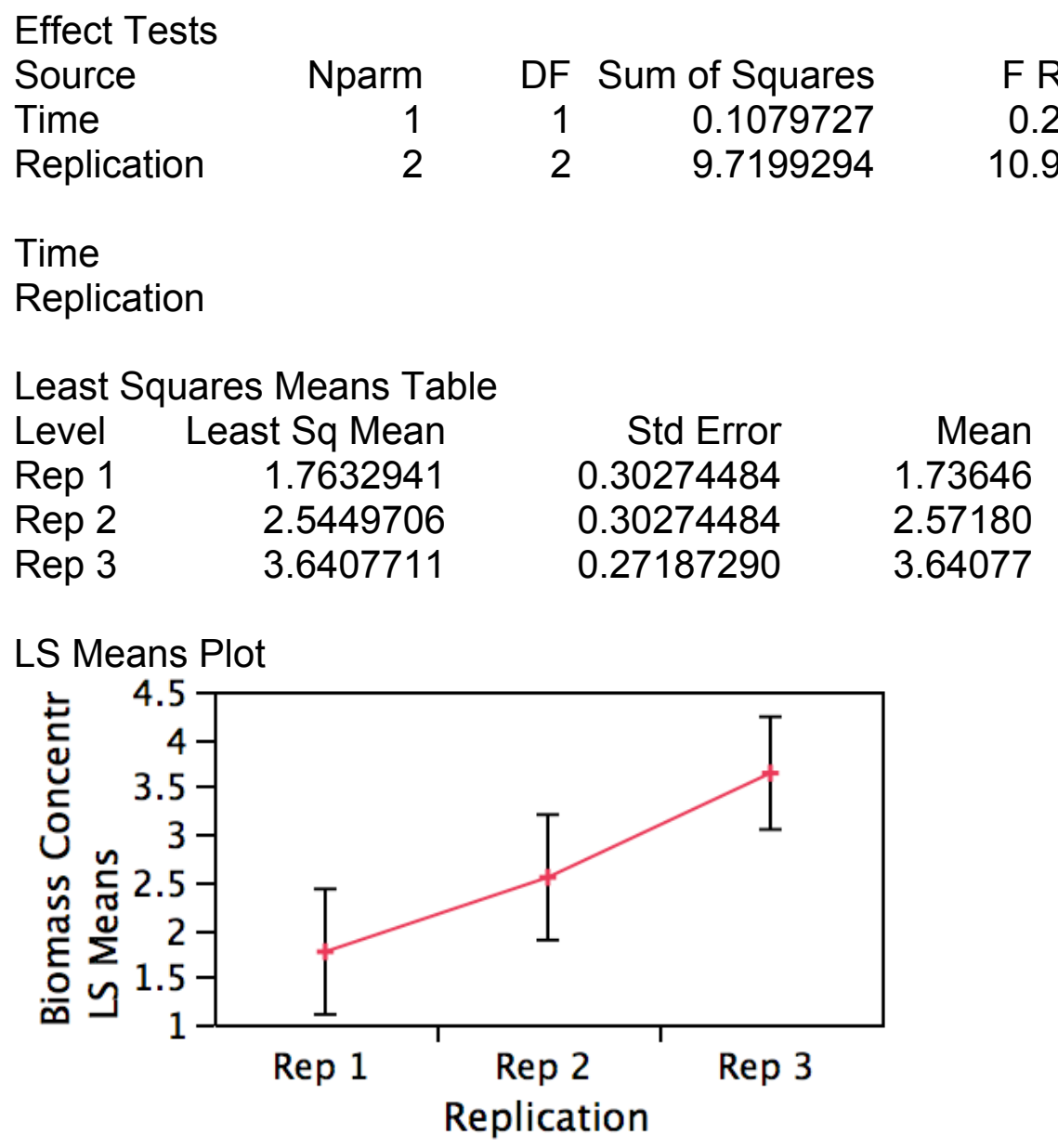

LSMeans Differences Tukey HSD

$\alpha=$

$0.050 Q=$

2.66776

Level Least Sq Mean

Rep 3 A $\quad 3.6407711$

Rep $2 \quad$ B $\quad 2.5449706$

$\begin{array}{lll}\text { Rep } 1 \quad \text { B } & 1.7632941\end{array}$

Levels not connected by same letter are significantly different. 
Response \%Fat

Whole Model

Regression Plot

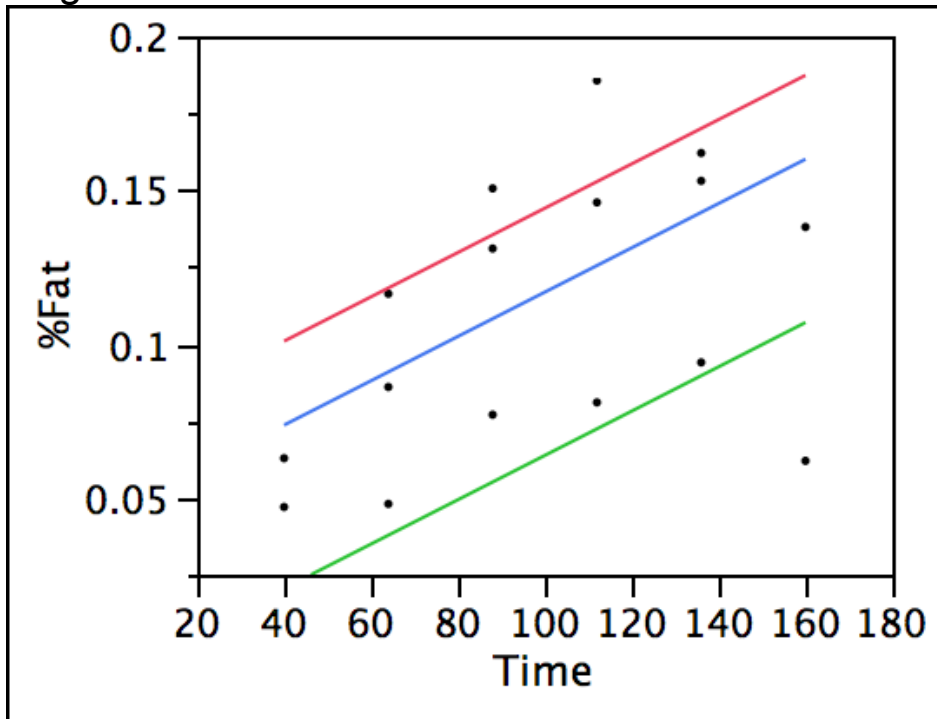

Rep 1

Rep 2 -

Rep 3 -

Summary of Fit

RSquare

0.736649

RSquare Adj

0.670811

Root Mean Square Error

0.025469

Mean of Response

0.108772

Observations (or Sum Wgts)

16

Analysis of Variance

Source

Model

Error

C. Total
DF Sum of Squares

$3 \quad 0.02177279$

$12 \quad 0.00778375$

$15 \quad 0.02955654$
Mean Square

0.007258

0.000649
F Ratio

11.1888

Prob $>$ F

0.0009

Parameter Estimates

\section{Term}

Intercept

Time

Replication[Rep 1]

Replication[Rep 2]
Estimate

0.0362122

0.0007202

0.0358782

$-0.044477$
Std Error

0.01847

0.000173

0.009403

0.009403 t Ratio

1.96

4.16

3.82

$-4.73$
Prob $>|t|$

0.0736

0.0013

0.0025

0.0005 


\begin{tabular}{lrrrr} 
Effect Tests & & & \\
Source & Nparm & DF & Sum of Squares & F R \\
Time & 1 & 1 & 0.01120435 & 17.273 \\
Replication & 2 & 2 & 0.01575742 & 12.14 \\
& & & & \\
Time & & & & \\
Replication & & & \\
\multicolumn{5}{l}{ Least Squares Means Table } \\
Level $\quad$ Least Sq Mean & Std Error & Mean \\
Rep 1 & 0.14411267 & 0.01157815 & 0.135470 \\
Rep 2 & 0.06375733 & 0.01157815 & 0.072400 \\
Rep 3 & 0.11683333 & 0.01039748 & 0.116833
\end{tabular}

LS Means Plot

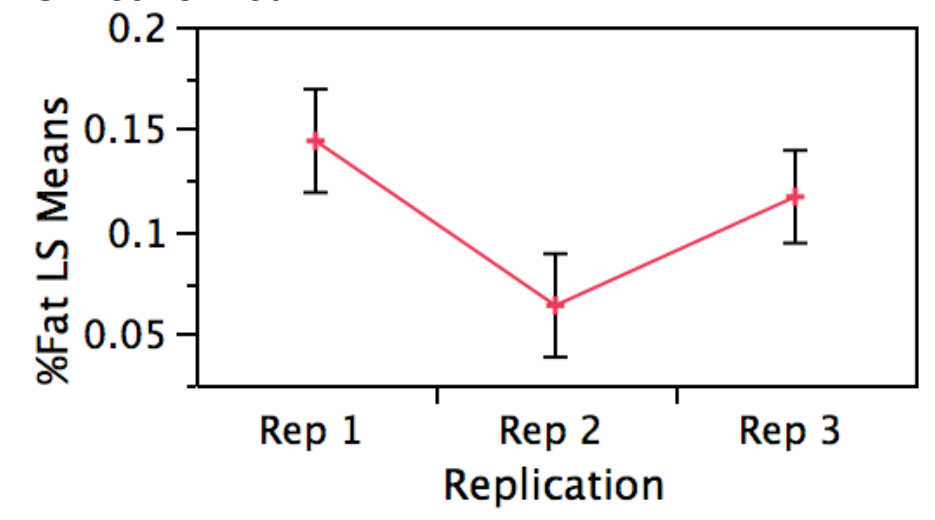

LSMeans Differences Tukey HSD

$\alpha=$

$0.050 Q=$

2.66776

Level Least Sq Mean

$\begin{array}{lll}\text { Rep } 1 \text { A } & 0.14411267\end{array}$

Rep 3 A 0.11683333

Rep 2 B 0.06375733

Levels not connected by same letter are significantly different. 
Response \%DHA

Whole Model

Regression Plot

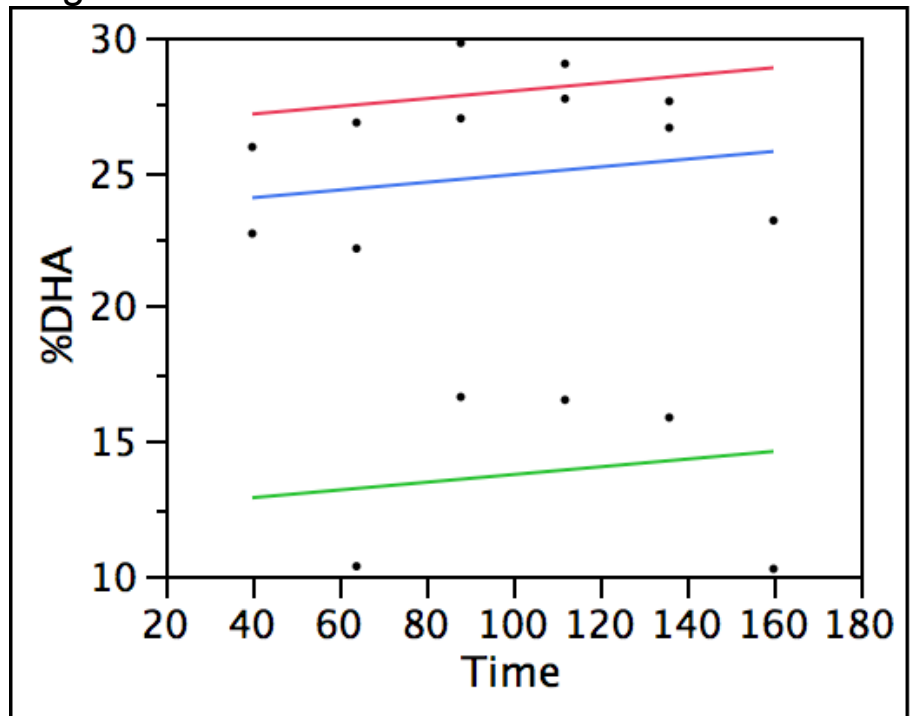

Rep 1 -

Rep 2 -

Rep 3 -

Summary of Fit

RSquare

RSquare Adj

Root Mean Square Error

Mean of Response

Observations (or Sum Wgts)

Analysis of Variance
Source

Model

Error

C. Total
DF Sum of Squares

$3 \quad 548.41374$

$12 \quad 80.21409$

15

628.62782
0.872398

0.840498

2.585441

22.38938
Parameter Estimates

Term

Intercept

Time

Replication[Rep 1]

Replication[Rep 2]

\section{Estimate} 20.784963

0.0143704

5.7864444

$-8.464444$
Mean Square

182.805

6.685
F Ratio

27.3475

Prob $>$ F

$<.0001$ 


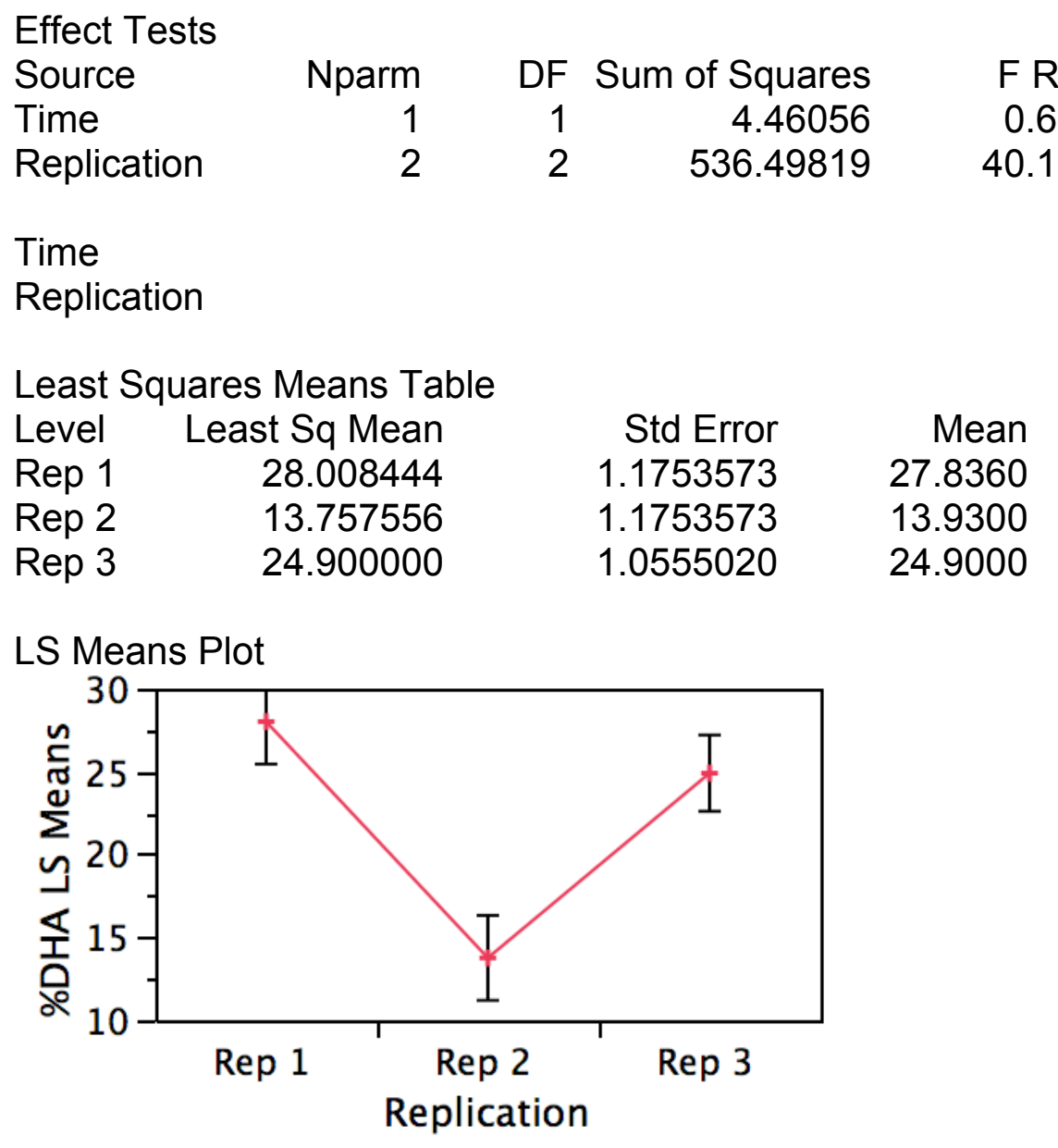

LSMeans Differences Tukey HSD

$\alpha=$

$0.050 Q=$

2.66776

Level Least Sq Mean

Rep 1 A

28.008444

Rep 3 A 24.900000

Rep $2 \quad$ B $\quad 13.757556$

Levels not connected by same letter are significantly different. 
Response Fat Concentration

Whole Model

Regression Plot

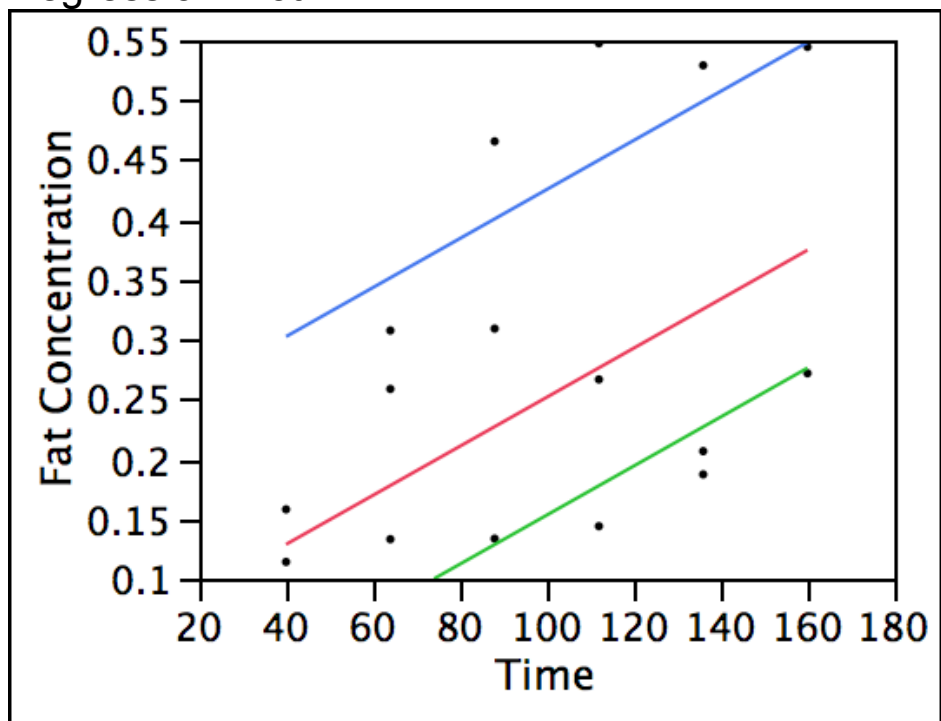

Rep 1

Rep 2 -

Rep 3 -

Summary of Fit

RSquare

0.791532

RSquare Adj

0.739415

Root Mean Square Error

0.07883

Mean of Response

0.285974

Observations (or Sum Wgts)

Analysis of Variance

Source

Model

Error

C. Total
DF Sum of Squares

$3 \quad 0.28313142$

$12 \quad 0.07456928$

$15 \quad 0.35770070$
Mean Square

0.094377

0.006214
F Ratio

15.1876

Prob $>\mathrm{F}$

0.0002

Parameter Estimates

\section{Term}

Intercept

Time

Replication[Rep 1]

Replication[Rep 2]

Estimate
0.071755
0.0020493
-0.025045
-0.123562

Std Error

0.057168

0.000536

0.029103

0.029103 t Ratio

1.26

3.82

$-0.86$

$-4.25$
Prob $>|t|$

0.2333

0.0024

0.4063

0.0011 
Effect Tests

Source

Time

Replication

Nparm

$\begin{array}{rr}\text { DF } & \text { Sum of Squares } \\ 1 & 0.09071337 \\ 2 & 0.20908117\end{array}$

F Ratio

Prob $>\mathrm{F}$

1
2

0.20908117

14.5980

16.8231

0.0024

0.0003

Time

Replication

Least Squares Means Table Level Least Sq Mean

Rep $1 \quad 0.25164183$

$\begin{array}{rr}\text { Std Error } & \text { Mean } \\ 0.03583642 & 0.227050 \\ 0.03583642 & 0.177716 \\ 0.03218205 & 0.425293\end{array}$

Rep 2
Rep 3

0.15312439

0.42529324

0.03218205

0.425293

LS Means Plot

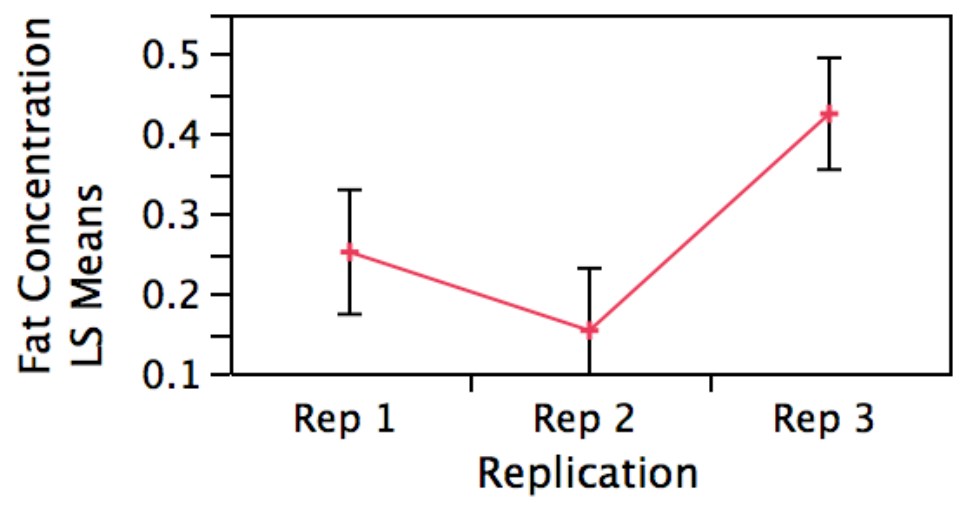

LSMeans Differences Tukey HSD

$\alpha=$

$0.050 Q=$

2.66776

Level Least Sq Mean

Rep 3 A $\quad 0.42529324$

Rep $1 \quad$ B $\quad 0.25164183$

Rep $2 \quad$ B 0.15312439

Levels not connected by same letter are significantly different. 
Response DHA Concentration

Whole Model

Regression Plot

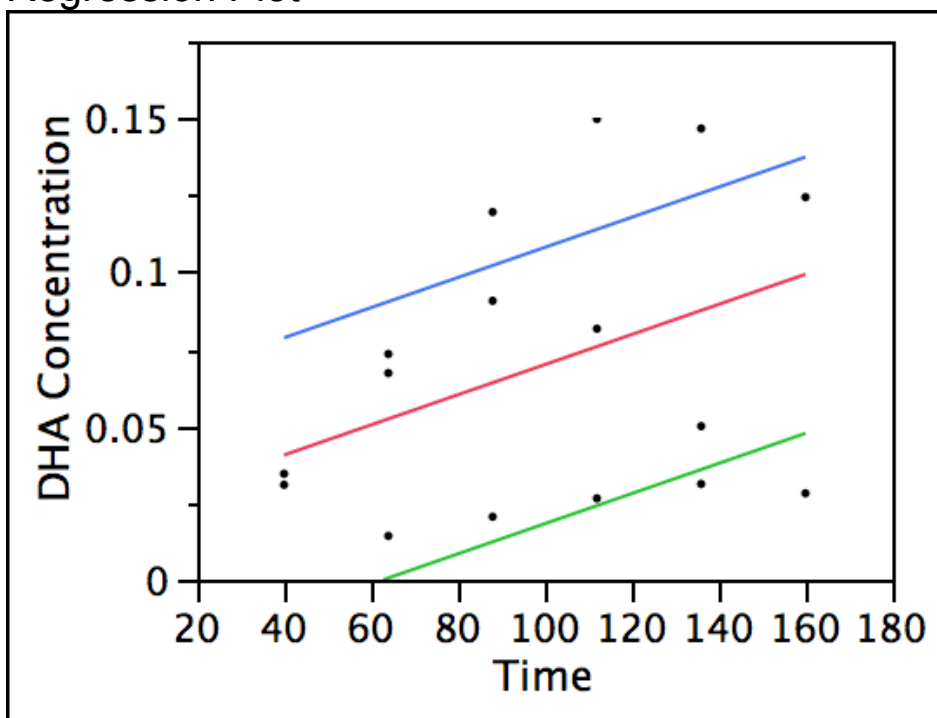

Rep 1

Rep 2 -

Rep 3 -

Summary of Fit

RSquare

0.76393

RSquare Adj

0.704913

Root Mean Square Error

0.025124

Mean of Response

0.068023

Observations (or Sum Wgts)

Analysis of Variance

Source

Model

Error

C. Total

DF Sum of Squares

$3 \quad 0.02451107$

$12 \quad 0.00757441$

15

0.03208549
Mean Square

0.008170

0.000631
F Ratio

12.9441

Prob $>\mathrm{F}$

0.0005

Parameter Estimates

Term

Intercept

Time

Replication[Rep 1]

Replication[Rep 2]

$\begin{array}{rrrr}\text { Estimate } & \text { Std Error } & \text { t Ratio } & \text { Prob }>|t| \\ 0.0163896 & 0.01822 & 0.90 & 0.3861 \\ 0.0004897 & 0.000171 & 2.86 & 0.0142 \\ 0.0045343 & 0.009275 & 0.49 & 0.6338 \\ -0.047174 & 0.009275 & -5.09 & 0.0003\end{array}$


Effect Tests

Source

Time

Replication

Nparm

$$
\begin{array}{rr}
\text { DF } & \text { Sum of Squares } \\
1 & 0.00517953 \\
2 & 0.02160696
\end{array}
$$

F Ratio

Prob $>\mathrm{F}$

$\begin{array}{lll}1 & 1 & 0.00517953\end{array}$

8.2058

0.0142

17.1157

0.0003

Time

Replication

Least Squares Means Table

Level Least Sq Mean

Rep $1 \quad 0.06989260$

Std Error Mean

Rep $2 \quad 0.01818446$

$0.01142139 \quad 0.064016$

Rep 3

0.10799770

0.01142139

0.024061

0.01025672

0.107998

LS Means Plot

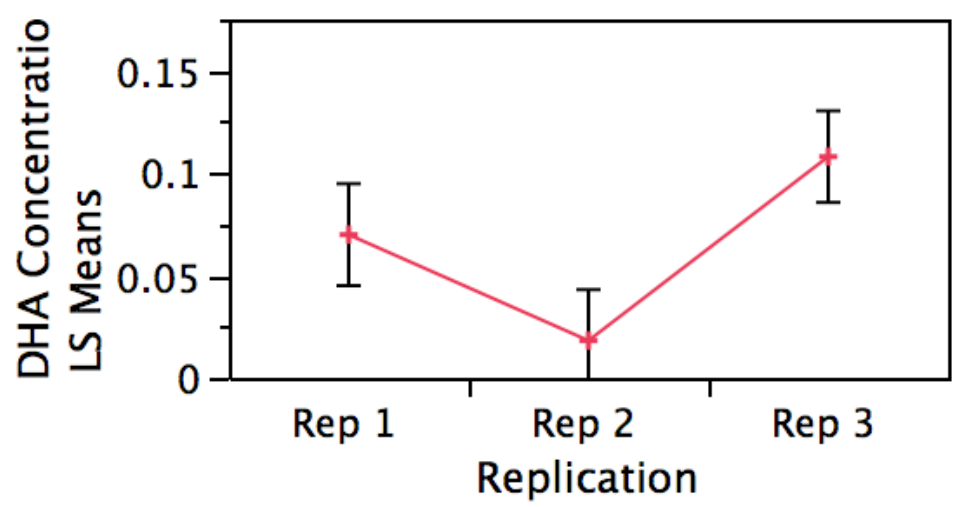

LSMeans Differences Tukey HSD

$\alpha=$

$0.050 Q=$

2.66776

Level Least Sq Mean

Rep 3 A $\quad 0.10799770$

Rep 1 A $\quad 0.06989260$

Rep 2 B 0.01818446

Levels not connected by same letter are significantly different. 
Response DHA Productivity

Whole Model

Regression Plot

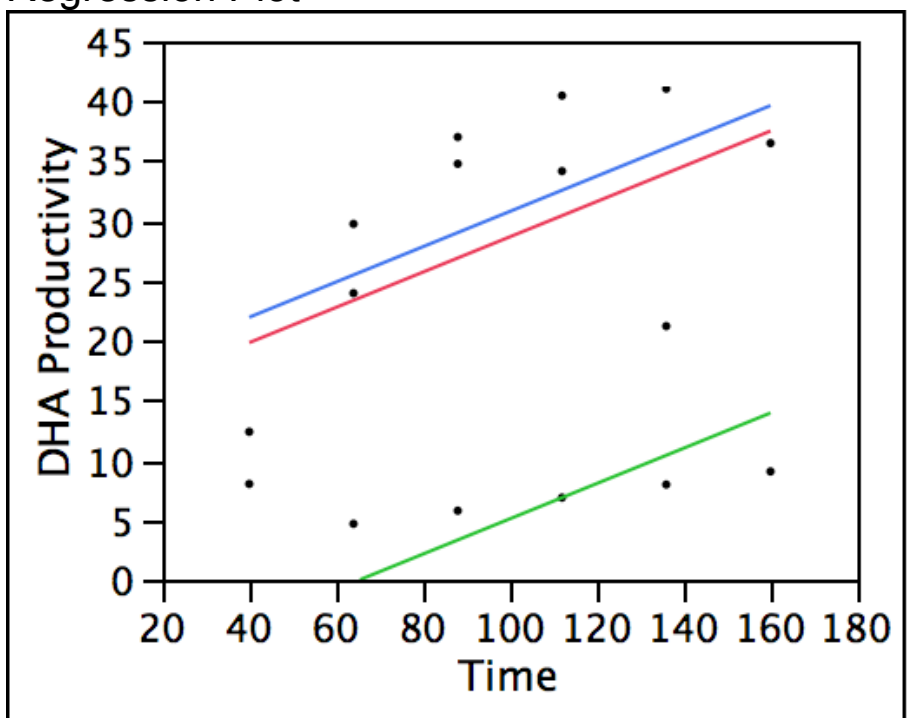

Rep 1 -

Rep 2 -

Rep 3 -

Summary of Fit

RSquare

0.742663

RSquare Adj

0.678328

Root Mean Square Error

7.966397

Mean of Response

22.08731

Observations (or Sum Wgts)

Analysis of Variance

Source

Model

Error

C. Total
DF Sum of Squares

$3 \quad 2197.8279$

12

15
761.5617

2959.3896
Mean Square

732.609

63.463
F Ratio

11.5438

Prob $>\mathrm{F}$

0.0008

Parameter Estimates

Term

Intercept

Time

Replication[Rep 1]

Replication[Rep 2]
Estimate

6.763505

0.1474433

7.1483534

$-16.41986$
Std Error

5.777291

0.054204

2.941061

2.941061 t Ratio

1.17

2.72

2.43

$-5.58$
Prob $>|t|$

0.2644

0.0186

0.0317

0.0001 


$\begin{array}{lrrrrr}\text { Effect Tests } & & & & & \\ \text { Source } & \text { Nparm } & \text { DF } & \text { Sum of Squares } & \text { F Ratio } & \text { Prob > F } \\ \text { Time } & 1 & 1 & 469.5740 & 7.3991 & 0.0186 \\ \text { Replication } & 2 & 2 & 2027.1554 & 15.9710 & 0.0004\end{array}$

Time

Replication

Least Squares Means Table

Level Least Sq Mean

Rep $1 \quad 28.656192$

Std Error

Mean

Rep 2

5.087979

3.6215722

26.8869

Rep 3

30.779344

3.6215722

6.8573

3.2522679

30.7793

LS Means Plot

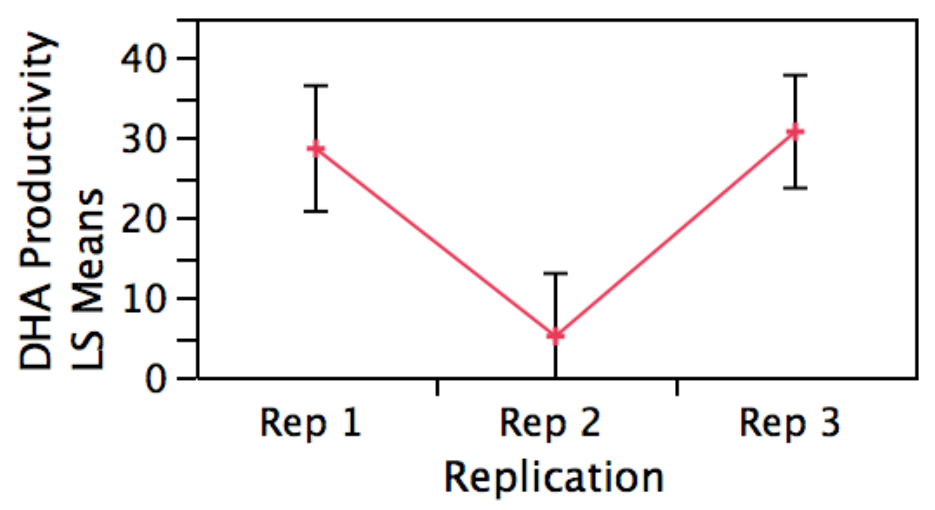

LSMeans Differences Tukey HSD

$\alpha=$

$0.050 \mathrm{Q}=$

2.66776

Level

Least Sq Mean

Rep 3 A

30.779344

Rep 1 A

28.656192

Rep $2 \quad B$

5.087979

Levels not connected by same letter are significantly different. 